\title{
WestVirginiaUniversity
}

THE RESEARCH REPOSITORY @ WVU

Graduate Theses, Dissertations, and Problem Reports

2006

\section{Development of a numerical model of a two-dimensional inertial gas separator}

Henry Z. Graham IV

West Virginia University

Follow this and additional works at: https://researchrepository.wvu.edu/etd

\section{Recommended Citation}

Graham, Henry Z. IV, "Development of a numerical model of a two-dimensional inertial gas separator" (2006). Graduate Theses, Dissertations, and Problem Reports. 1954.

https://researchrepository.wvu.edu/etd/1954

This Thesis is protected by copyright and/or related rights. It has been brought to you by the The Research Repository @ WVU with permission from the rights-holder(s). You are free to use this Thesis in any way that is permitted by the copyright and related rights legislation that applies to your use. For other uses you must obtain permission from the rights-holder(s) directly, unless additional rights are indicated by a Creative Commons license in the record and/ or on the work itself. This Thesis has been accepted for inclusion in WVU Graduate Theses, Dissertations, and Problem Reports collection by an authorized administrator of The Research Repository @ WVU. For more information, please contact researchrepository@mail.wvu.edu. 


\title{
Development of a Numerical Model of a Two-Dimensional Inertial Gas Separator
}

\author{
Henry Z. Graham IV
}

Thesis submitted to the

\author{
College of Engineering and Mineral Resources \\ at West Virginia University \\ in partial fulfillment of the requirements for \\ the degree of
}

\author{
Master of Science \\ in \\ Mechanical Engineering \\ James Smith, Ph.D., Chair \\ Gregory Thompson, Ph.D. \\ Kenneth Means, Ph.D.
}

Department of Mechanical and Aerospace Engineering

Morgantown, West Virginia

2006 


\section{Abstract \\ Development of a Numerical Model of a Two-Dimensional Inertial Gas Separator}

Henry Z Graham IV

The separation of gases is required for a variety of applications such as purification for industrial processes, natural gas production, isotope formation, etc. Gas separation is a costly expenditure for businesses, so new and improved methods are being continuously investigated. Separation techniques related to the method in this thesis are diffusion separators such as mechanical centrifuges, vortexes and the use of shock waves to cause the separation based on the molecular weight of the different gases. These methods and others are constantly being investigated and improved to increase their effectiveness.

The purpose of this thesis was to determine if the design of a supersonic gas separator in Figure 1 can be modeled using a numerical computer program to accurately model the device. This thesis will strictly be concerned with the gas dynamics aspects of this device and not the diffusive separation aspects. The design was modeled using a CFD (computational fluid dynamics) program called Fluent which was then compared to analytic results to verify the Fluent results. The program was run using air and the pressure differences of the gas were varied by adjusting the inlet and outlet pressures in the model. This was done to achieve different speeds of the flow which is the main force driving the gas separation. The physical effects such as gas speed, temperature, and pressure in the device are computed numerically by Fluent. These results are then compared to those from an analytic model previous work in literature to gain a better understanding of the effects of the device.

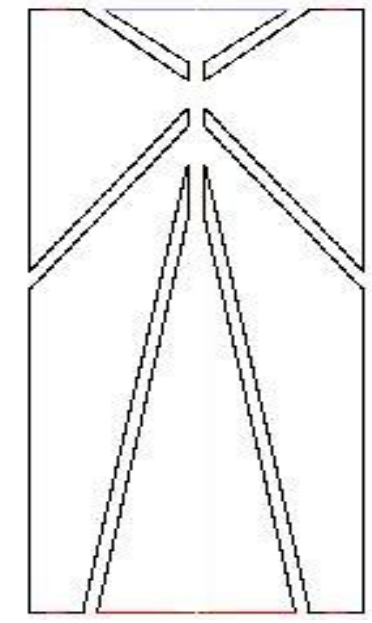

Figure 1: Full Model of Gas Separator

The results from the Fluent cases correlated to the analytic results. When the downstream pressure was dropped below $30 \%$ of the stagnation pressure, the supersonic expansion fan was able to attach to the first skimmer and began the formation of a supersonic beam. This caused the skimmer to not act as a sonic throat when the 
supersonic inner core of the barrel shock that was formed in the first chamber maintained its velocity through the skimmer throat. The formation of a supersonic beam at lower pressure ratios corresponds to results found in literature, and the converging-diverging nozzle aspects of the device at higher pressure ratios also corresponds to compressible gas theory. 


\section{Table of Contents}

$\underline{\text { Section }}$

$\underline{\text { Page }}$

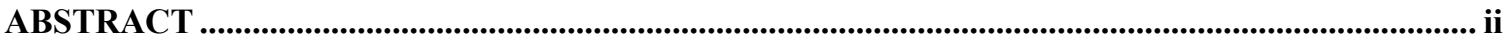

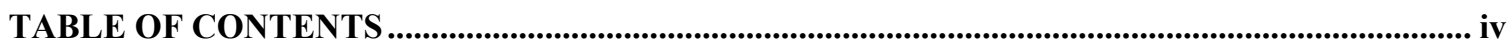

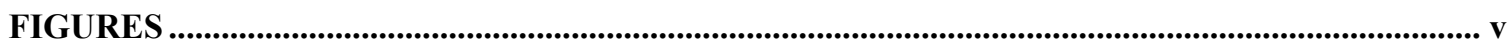

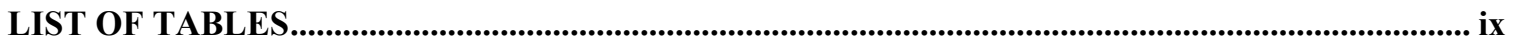

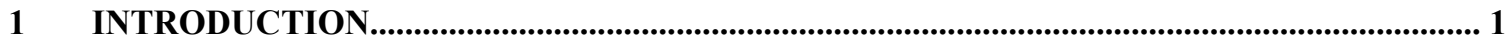

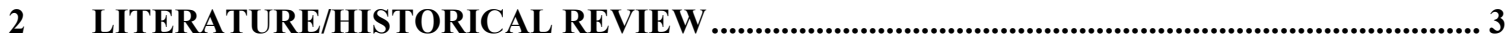

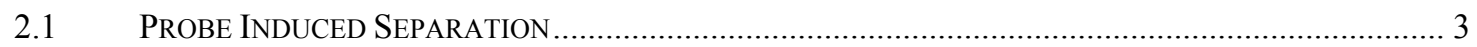

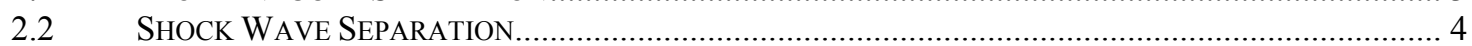

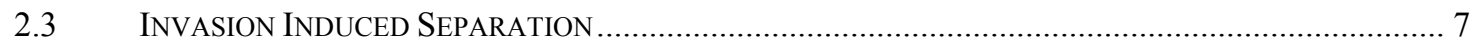

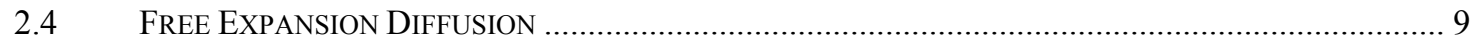

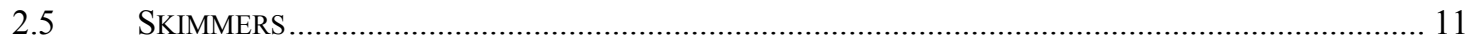

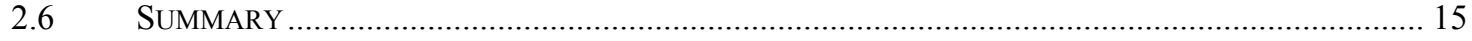

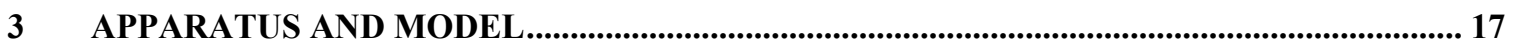

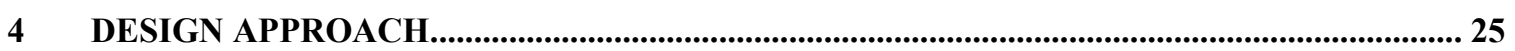

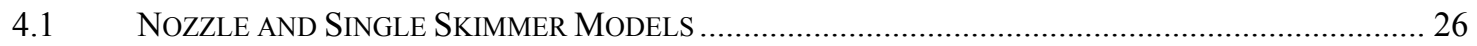

4.2 Two SKIMMER MODELS WITH SIMILAR $1^{\text {ST }}$ AND $2^{\text {ND }}$ SKIMMERS ………………...................... 28

4.3 Two SKIMMER MODELS WITH DIFFERING $1^{\text {ST }}$ AND $2^{\text {ND }}$ SKIMMERS ……….............................. 31

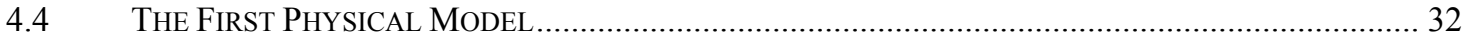

4.5 THE SECOND PHYSICAL MODEL

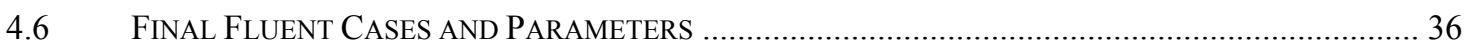

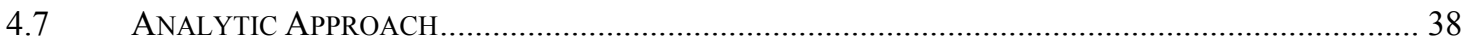

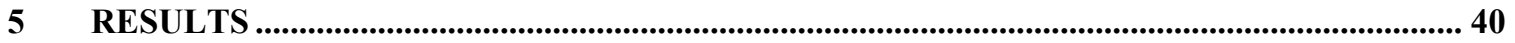

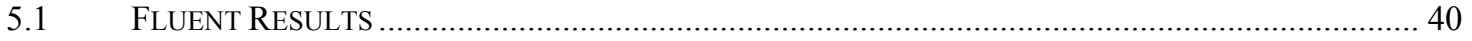

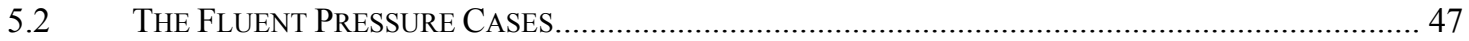

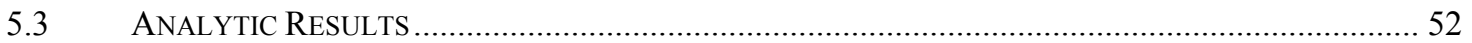

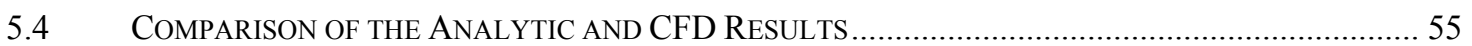

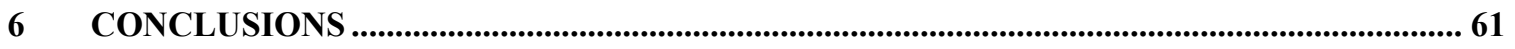

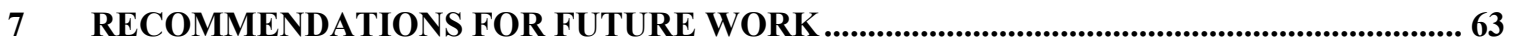

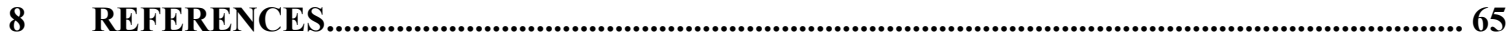

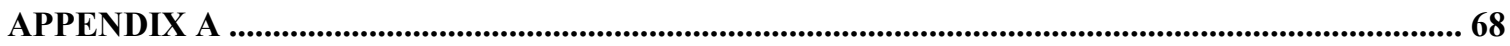

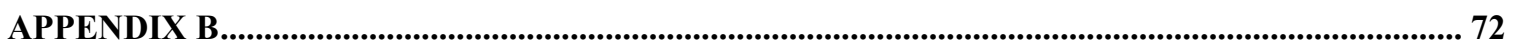




\section{Figures}

$\underline{\text { Figure }}$

$\underline{\text { Page }}$

Figure 1: Full Model of Gas Separator ........................................................................ ii

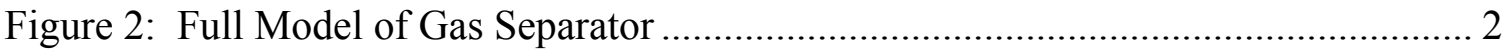

Figure 3: The Probe Gas Separator by Fenn [1] ................................................... 4

Figure 4: The Gas Separator by Andres [3] f........................................................... 5

Figure 5: The Gas Separator by Nasikas Utilizing Normal Shock Waves [4]................. 6

Figure 6: The Gas Separator by Betting et al. [5] ...................................................... 7

Figure 7: Invasion Separator by Campargue [9] ....................................................... 9

Figure 8: The Free Jet Diffusive Separator by Dickens [10] ..................................... 10

Figure 9: Supersonic Beam Separator by Brandt [11] ............................................. 11

Figure 10: Nozzle Skimmer Separator by Becker [12] ........................................... 12

Figure 11: Apparatus for Producing a Beam of Particles by Campargue [15] ............... 13

Figure 12: The Particle Separator by Dahneke [16] .................................................. 14

Figure 13: Picture of the Aerodynamic Separator by Maldague [17] ........................... 14

Figure 14: The Supersonic Gas Separator by Alferov [18] ...................................... 15

Figure 15: Side Dimensional Drawing of Sonic Nozzle (inches) ................................ 18

Figure 16: Front Dimensional Drawing of Sonic Nozzle (inches) ............................... 18

Figure 17: A Solid Model of the Sonic Nozzle........................................................... 19

Figure 18: Side Dimensional Drawing of First Skimmer Section (inches) .................... 20

Figure 19: Front Dimensional Drawing of First Skimmer Section (inches)................... 20

Figure 20: A Solid Model of the First Skimmer Section .......................................... 21

Figure 21: Side Dimensional View of Second Skimmer Section (inches) .................... 22 
Figure 22: Front Dimensional Drawing of Second Skimmer Section (inches) .............. 22

Figure 23: A Solid Model of the Second Skimmer Section......................................... 23

Figure 24: Schlieren Image of Barrel Shock Attached to Skimmer [27]........................ 24

Figure 25: The Meshed Model of the Single Skimmer Design ................................... 27

Figure 26: Contour Plot of the Mach Value of the Gas in the Single Skimmer Model... 27

Figure 27: Mach Contour Plot of Single Chamber Two Skimmer Model...................... 28

Figure 28: Mach Contour Plot of the Two Skimmer Model with Segregated Chambers 29

Figure 29: Mach Contour Plot of Two Skimmer Model with Side Walls ...................... 30

Figure 30: Mach Contour Plot of the Two Skimmer Model with Differing Half Angles 32

Figure 31: Meshed Model with Final Nozzle and Skimmer Dimensions...................... 33

Figure 32: The Final Two Skimmer Model with the Adjusted Wall Spacing ................. 34

Figure 33: The Gambit Model of the Second Physical Design .................................... 35

Figure 34: Sectioned Model Including both the Nozzle and First Skimmer .................. 36

Figure 35: Sectioned Model Including both the First and Second Skimmers ................ 36

Figure 36: Contour Plot of Absolute Pressure in psi ................................................ 41

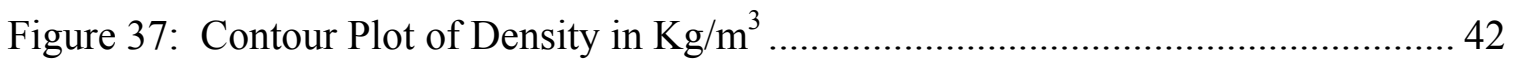

Figure 38: Contour Plot of the Mach Number of the Gas........................................... 42

Figure 39: Contour Plot of The Static Temperature in Kelvin ................................... 43

Figure 40: Different Mesh Comparisons of Static Pressure ....................................... 44

Figure 41: Different Mesh Comparisons of Density................................................ 44

Figure 42: Different Mesh Comparisons of Velocity Magnitude.................................. 45

Figure 43: Different Mesh Comparisons of Static Temperature ................................. 45

Figure 44: Grid Independence Static Pressure Percent Difference............................... 46 
Figure 45: Grid Independence Velocity Magnitude Percent Difference

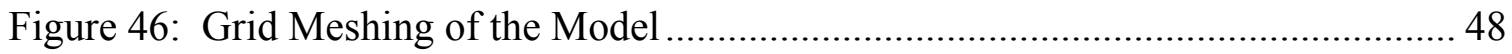

Figure 47: Zoomed in View of the Meshed Model...................................................... 48

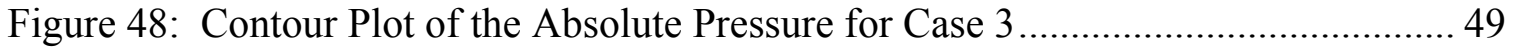

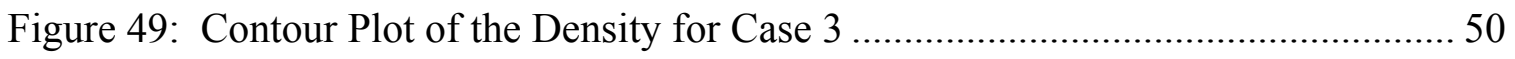

Figure 50: Contour Plot of the Mach Speed of the Gas for Case 3 ............................... 50

Figure 51: Contour Plot of the Static Temperature for Case 3 ................................... 51

Figure 52: Contour Plot of the Velocity Magnitude for Case 3 ................................... 52

Figure 53: Mach Number Percent Difference between Fluent and Analytic.................. 56

Figure 54: Static Temperature Percent Difference between Fluent and Analytic ........... 57

Figure 55: Absolute Pressure Percent Difference between Fluent and Analytic............ 57

Figure 56: The Mass Flow through each Outlet for each Case..................................... 58

Figure 57: Centerline Mach Number for each of the Pressure Cases ............................. 59

Figure 58: Centerline Static Temperature Plot for each of the Pressure Cases .............. 59

Figure 59: Centerline Absolute Pressure Plot for each of the Pressure Cases................. 60

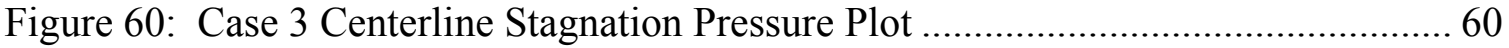

Figure 61: Mach Contour Plot of the Single Skimmer Model...................................... 68

Figure 62: Mach Contour Plot of the Single Chamber Two Skimmer Model................. 68

Figure 63: Mach Vector Plot of the Two Skimmer Model with Segregated Chambers.. 69

Figure 64: Mach Contour Plot of Two Skimmer Model with Side Walls ...................... 69

Figure 65: Mach Contour Plot of the Two Skimmer Model with the Final Dimensions 70

Figure 66: Mach Contour Plot of the Second Physical Design .................................. 70

Figure 67: Mach Contour Plot of the First Section of the First Physical Model ............. 71 
Figure 68: Mach Contour Plot of the Second Section of the First Physical Model........ 71

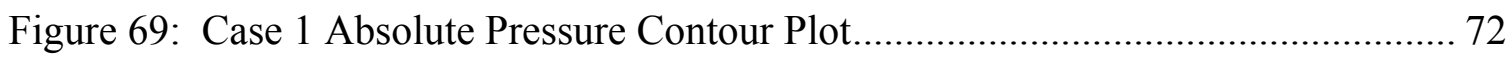

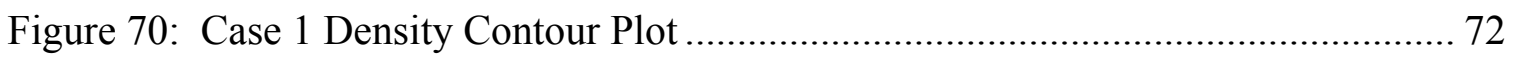

Figure 71: Case 1 Mach Number Contour Plot ...................................................... 73

Figure 72: Case 1 Static Temperature Contour Plot .................................................. 73

Figure 73: Case 1 Velocity Magnitude Contour Plot................................................. 74

Figure 74: Case 2 Absolute Pressure Contour Plot................................................... 74

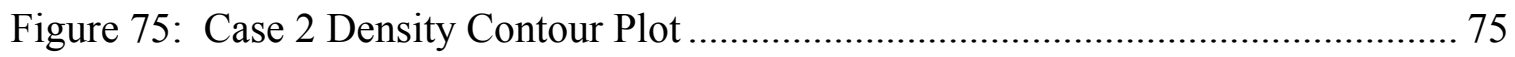

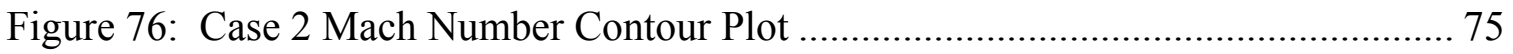

Figure 77: Case 2 Static Temperature Contour Plot ................................................ 76

Figure 78: Case 2 Velocity Magnitude Contour Plot.................................................... 76

Figure 79: Case 4 Absolute Pressure Contour Plot..................................................... 77

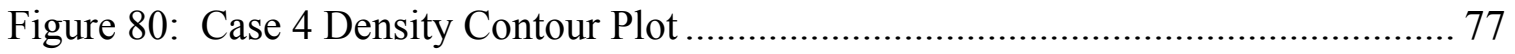

Figure 81: Case 4 Mach Number Contour Plot ...................................................... 78

Figure 82: Case 4 Static Temperature Contour Plot ............................................. 78

Figure 83: Case 4 Velocity Magnitude Contour Plot............................................... 79

Figure 84: Case 5 Absolute Pressure Contour Plot.................................................... 79

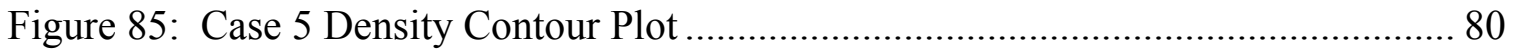

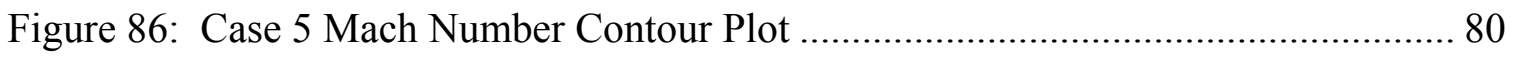

Figure 87: Case 5 Static Temperature Contour Plot ................................................ 81

Figure 88: Case 5 Velocity Magnitude Contour Plot................................................ 81 


\section{List of Tables}

Table $\quad \underline{\text { Page }}$

Table 1: Pressure Values for Each of the Fluent Cases ............................................ 37

Table 2: Mesh Sizes for the Grid Independence Cases............................................. 40

Table 3: Percent Difference of CFD and Analytic Values at Various Locations ............ 55

Table 4: Velocity Percent Difference for Nozzle Throat............................................ 55

Table 5: Percent Difference of Mass Flow Rate of CFD and Analytic Values ............... 58

Table 6: Case 1 Percent Difference of CFD and Analytic Results ............................... 82

Table 7: Case 2 Percent Difference of CFD and Analytic Results ............................... 82

Table 8: Case 4 Percent Difference of CFD and Analytic Results ............................... 82

Table 9: Case 5 Percent Difference of CFD and Analytic Results ............................... 83 


\section{Introduction}

The separation of gases is required for a variety of applications such as purification for industrial processes, natural gas production, isotope formation, etc. Gas separation is a costly expenditure for businesses, so new and improved methods are being continuously investigated. Separation techniques related to the method in this thesis are diffusion separators such as mechanical centrifuges, vortexes and the use of shock waves to cause the separation based on the molecular weight of the different gases. These methods and others are constantly being investigated and improved to increase their effectiveness.

The purpose of this thesis was to determine if the design of a supersonic gas separator in Figure 2 can be modeled using a numerical computer program to accurately model the device. This thesis will strictly be concerned with the gas dynamics aspects of this device and not the diffusive separation aspects. The design was modeled using a CFD (computational fluid dynamics) program called Fluent which were then compared to analytic results to verify the Fluent results. The program was run using air and the pressure differences of the gas were varied by adjusting the inlet and outlet pressures in the model. This was done to achieve different speeds of the flow which is the main force driving the gas separation. The physical effects such as gas speed, temperature, and pressure in the device are computed numerically by Fluent. These results are then compared to those from an analytic model previous work in literature to gain a better understanding of the effects of the device. 


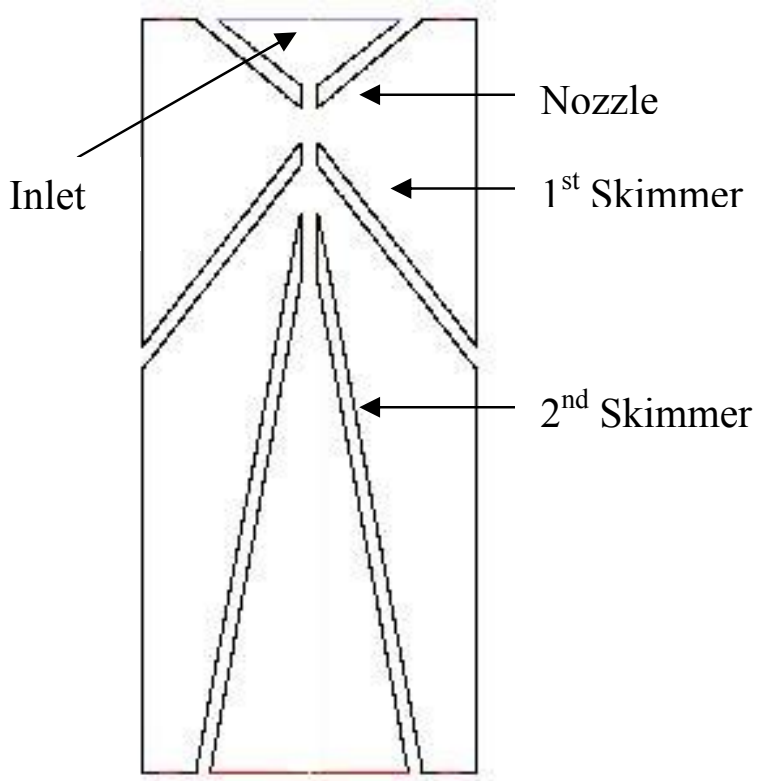

Figure 2: Full Model of Gas Separator

The design of the device as shown in Figure 2 consists of a sonic nozzle and two skimmers with outlets in each chamber to remove the separated gases. The separator works by creating a pressure difference which forces the gaseous mixture through a nozzle after which it freely expands to a supersonic velocity. The gaseous stream then forms a barrel shock which attaches itself to the entrance of the skimmer. The separation done by this type of device occurs when this expansion causes a diffusion of the different molecular weights of the components of the gaseous mixture, concentrating the lighter components outward where they are then diverted by the skimmers. The heavier components are concentrated toward the central axis of the flow and are left to pass through the skimmer. Therefore it is necessary to know whether Fluent can model the basic flow rates and metrics of a gas as it passes through the device so that it can be later used in the development and modification of the device and similar inventions. 


\section{Literature/Historical Review}

Although this thesis is concerned with the gas dynamics aspect, the underlying purpose of the device is diffusive gas separation, it is therefore desirable to understand other work done with diffusion separators in order to gain a better understanding of the device analyzed in this thesis. Diffusion separation encompasses the following kinds of separation; probe induced, free expansion, background invasion, use of a normal shock wave, and centrifugal separation. These methods often have similar characteristics such as nozzles, skimmers, curved surfaces, and extraction probes which facilitate the separation of the gaseous mixture. The kind of flow in these types of separations are high velocity, and usually supersonic, and in most cases uses the shear in a shock wave to cause part or all of the separation. The separation caused by the device in this thesis is free expansion, but due to the use of other techniques such as skimmers, a nozzle and the formation of shock waves it is important to gain a better understanding of other methods of diffusion separation. The following section overviews the past and current technology of diffusion separation that contains pertinent information for this thesis.

\subsection{Probe Induced Separation}

A type of separation of a gaseous mixture is one that uses a probe in the flow to cause a shock wave that separates the species based on molecular weight. The bow shock wave formed by the probe deflects the lighter gas of the mixture while the heavier gases continue through and is removed by the probe. Fenn [1] used this technique in his patent in 1968. His device shown in Figure 3 accelerated the gaseous mixture to supersonic speeds. Then probes are placed in the path of the flow which creates shocks waves in 
front of each probe. Due to the rapid decelerations caused by the shocks the lighter gases tend to be deflected more and the mixture extracted by the probes has a higher concentration of the denser gas than the original mixture. This method was further improved with the 1971 Patent by Fenn [2]. This patent is concerned with improving the efficiency of his previous one but still uses the same method.

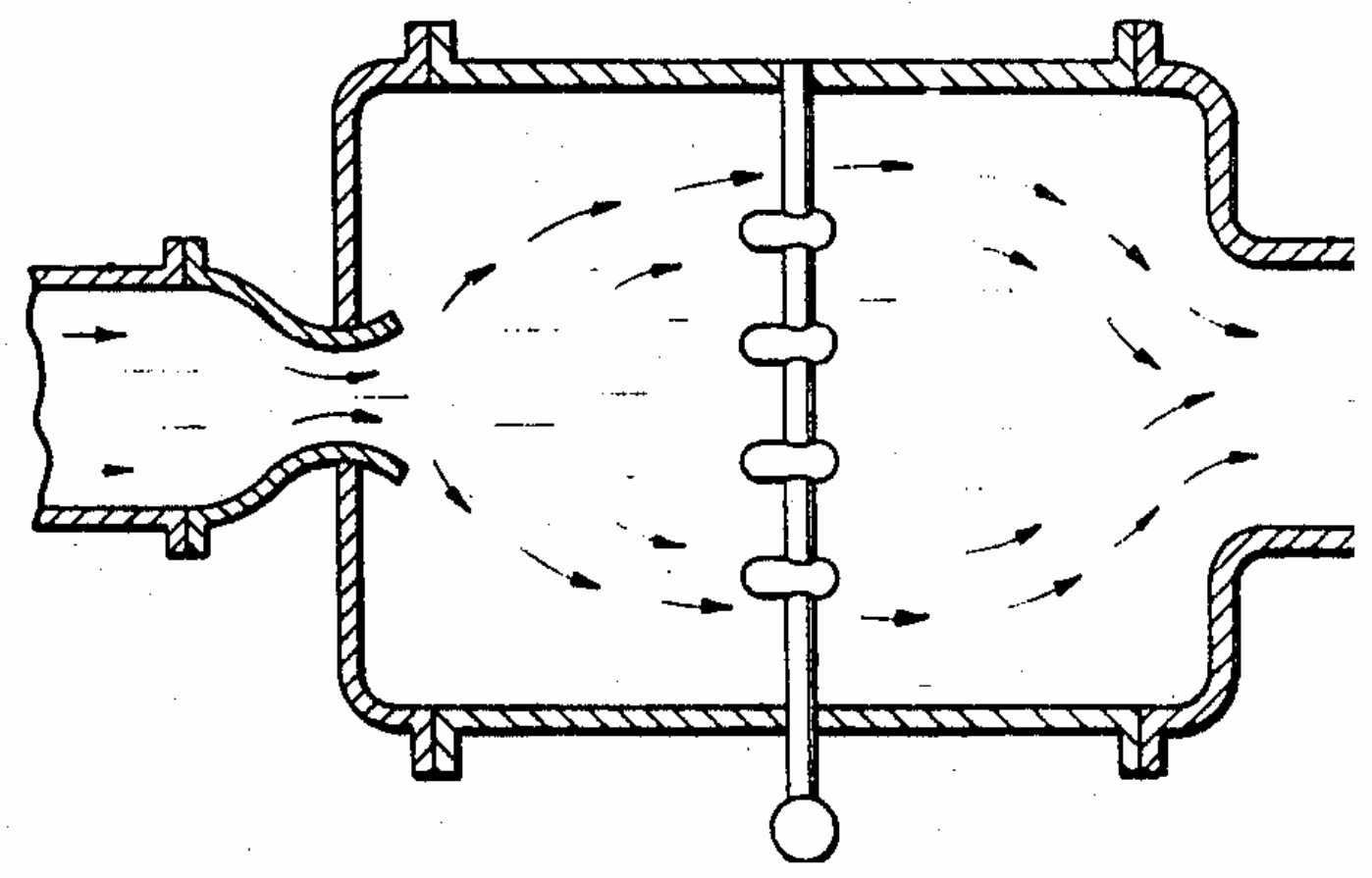

Figure 3: The Probe Gas Separator by Fenn [1]

\subsection{Shock Wave Separation}

Creating a shock wave in the gaseous flow is another popular method of gas separation. The gas mixture is increased to supersonic speeds, and then a shock wave is created which rapidly drops the speed of the gas flow. The heavier molecules have a higher momentum and aren't slowed as much as the lighter gases. This causes a speed difference between the different gases which can be used effectively to separate them. This works especially well for condensed particles and mixtures with large difference in 
molecular weights between the components. The patent by Andres [3] applies the method of accelerating and decelerating the gaseous flow, but it uses a membrane downstream of the nozzle where the heavier components pass through. As seen in Figure 4 the gas is admitted through a nozzle and then a shock wave creates the differing velocities between the particles and the ones with the higher momentum pass through the membrane in greater concentration.

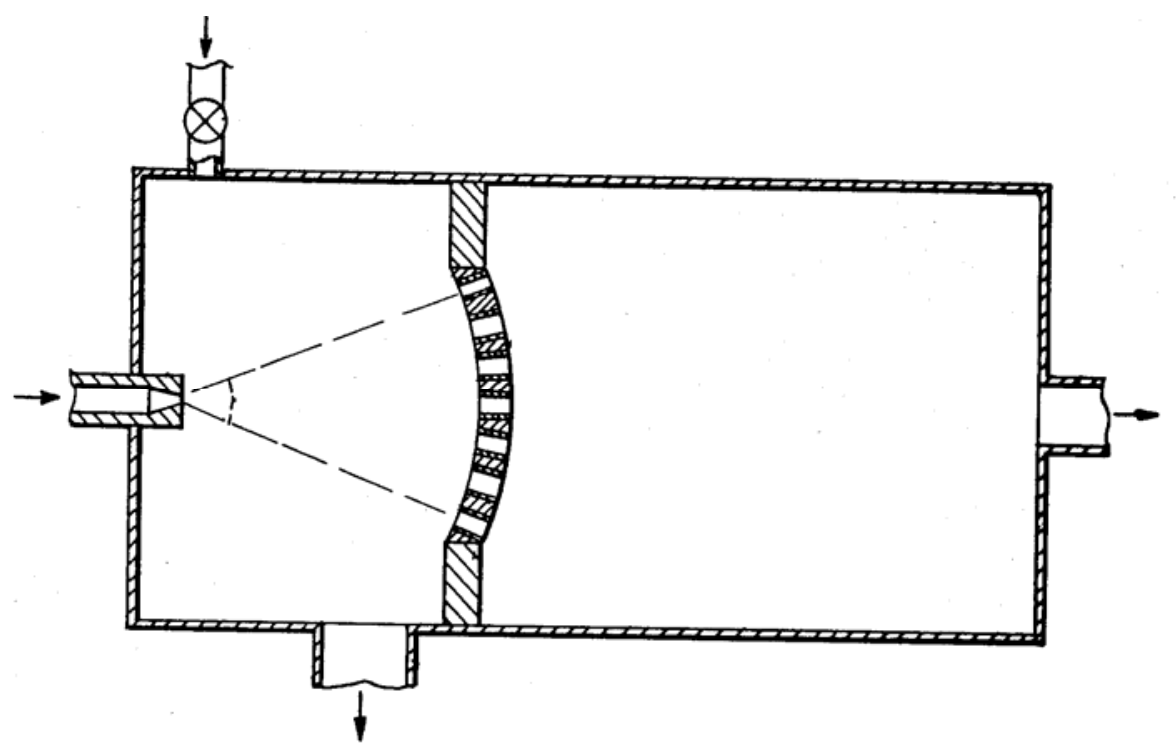

Figure 4: The Gas Separator by Andres [3]

The 1994 patent by Nasikas [4] shown in Figure 5 is a liquid droplet-gas mixture separator which uses normal shocks to create a velocity difference between the components based on molecular weight. The flow achieves supersonic speeds in a Laval nozzle where the desired part of the mixture is condensed into liquid droplets. The device then incurs separation of the droplets from the gases by causing a normal shock which reduces the speed of the flow while droplets maintain a relatively high speed compared to the rest of the mixture. The flow then travels through a bend where centrifugal forces separate the components based on molecular weight. This is done with 
greater efficiency due to higher speed of the condensed molecules. A separator plate then peels off the layer of heavier enriched flow that is concentrated along the top portion of the bend.

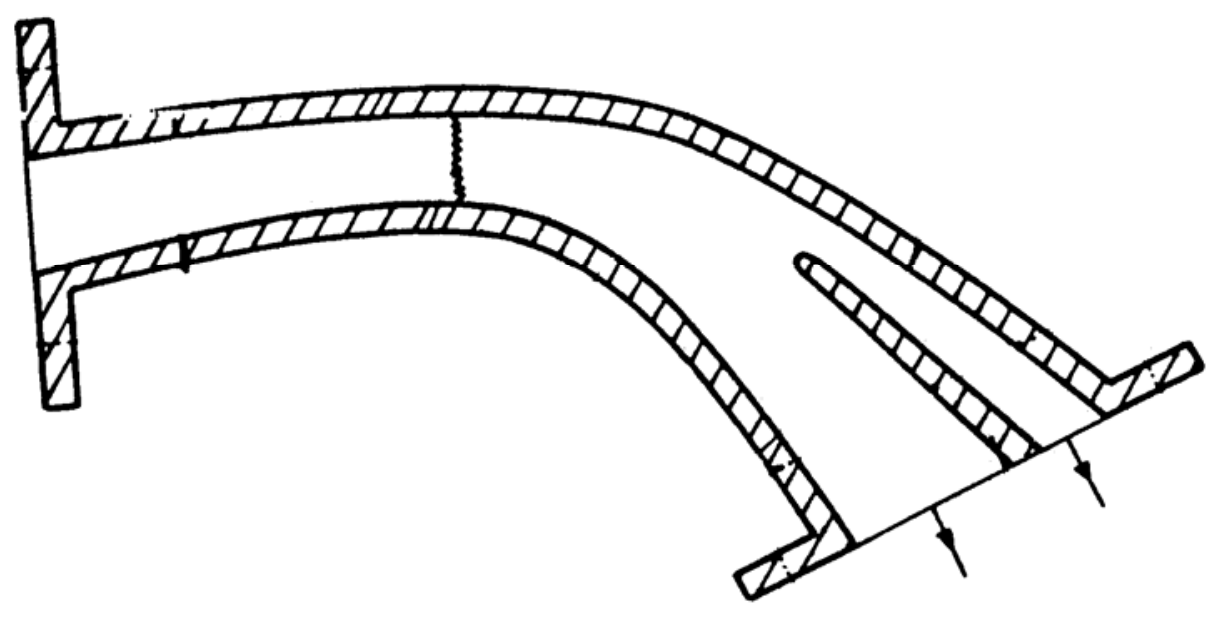

Figure 5: The Gas Separator by Nasikas Utilizing Normal Shock Waves [4]

The patent by Betting et al. $[5,6,7]$ shown in Figure 6 is another example of a supersonic separator using a shock wave to separate the different components of a mixture. It works by inducing a swirl and expanding the flow to supersonic speeds that causes the condensation of the desired part of the flow. The axial flow is then decreased to subsonic flow by a controlled shock wave. This increases the swirl ratio because the tangential velocity either increases or remains unchanged, improving the collection efficiency of particles removed after the shock wave. 


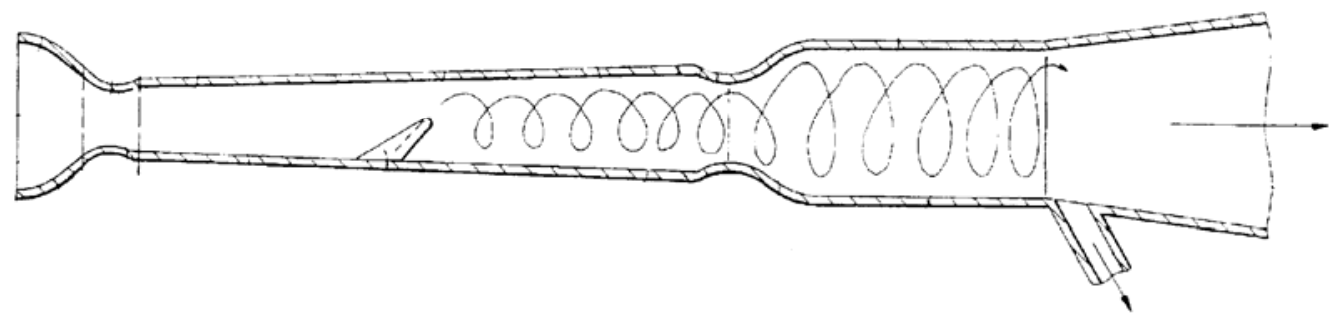

Figure 6: The Gas Separator by Betting et al. [5]

The patent by Niemann [35] separates uranium isotopes by using an oblique compression shock wave which deflects the lighter components while the heavier continue straight through. It works by speeding the gas to a supersonic velocity. It then passes the gas by a protrusion which causes the oblique shock wave which separates the components of the mixture based on their molecular weight.

\subsection{Invasion Induced Separation}

Another method of separating a mixture of gases based on molecular weight utilizes the technique of passing a mixture through a free stream shock wave. The method described by Campargue [8,9] uses a similar nozzle and skimmer design described in this thesis. The difference being that it doesn't use free stream diffusion to separate the gas mixture. It separates the gases by passing a mixture that is in the background through the shockwave which causes the separation of the gases based on their molecular weights. A barrel shock structure is formed by an auxiliary gas that freely expands as it leaves the nozzle which then attaches to the skimmer. The gas flow inside the shock structure remains supersonic. The walls of the barrel shock act as a barrier which lets in the lighter gas component of the mixture outside of the barrel shock. 
The lighter gas is then carried by the interior flow of the shock barrel through the skimmer.

The paper by Campargue [8] is an analysis of the flow behavior of a freely expanding gaseous flow and the separation techniques using the invasion method. It was found that the shock structure that is attached from the nozzle to the skimmer is visible through the use of Schlieren visualization. Within the shock structure the gases behave according to the conditions according to the behavior of a perfect vacuum. It was also found that the most efficient skimming and a high intensity molecular beam can be obtained only when the skimmer opening is located upstream of the Mach disk. This is because the divergent streamlines of flow in the subsonic flow result in less flux if the skimmer is downstream of the Mach disk. Campargue also found that if a background gas is introduced containing a mixture of heavier and lighter components, the lighter components will pass through the shock structure more easily and travel through the skimmer. The auxiliary gas which is used to create the barrel shock wave is then removed by condensation downstream of the skimmer, leaving a higher concentration of the lighter gases than was initially introduced in the mixture.

The patent by Campargue [9] in Figure 7 uses this invasion method to separate the lighter components of a mixture of gases. The auxiliary gas which forms a shock over the skimmer acts as the barrier for separation. Part of the background gas which is comprised of a higher portion of the lighter gas, passes through the barrel shock and leaves through the skimmer. 


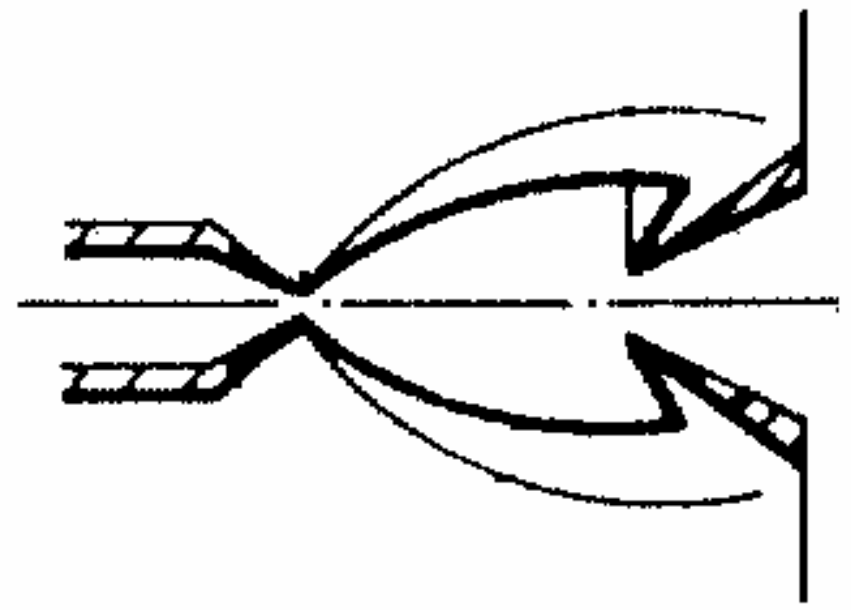

Figure 7: Invasion Separator by Campargue [9]

\subsection{Free Expansion Diffusion}

Free expansion diffusion works by allowing the gas molecules to separate based on their ability to diffuse which is determined by their molecular weight. The gaseous mixture is passed into an unconstrained chamber where it is allowed to freely expand. If the mixture is supersonic in the expansion region, then it will form an expansion shock wave. If the flow is subsonic then it will simply form a column along the axis of the flow. In both cases the components of the mixture will separate due to their different diffusion rates. The lighter components will diffuse radially at a faster rate than the heavier components. This will cause a higher concentration of the lighter gases along the periphery of the flow and a higher concentration of the heavier components along the core of the flow.

The Dickens patent [10] works by passing the gaseous mixture through a nozzle into an unrestricted chamber and the flow is collimated. The lighter components move radially outward at a faster rate than the heavier components. As can be seen in Figure 8 skimmers are placed downstream from the nozzle which removes the outer surface of the 
column of gas which is more concentrated with the lighter components than the core of the flow.

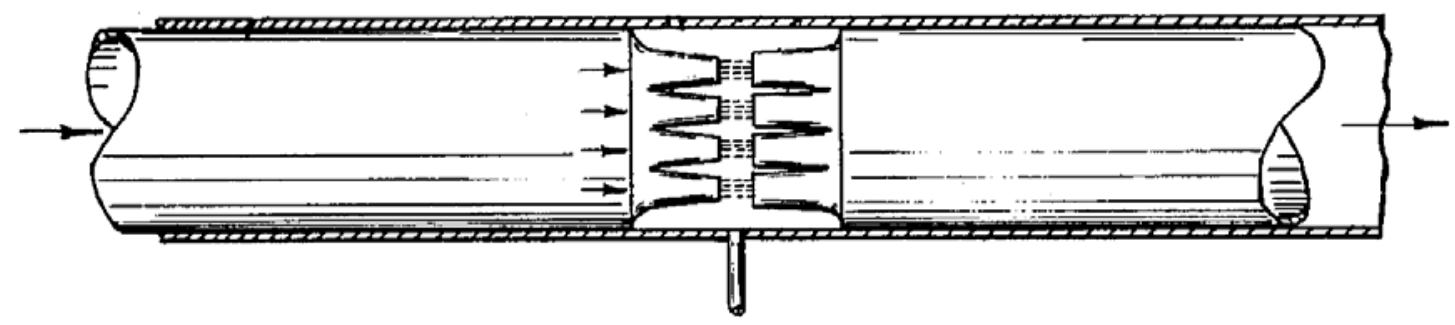

Figure 8: The Free Jet Diffusive Separator by Dickens [10]

The 1989 patent by Brandt [11], shown in Figure 9, employs the nozzle/skimmer arrangement to form a supersonic beam of gas. The free expansion of the gas forms a barrel shock structure that attaches to the front of the first skimmer. The flow inside this structure undergoes diffusive separation where the lighter components are concentrated out towards the periphery of the flow. A skimmer is placed down stream of the nozzle that allows the core of the flow to pass through which deflects the outer portion of the flow. 


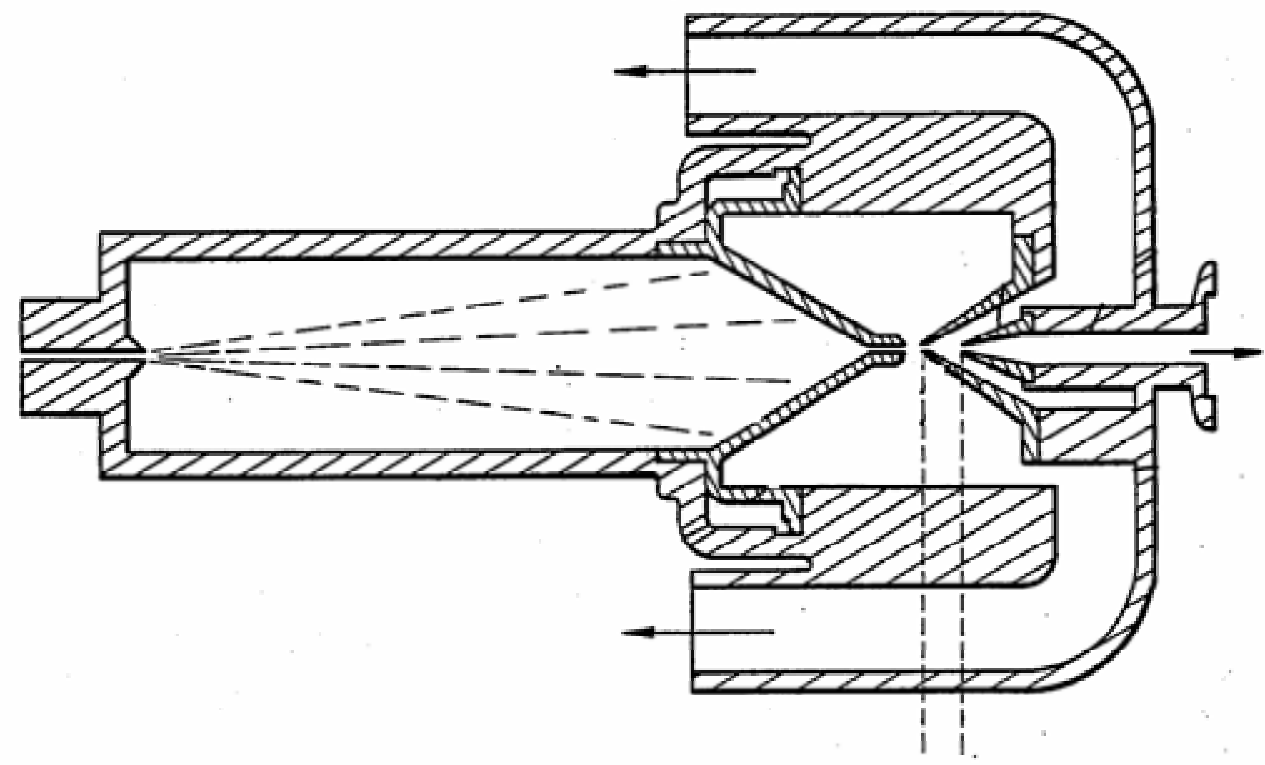

Figure 9: Supersonic Beam Separator by Brandt [11]

The patent by Campargue $[8,9]$ which uses the invasion method to separate the lighter components of a mixture of gases also uses free expansion diffusion to cause separation. An auxiliary gas freely expands from a nozzle into a vacuum chamber where it achieves supersonic speeds. The free expansion shock structure attaches to the skimmer.

\subsection{Skimmers}

The device that is the subject of this thesis [Figure 2] uses skimmers to remove the outer layer of the flow from the flow with a higher concentration of heavier molecules along the central axis. The skimmers are essentially diverging nozzles that are offset downstream a certain distance from the nozzle in order to deflect the outer periphery of the gaseous stream. The following are examples of skimmers used with various types of diffusion separators to help form a better understanding of their use. 
Dickens [10] uses diffusion to separate gases based on molecular weight. Skimmers were used to remove the outer surface of the gas column containing a higher concentration of lighter gases from the inner core of the flow.

The patents by Becker $[12,13$, and 14] are another example of skimmers being used to separate a flow. In the device shown in Figure 10, the heavier and lighter species are concentrated in different parts of the flow by centrifugal forces. Then a skimmer was placed in the path of the flow to separate the two portions of the gas with different concentrations.

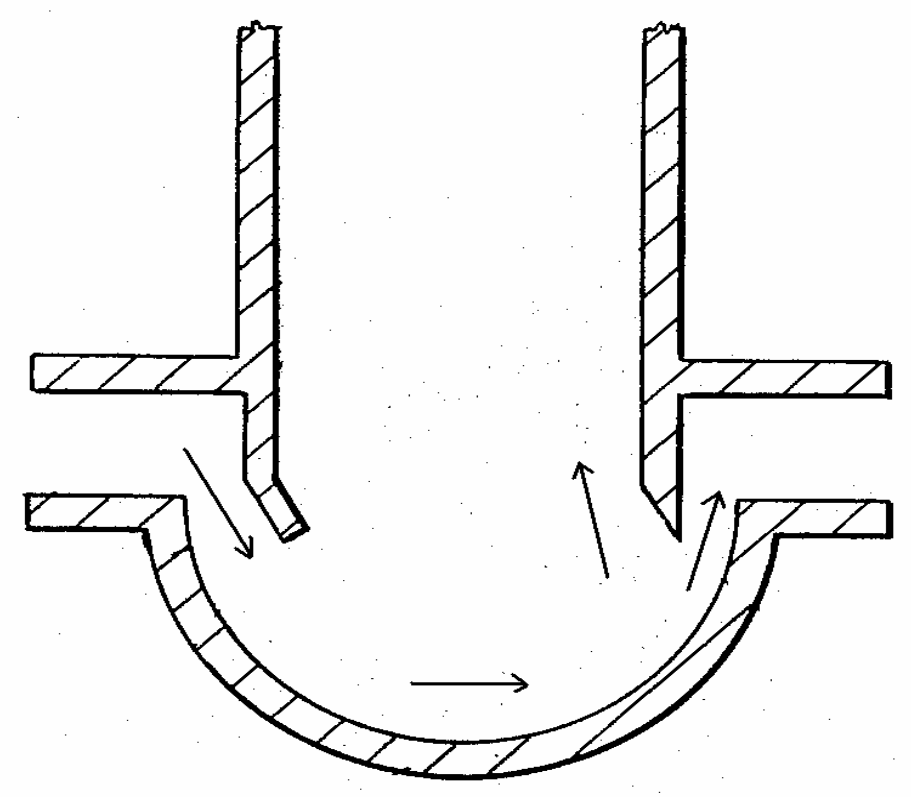

Figure 10: Nozzle Skimmer Separator by Becker [12]

The patent by Campargue [15] shown in Figure 11 is an apparatus for the creation of a beam of gas using a nozzle and two frustoconical diverters. The device is solely for the production of a beam using a single gas but it employs a similar theory to the present invention being researched for this thesis. It requires a near vacuum so that a free expansion shock wave isn't formed. The device uses skimmers in order to create a 
supersonic beam. These skimmers are in a similar arrangement as the device used in this thesis, and still act to remove the outer periphery of gas.

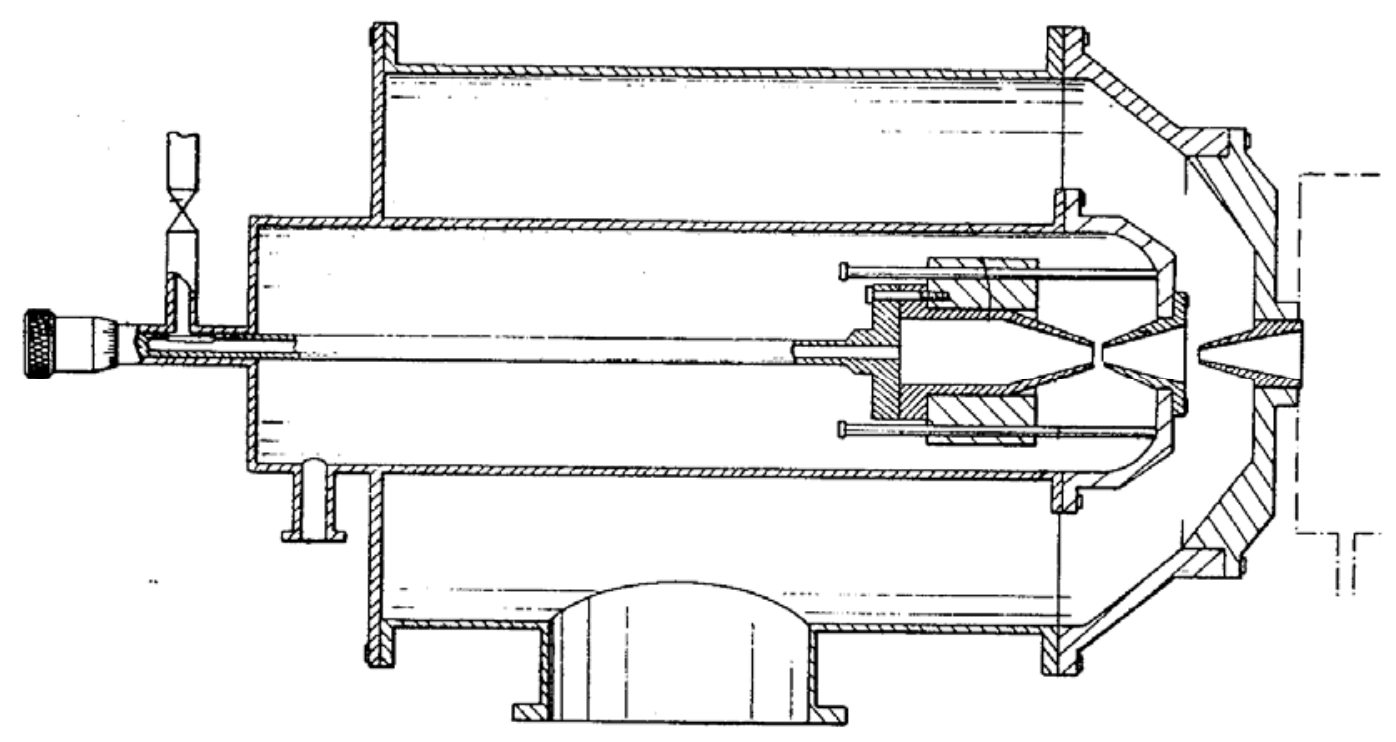

Figure 11: Apparatus for Producing a Beam of Particles by Campargue [15]

Campargue's patent [9] which uses a free expansion shock wave of an auxiliary gas also uses a skimmer to separate the gas stream into two separate flows. The skimmer is conical and functions by only allowing the inner flow of the barrel shock to pass through. This inner flow that passes through the skimmer is the separated lighter constituents of the injected background gas.

Another patent using a nozzle and a series of skimmers by Dahneke [16] shown in Figure 12 is designed to remove particles from a gaseous flow. It therefore isn't designed for gas-gas separation but it uses a similar setup the device used for this thesis. It relies on the trajectories of the particles based on their mass and the dimensions of the separator. The skimmers are placed based on the trajectory of the particles exiting the nozzle. The trajectory of the particles is determined by their mass and size so that the 
heavier particles are able to pass through the skimmers. The trajectory determines how they are separated by the skimmers.

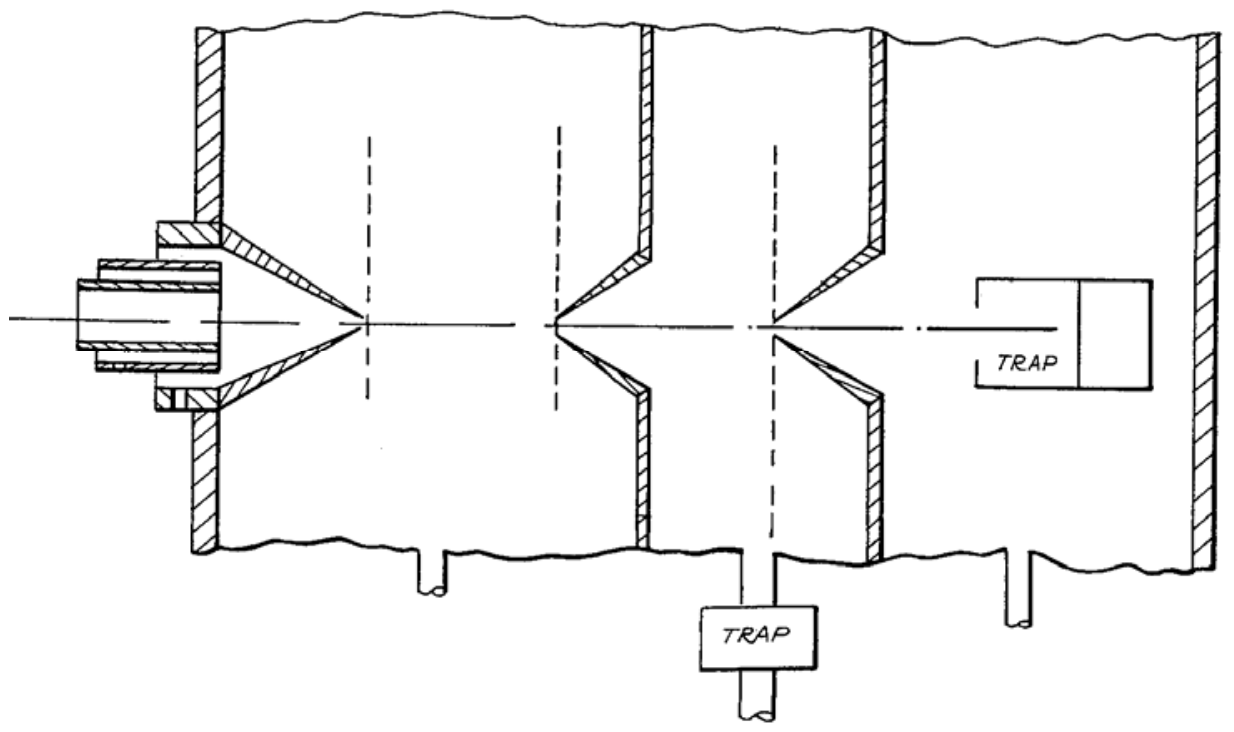

Figure 12: The Particle Separator by Dahneke [16]

The aerodynamic separator by Maldague [17] shown in Figure 13 is a separator that uses centrifugal forces to separate the gas mixture based on molecular weight. To remove the outer layer of the gas flow the device uses a skimmer. This peels off the part of the flow consisting of a higher concentration of heavier particles than the central core of the flow.

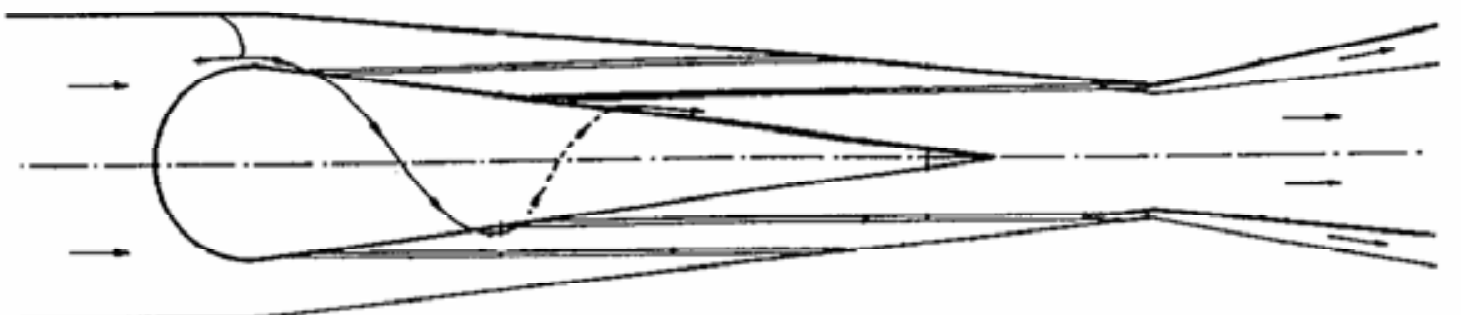

Figure 13: Picture of the Aerodynamic Separator by Maldague [17] 
The patent by Nasikas [4] uses a shock wave and a bend to separate condensed particles from a gas flow. To divide the flow the invention uses a skimmer which separates the part of the flow concentrated with condensed particles from the part with a higher concentration of light particles.

The two inventions by Betting and Alferov $[5,18]$ which induce a swirl on the flow to cause separation also use skimmers along the periphery of the structure to remove the outer portion of the flow which has a higher concentration of heavier particles from the rest of the flow. Figure 14 is the invention by Alferov which works by speed the gas up to supersonic speeds until the desired constituents of the gas mixture are condensed and removed by the outer skimmer.

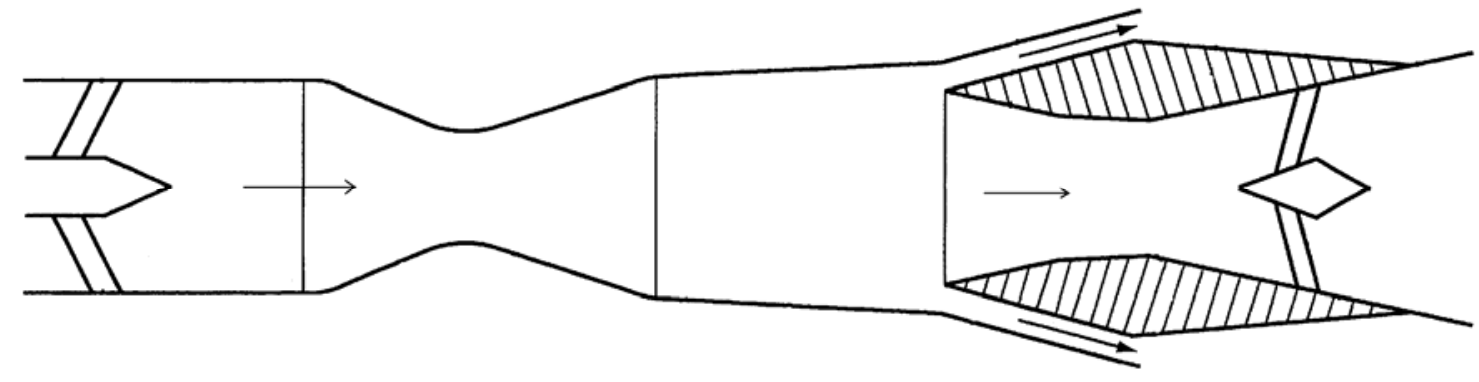

Figure 14: The Supersonic Gas Separator by Alferov [18]

The skimmers used by these devices serve the same purpose as the one used in this thesis, although the method of separation isn't always the same. Therefore a good understanding about them is necessary to the understanding of the current work.

\subsection{Summary}

The inventions described in this literature review use diffusive separation similar to the type used by the device in this thesis. Whether the people have used centrifugal 
forces, shock waves, and free diffusion to separate one gas from another, all these inventions use the same idea of separating gases based on their molecular weight. 


\section{Apparatus and Model}

The gas separator used in this invention [Figure 2] is of the same configuration as the one used by Brandt [11]. It consists of a nozzle to accelerate the gas to supersonic velocity and two skimmers to divert the outer periphery of the gas allowing the central core to pass through which is the same process used by previous researchers $[19,20,21$, 22, 37]. The skimmers break the device up into three chambers. As seen in Figure 2 in Chapter 1 the first chamber is located in between the nozzle and the first skimmer, the second chamber is located in between the first and second skimmer and the third chamber is located after the second skimmer. The system is powered by a pressure difference which is controlled upstream of the nozzle and in each of the chambers. The purpose of the design is to separate one species of gas from another based upon molecular weight. In order to do this, the gas will need to be accelerated to supersonic speeds to create the necessary diffusive separation $[19,20,23,24,25,26,27,34]$. According to supersonic theory [33] the downstream pressure is required to be less than $52.828 \%$ of the stagnation pressure to achieve supersonic speeds. There is an inlet and two separate outlets on each side of the device in both of the first two chambers. There is a final outlet at the end opposite the inlet after the second skimmer. The device will be 5.91 in long and the cross section will be 1.85 in by 1 in.

The nozzle used in this device is a sonic nozzle [19, 20, 26-32]. Figures 15 and 16 are dimensional drawings of the nozzle and skimmer and Figure 17 is a solid model of the nozzle section made using Pro Engineer. The physical model will have a nozzle that has a $0.076 \mathrm{in}$ by $0.2 \mathrm{in}$ rectangular throat with a thickness of $0.102 \mathrm{in}$. The half angle of the nozzle is 38 degrees. All of units in the following dimensional figures are in inches. 


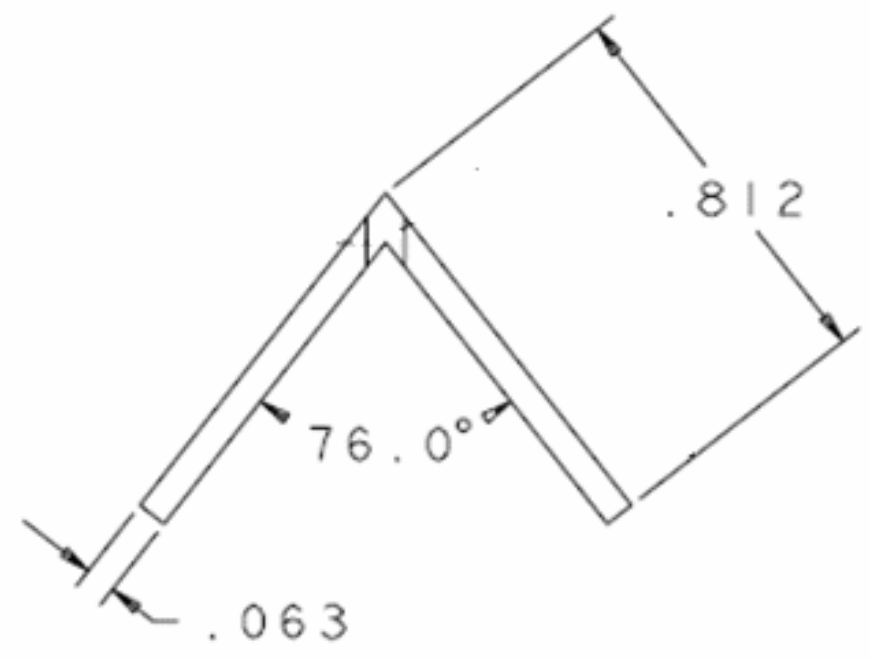

Figure 15: Side Dimensional Drawing of Sonic Nozzle (inches)

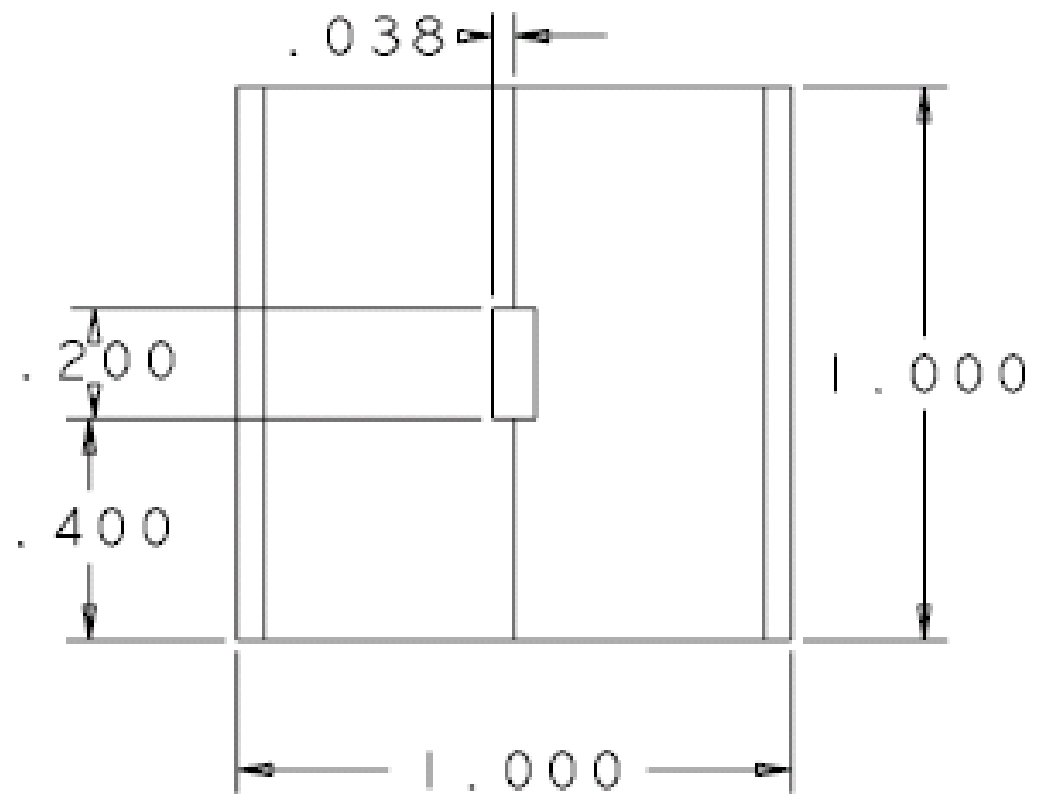

Figure 16: Front Dimensional Drawing of Sonic Nozzle (inches) 


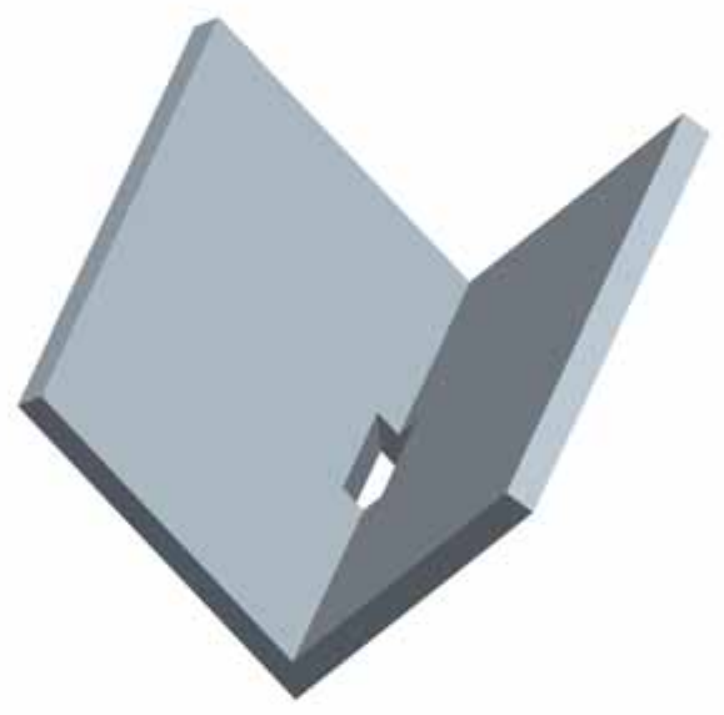

Figure 17: A Solid Model of the Sonic Nozzle

The offset distance between the nozzle and the first skimmer is $0.1575 \mathrm{in}$ and the distance between the nozzle and the second skimmer is 0.4724 in. Figures 18 and 19 are dimensional drawings and Figure 20 is a solid model of the first skimmer section. The half angle of the first skimmer is 40 degrees with a throat cross-section that is 0.078 in by $0.2 \mathrm{in}$. 


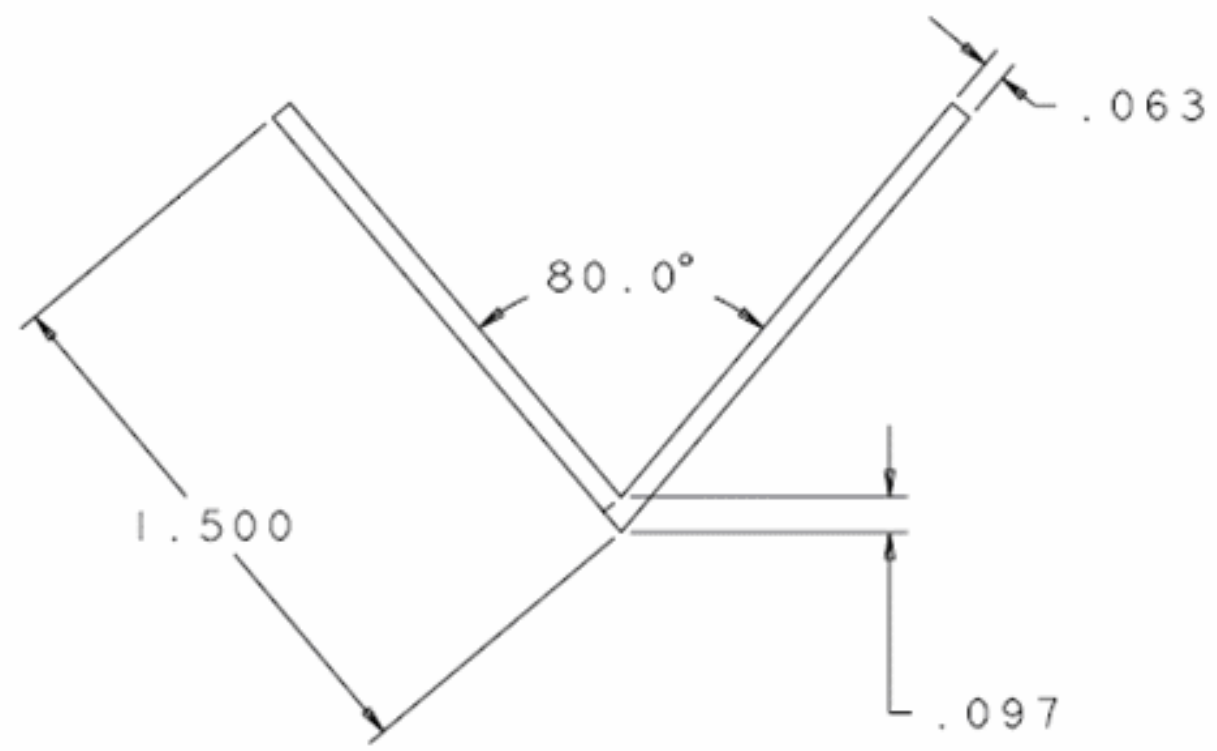

Figure 18: Side Dimensional Drawing of First Skimmer Section (inches)

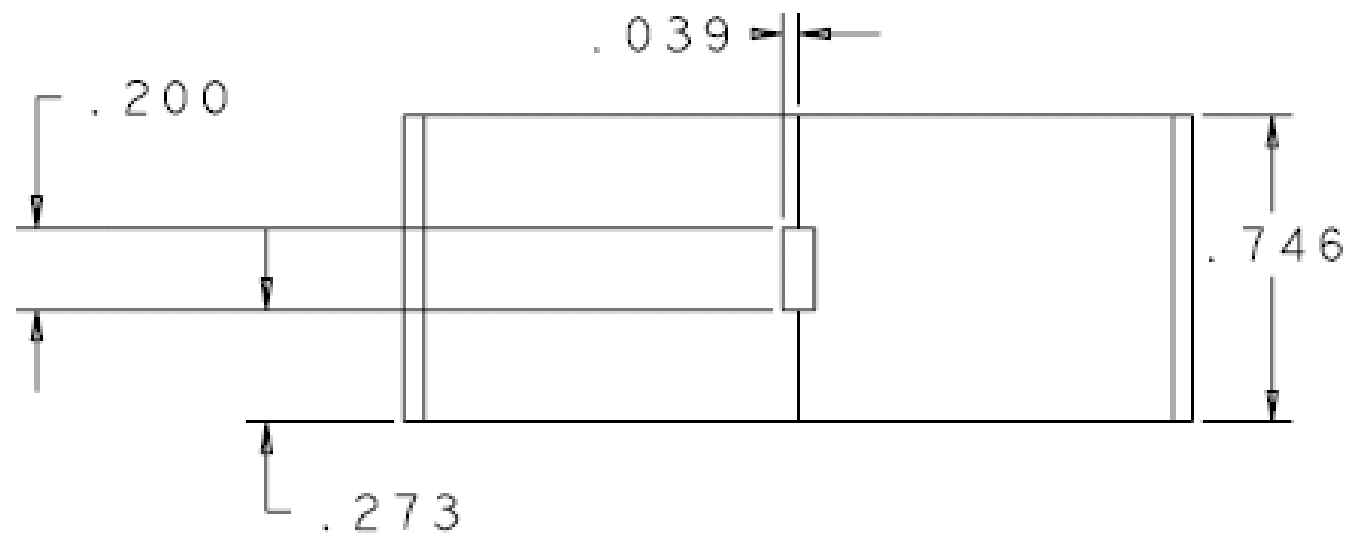

Figure 19: Front Dimensional Drawing of First Skimmer Section (inches) 


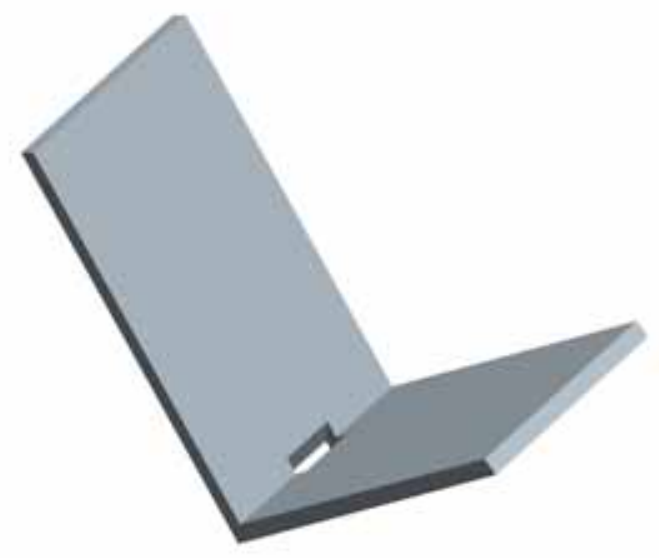

Figure 20: A Solid Model of the First Skimmer Section

Figures 21 and 22 are dimensional drawings of the second skimmer and Figure 23 is a solid model of this skimmer section. The half angle of this skimmer is 20 degrees with the same throat cross-section as the nozzle. 


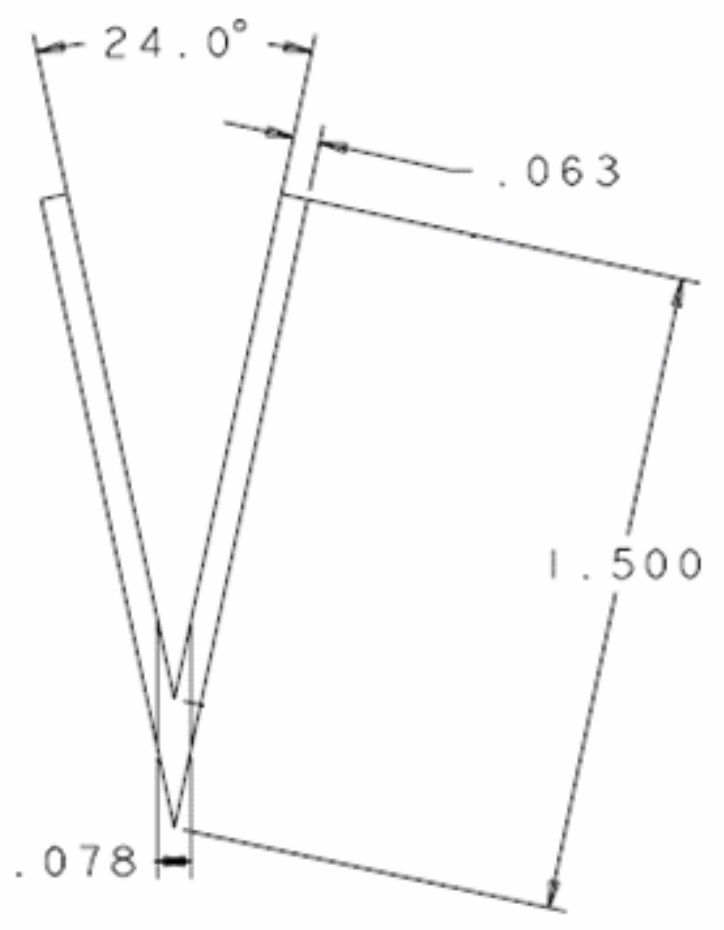

Figure 21: Side Dimensional View of Second Skimmer Section (inches)

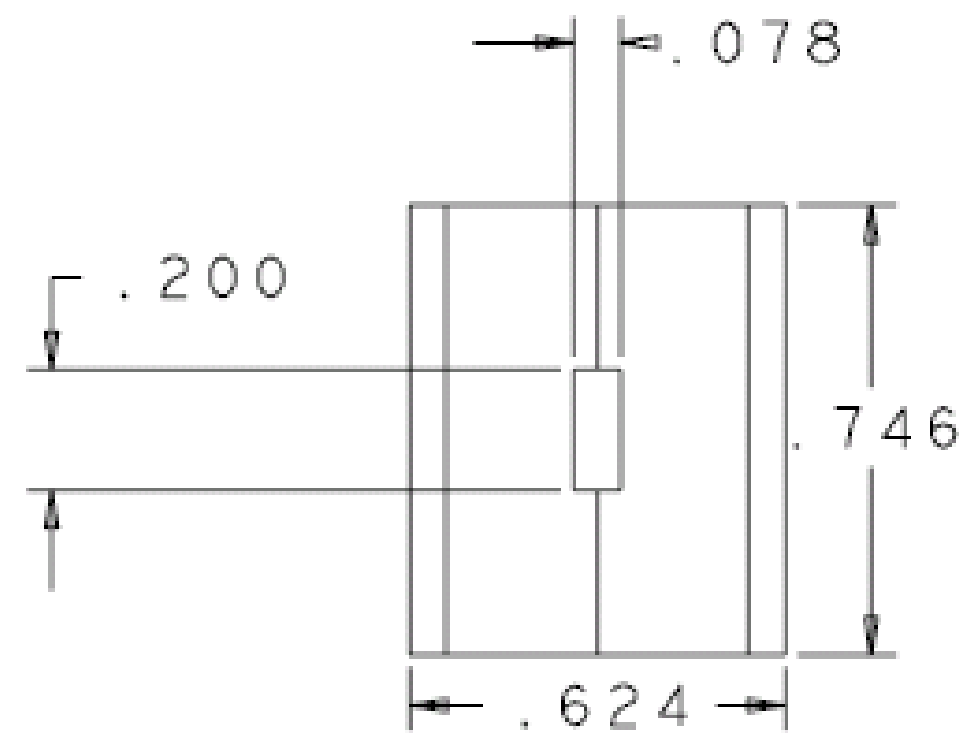

Figure 22: Front Dimensional Drawing of Second Skimmer Section (inches) 


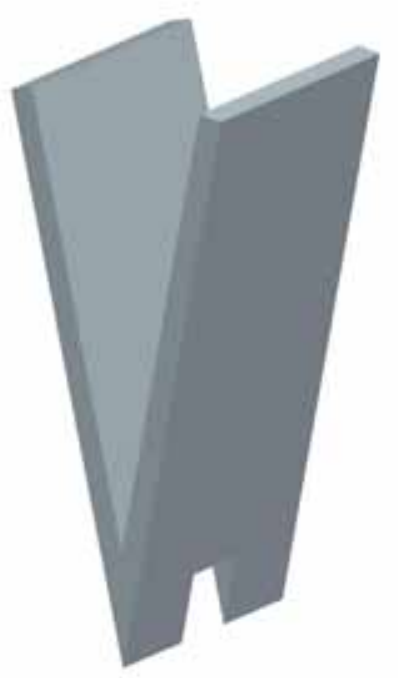

Figure 23: A Solid Model of the Second Skimmer Section

The type of nozzle on the device is converging and it has a rectangular slit opening. When the gas leaves the nozzle, it freely expands in the chamber after the nozzle to a supersonic velocity. A shock structure often called a barrel shock $[8,9,11]$ forms in the first chamber around the axial flow of the gas and attaches to the lips of the skimmer. The gas inside this shock structure remains supersonic and provides a diffusive separation of the different components of the gas based on their molecular weight. Figure 24 is a picture of the shock structure in between the nozzle and the first skimmer. 


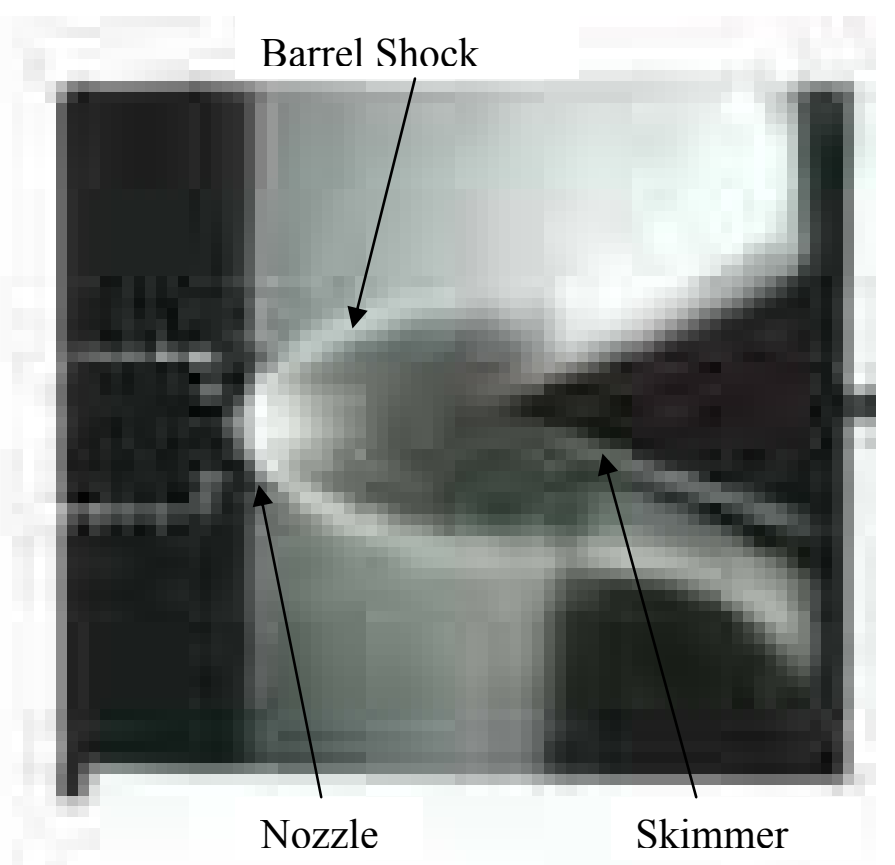

Figure 24: Schlieren Image of Barrel Shock Attached to Skimmer [27]

The lighter gases will have a higher diffusivity than the heavier components and will move radially outward at a faster rate $[24,25,32]$. Therefore the heavier gases will be more concentrated along the core of the flow while the lighter components will be more concentrated along the periphery. The lighter constituents that moved radially outward are deflected by the skimmers, leaving through the two side outlets in the first chamber. The second skimmer will work in much the same way as the first skimmer does in removing the lighter components of the gas mixture.

According to supersonic beam theory a Mach disk occurs at a distance $X_{m}$ downstream from the nozzle during a free expansion where the flow turns from supersonic to subsonic speed $[8,15,18,24-27,32]$. This distance is dependant on the diameter of the nozzle exit plane, and the stagnation and back pressures. The distance is important because the most efficient beam formation occurs when the first skimmer is located upstream of this point, allowing the barrel shock to attach to the skimmer. 


\section{Design Approach}

The use of Fluent is necessary for the development of the device used in this thesis because of the large number of configurations as well as conditions of the flow that can be used and which determine the amount of separation achieved by the device. If a CFD program wasn't used in the design process then a separate physical model would need to be created each time a setting was changed. This would cost considerable time and money. Therefore many CFD models can be created and run for each physical model built which will greatly facilitate the design process. The computational model is also crucial for the future development of a computer program to automate the solving of many of the flow characteristics of the device based on the design and initial conditions. This will be used to speed up the design and construction of new models based upon the desired conditions.

Starting from just a single nozzle the model was evolved to a nozzle and a single skimmer and finally a second skimmer was added. This was done to make sure that the Fluent models that were built produced results that physically made sense at each stage of the device. The results from Fluent depend on the model, the meshing of the interior of the model and the initial conditions the fluid was set at. When Fluent is run it calculates the different aspects of the flow at each nodal point in an iterative process. The models are computed for thousands of iterations until the desire level of convergence is obtained. The order of convergence is simply the change in values at each nodal point from one iteration to the next. Typically the further the model is converged, the more accurate the results are. Therefore a balance has to be maintained between the complexities of the mesh, the time allowed for it to be solved and the desired accuracy of the results. As can 
be seen in the first three cases in Section 4.1, when the meshing of the model isn't symmetric, it can greatly influence the accuracy of the results.

The Fluent cases that follow briefly show the evolution of the Fluent model ending with the final model which will be compared to analytic calculations to determine the level of correlation between the Fluent and analytic results. The development of the final model consisted of varying the design and mesh configuration in order to improve the convergence rate and accuracy of the model. Which was done be continual observation of the results and improvements as well as computational time, some models were converged farther than others before eventually being discarded for a newer model when changes were made.

\subsection{Nozzle and Single Skimmer Models}

The model shown in Figure 25 is a one skimmer model done to show the supersonic effects of Fluent. The skimmer was 1.1811in from front to back, both the skimmer and the nozzle have a 40 degree half angle and the offset distance between the two is $0.1969 \mathrm{in}$. It was run for 18,715 iterations and until approximately second order convergence. The mesh has 62,276 nodes, and as can be seen from Figure 26 the flow trailed off to the left after the skimmer when it should have continued straight down the middle. This is because the mesh wasn't symmetric which caused an error in calculations. To solve this problem the next models were done using the symmetry option in Gambit which is the software used to create the models that are run in Fluent. 


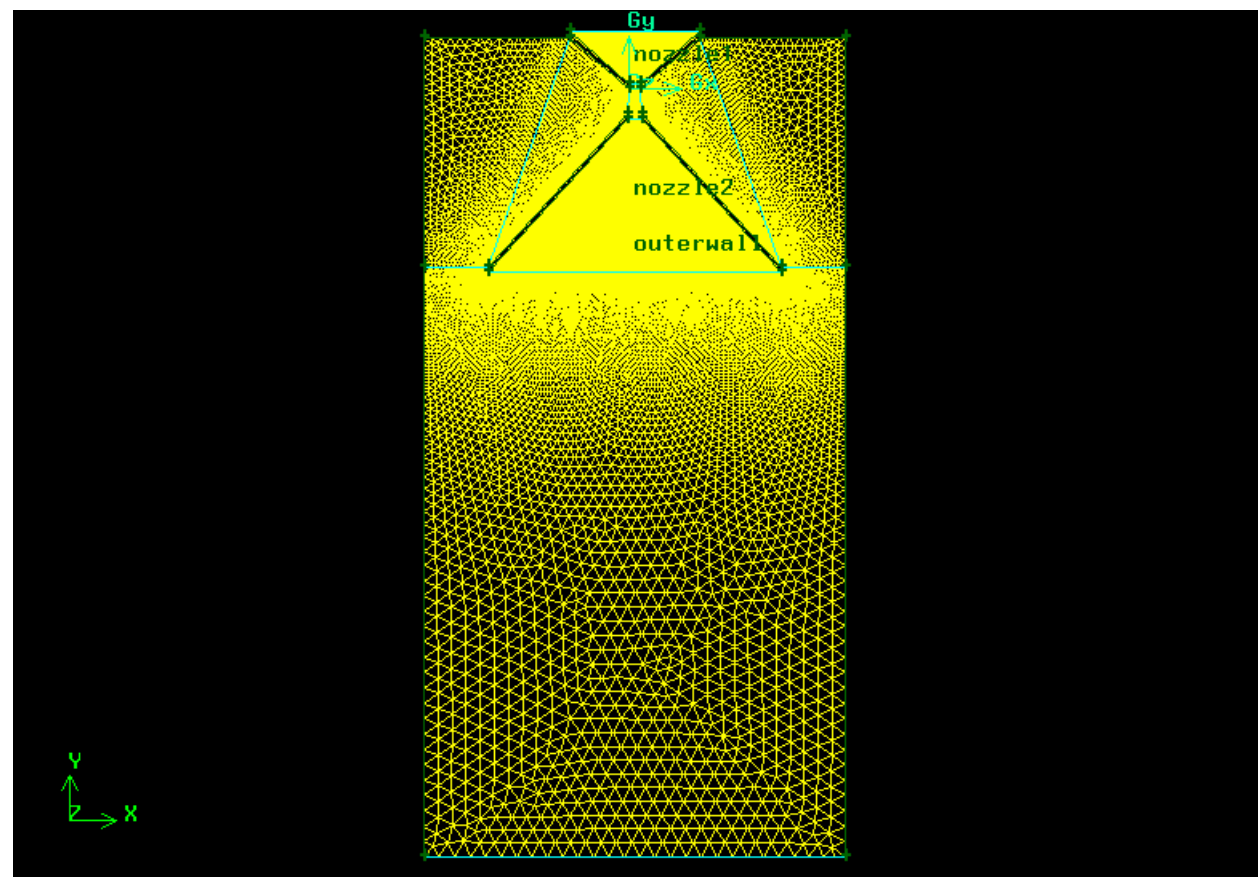

Figure 25: The Meshed Model of the Single Skimmer Design

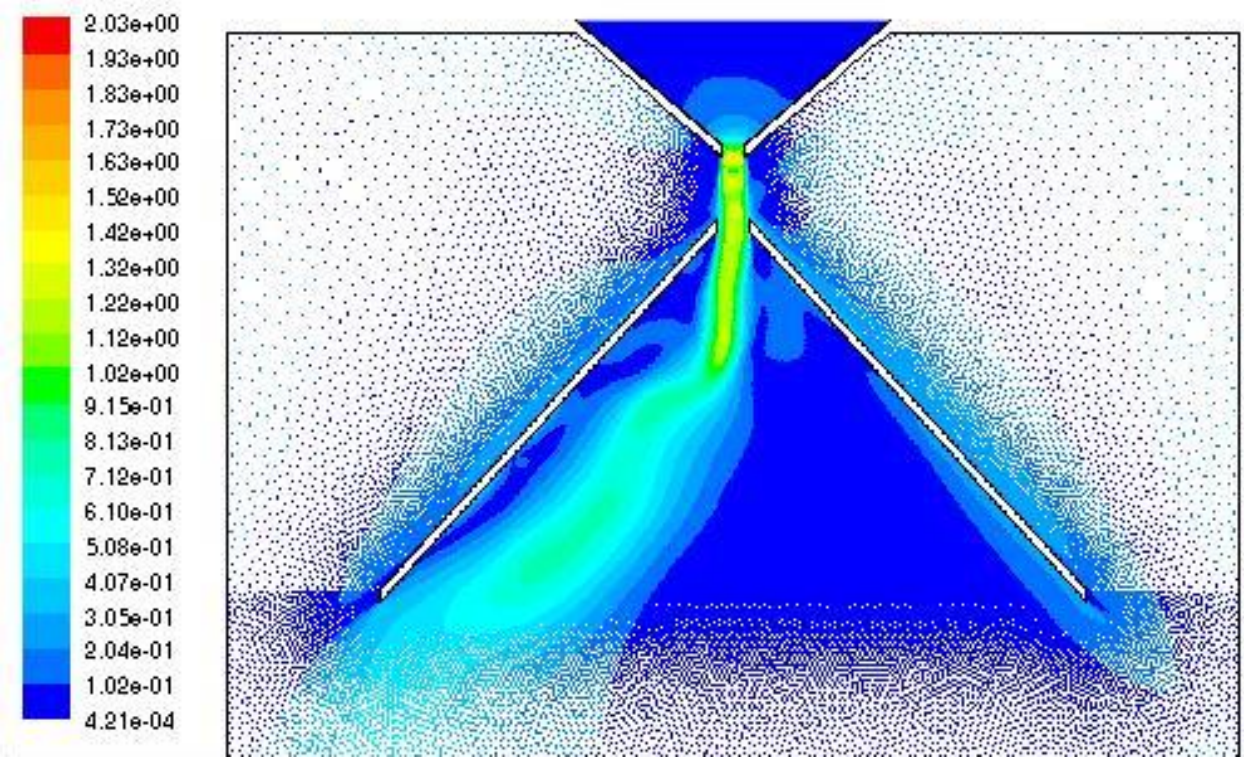

Figure 26: Contour Plot of the Mach Value of the Gas in the Single Skimmer Model

For the mesh shown in the Mach vector plot in Figure 61 in Appendix A, the problem of the flow veering off was similar to the previous model. The model was changed so that the side and bottom walls attached to the skimmer and set as pressure 
outlets. There were 26,413 nodes in the mesh and the inlet pressure was $50 \mathrm{psi}$ and was run for 107,904 iterations. The flow still trailed off due to the asymmetric mesh.

\subsection{Two Skimmer Models with Similar $1^{\text {st }}$ and $2^{\text {nd }}$ Skimmers}

The next design shown in Figure 27 is the Mach vector plot of the flow in the device, which was run with a 20 psi inlet gage pressure and a $14.7 \mathrm{psi}$ background pressure. It was run 93,716 iterations until better than third order convergence. The model had 49,694 nodes and it was done simply to view how Fluent would model the effect of flow around to skimmers. The offset distance between the nozzle and first skimmer is 0.1969 in, and the distance between the front of the first skimmer and the second is $1.2598 \mathrm{in}$.
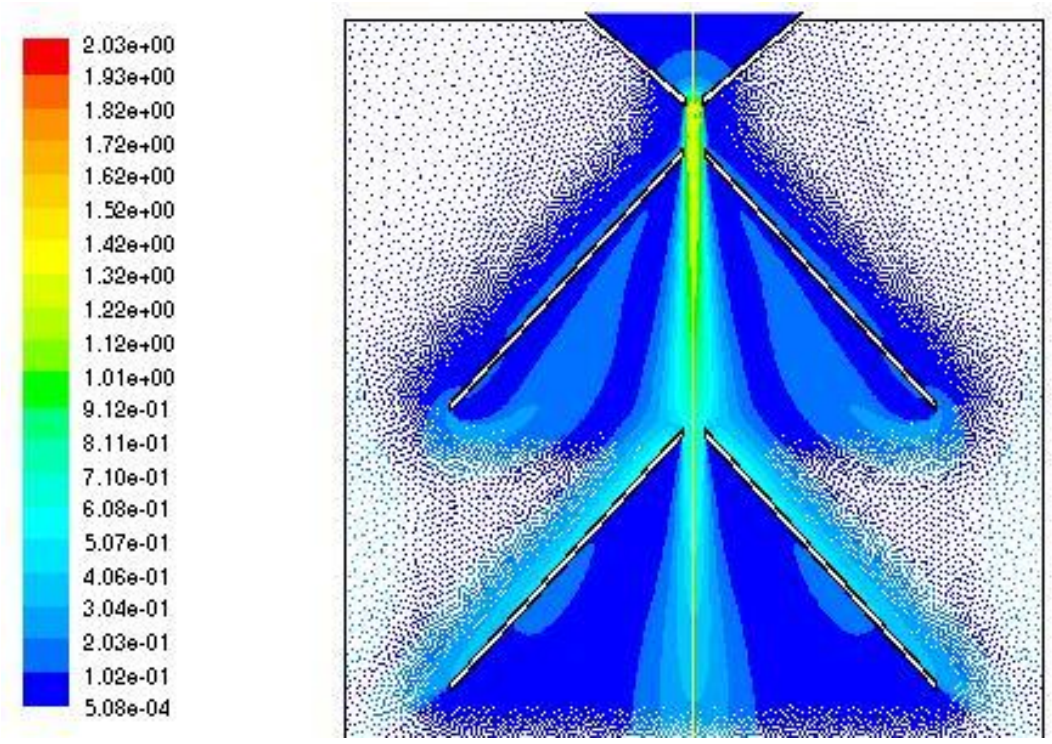

Figure 27: Mach Contour Plot of Single Chamber Two Skimmer Model

The previous model was then adjusted to have a 0.5906in offset distance between the nozzle and skimmer and is shown in the Mach vector plot in Figure 62 in Appendix A. It has 52,954 nodes and was run 50,908 iterations until approximately third order convergence. The inlet pressure was increased to 30psi in order to achieve a higher Mach 
number. Both Figure 27 above and Figure 62 in Appendix A show the flow continuing straight through the device due to the corrected mesh.

The following model shown in Figure 28, which is a Mach gradient picture of the Fluent model, was constructed with two skimmers to view the effect of two skimmers with two segregated chambers. This was done because it was the next step in the development of the Fluent model which would more resemble the final model which would need two separate chambers. The number of nodes the mesh consists of is 18,791. The inlet pressure was set to $77.35 \mathrm{psi}$, and it was run for 122,590 iterations to second order convergence. The offset distance from the nozzle to the first skimmer is 0.3937 in for this case.

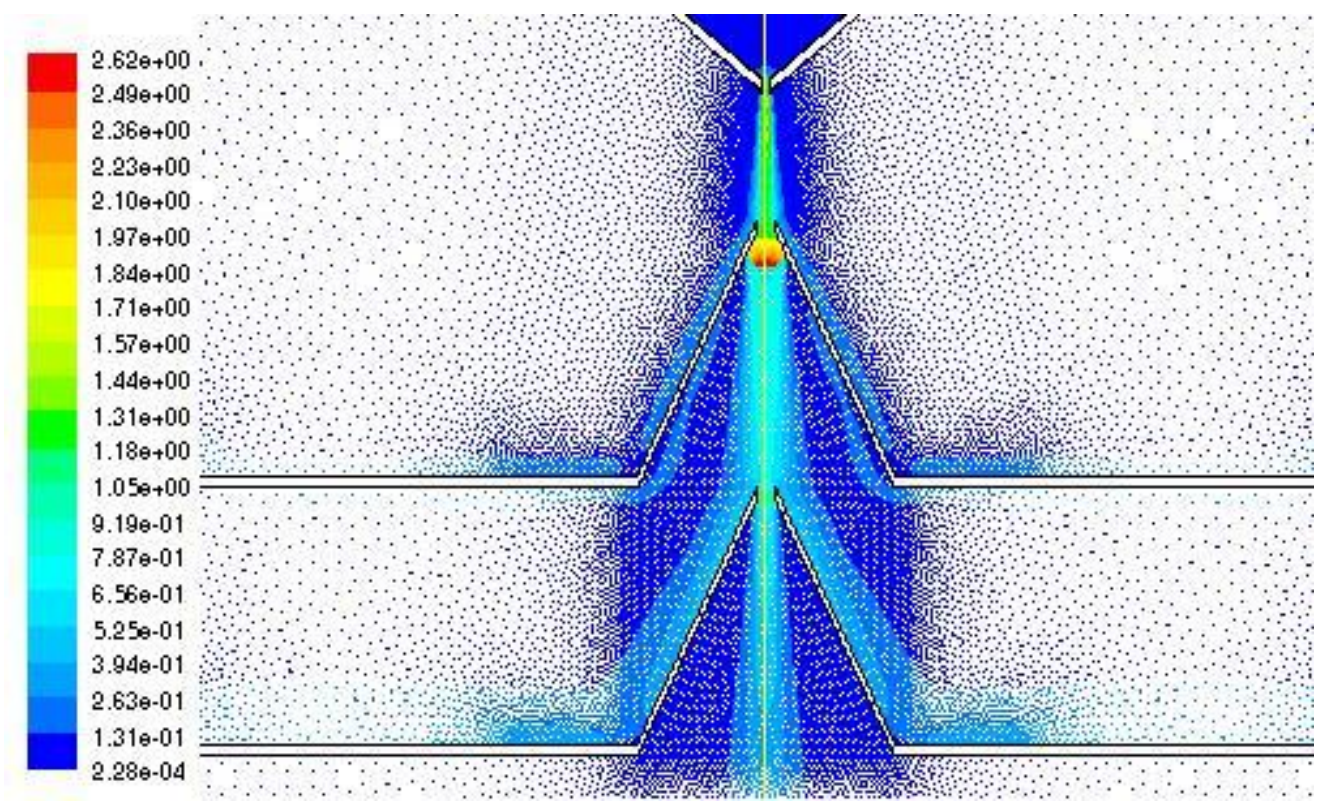

Figure 28: Mach Contour Plot of the Two Skimmer Model with Segregated Chambers

A second model was done with this configuration is shown in the Mach vector plot in Figure 63 in Appendix A. The initial offset distance was changed from 0.3937 to 0.9843in to see the how it would change the flow. The mesh was constructed with 21,954 nodes and run for 52,653 iterations until second order convergence. Figure 28 
above and Figure 63 in Appendix A both show the expected results of the gas accelerating through each chamber with a portion being diverted by each skimmer.

The first model that was done with two skimmers that end at the side walls is shown in the shown in Figure 29 which is the Mach gradient plot. The inlet pressure was set at 30psi gage with $14.7 \mathrm{psi}$ background. The model was run for about 46,000 iterations until approximately second order convergence of the residuals. The model is 5.9055in long with 0.1181 in outlets at the base of each skimmer. The skimmers have 0.0394in thick walls and 40 degree half angles. The offset distance between the nozzle and the first skimmer is 0.0394 in and from the front of the first skimmer to the second skimmer it is $1.3780 \mathrm{in}$.
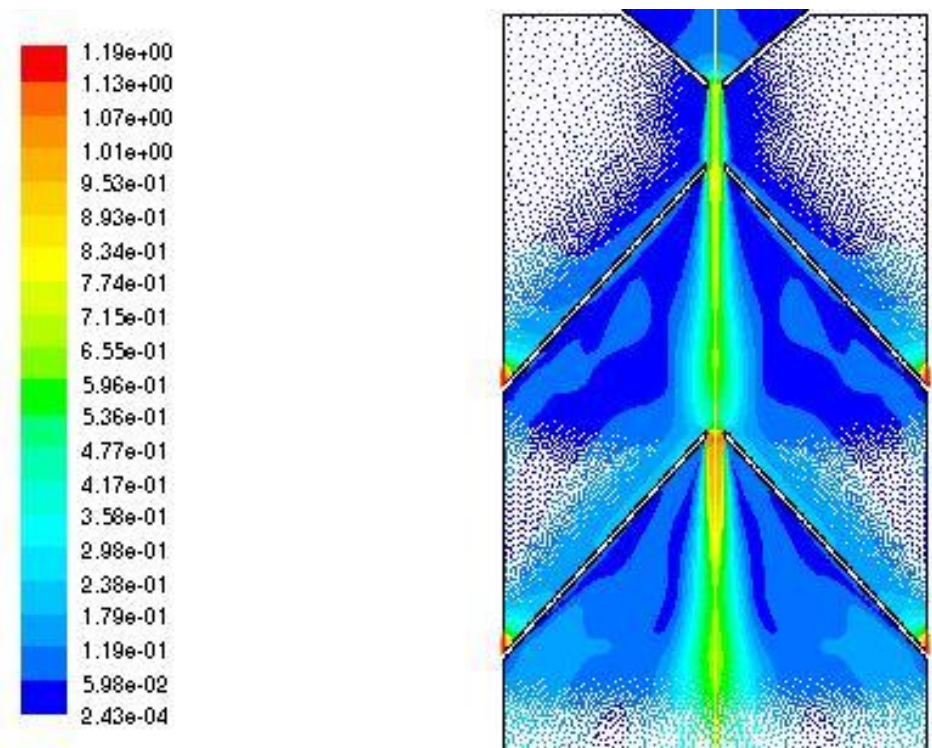

Figure 29: Mach Contour Plot of Two Skimmer Model with Side Walls

The following model shown in the Mach contour plot of Figure 64 in Appendix A has 20,518 nodes and is identical to the previous mesh except that the offset distance from the nozzle to the first skimmer is $0.5906 \mathrm{in}$. It was done with a $60 \mathrm{psi}$ inlet gage pressure instead of a 30psi as with the last mesh but with the same background pressure. 
The model was run approximately 160,000 iterations until about second order convergence.

\subsection{Two Skimmer Models with Differing $1^{\text {st }}$ and $2^{\text {nd }}$ Skimmers}

A new model was created with two skimmers of differing half angles and is shown by the Mach contour plot in Figure 30. The first skimmer half angle was 40 degrees and the second was 12 degrees. The offset distance from the nozzle to first skimmer is $0.1574 \mathrm{in}$ and from the nozzle to the second skimmer is $0.5118 \mathrm{in}$. The mesh was constructed with approximately 10,000 nodes and was run 75,000 iterations until second order convergence at $100 \mathrm{psi}$ inlet pressure. The model was setup again with a $0.5118,0.5512$ and 0.5906 inch second offset distance and run at 80psi for 60,000 iterations. The model was then adjusted to a 0.6299in second offset distance and run at 60, 70, and 80psi for 100,000 iterations until approximately second order convergence. The final comparative runs for the model were done at $60,70,80,90$, and 100psi inlet pressures for a model with a 0.1575 in first offset distance and both a 0.4724 and 0.6299 in second offset distance for 100,000 iterations until approximately second order convergence. This was done to view the effects that varying the inlet pressures and second skimmer distances would have on the results. The effects were expected in that the expansion of the gas increased in each chamber as the pressure was increased. 

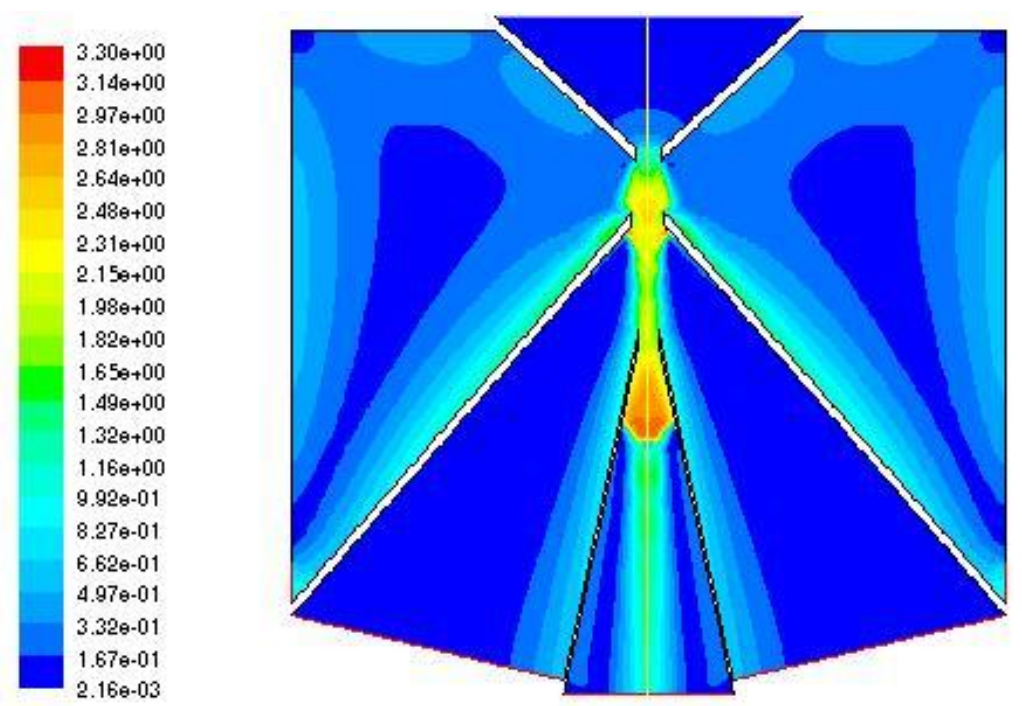

Figure 30: Mach Contour Plot of the Two Skimmer Model with Differing Half Angles

The model was changed so that the first offset distance is $0.3937 \mathrm{in}$ and the second is $0.7874 \mathrm{in}$. The mesh has 17,456 nodes and was run at an inlet absolute pressure of 64.7psi for 86,208 iterations until second order convergence. One last mesh was run with this configuration having a 0.5906 in first offset distance and a 0.7874 in second offset distance. It was run for 100,238 iterations until it reach second order convergence.

\subsection{The First Physical Model}

When the exact setup of the physical model, shown in the meshed model in Figure 31, was decided upon a new Fluent model was created to mirror it. The model has a distance from nozzle to the first skimmer throat of 0.1575 in and from the nozzle to the second skimmer throat of 0.4724in. The width of the nozzle and second skimmer throats are 0.078in and the width of the first skimmer throat is 0.079in and the depth of the nozzle and both skimmer throats in Fluent are 1in. The half angle of the first skimmer is 40 degrees, the half angle of the second skimmer was changed to 12 degrees and the nozzle is 38 degrees. The model has 18,837 nodes and was run at 60 psi for 200,000 iterations until approximately second order convergence was achieved with different 
meshes attempting to improve convergence and different viscous models. Fourth order convergence was obtained with the 11,035 node mesh after 250,000 iterations, and a 9,071 node mesh was also run until third order convergence. The main purpose of this was in comparison of three different viscous models; the SA, K-Epsilon, and K-Omega. Although equal convergence for each model wasn't achieved for each viscous model due to time required and adjusting the model.

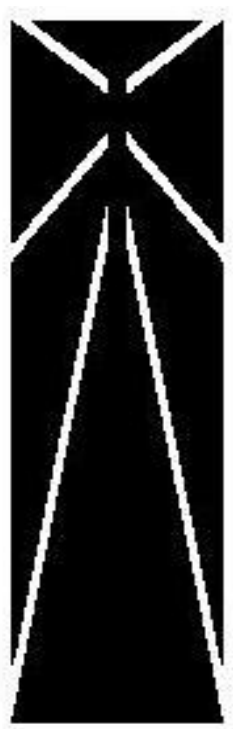

Figure 31: Meshed Model with Final Nozzle and Skimmer Dimensions

The model was then adjusted by moving each wall outward by about 0.2362 in to allow for outlets at the top and bottom of the device that mirrored the location in the physical model. This model is shown in Figure 32 which is a meshed grid. It was run with a $60 \mathrm{psi}$ inlet gage pressure and a $14.7 \mathrm{psi}$ background pressure. Figure 65 in Appendix A is the Mach gradient plot done in Fluent. The meshing was adjusted from a course 9,744 node mesh up to a fine 38,286 node mesh. The finer mesh was kept course in the locations of low velocity gradients in order to reduce the computational time of Fluent. The grids were run to better than third order convergence in as many as 400,000 iterations. 


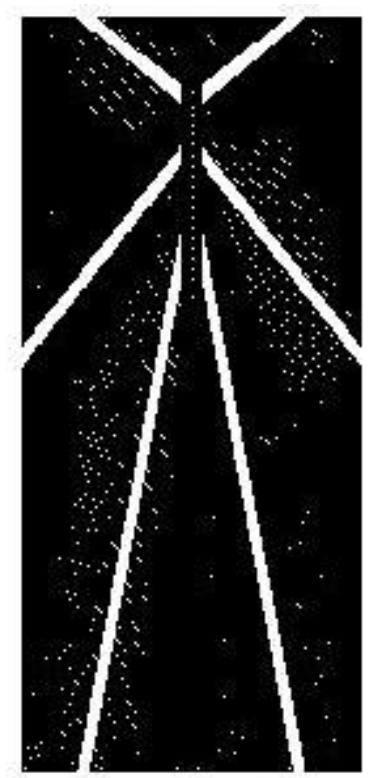

Figure 32: The Final Two Skimmer Model with the Adjusted Wall Spacing

\subsection{The Second Physical Model}

A second physical model was soon after constructed for this project and several models of it were created and run with an inlet pressure of 50psi. The meshing went from 14,471 to 54,318 nodes and was run approximately 150,000 iterations to better than second order convergence. The Fluent model is shown in Figure 33 and the Mach gradient plot done in Fluent is shown in Figure 66 in Appendix A. It was decided not to use this model since the means to visualize it using a Schlieren system wouldn't be available. 


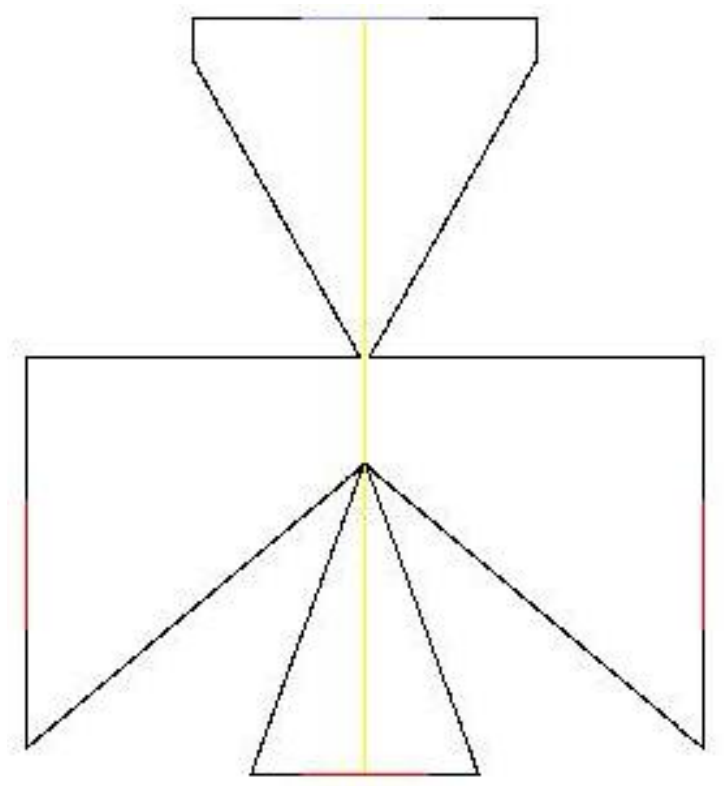

Figure 33: The Gambit Model of the Second Physical Design

In returning back to the model shown in Figure 32, an attempt was made to improve the speed at which the model converged. The model was broken into two sections. The first section consisted of the nozzle and first skimmer and is shown in Figure 34. The second section consisted of both skimmers and is shown in Figure 35. The model of the first section was run 160,000 iterations and the second for 360,000 iterations until third order convergence and the results in the throats appeared to be in error. The Fluent Mach gradient plot for both sections can be seen in Figure 67 and Figure 68 in Appendix A. Since the model wasn't converging properly the models were scrapped for the whole model with several adjustments to the design and mesh in order to improve convergence and decrease computational time. 


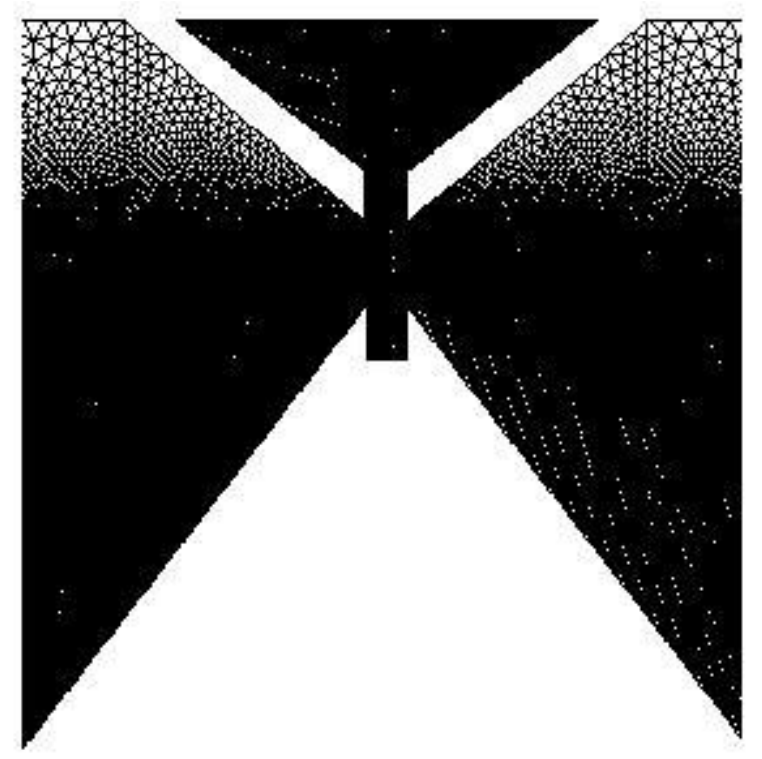

Figure 34: Sectioned Model Including both the Nozzle and First Skimmer

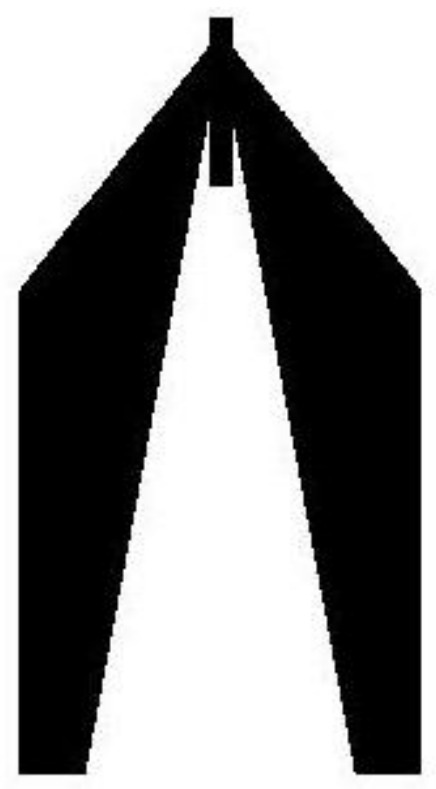

Figure 35: Sectioned Model Including both the First and Second Skimmers

\subsection{Final Fluent Cases and Parameters}

There will be five different cases that will be run to compare the effect that varying the pressure will have on the flow field. Table 1 shows each of the pressure cases. The 
pressure cases will start with 20psi in the first and second chamber and 30psi in the third chamber. The pressure will then be increased by 5 psi for each additional case ending with 40psi in the first and second chamber and 50psi in the third chamber. The drop in pressure was chosen because a $52.828 \%$ drop in pressure is required for a gas to achieve sonic flow. A slightly higher pressure was chosen for the third chamber in order to increase amount of gas removed through the first and second chambers.

Table 1: Pressure Values for Each of the Fluent Cases

\begin{tabular}{|c|c|c|c|c|}
\hline Case & $\begin{array}{c}\text { Inlet } \\
\text { Pressure }\end{array}$ & $\begin{array}{c}\text { 1st Chamber } \\
\text { Pressure }\end{array}$ & $\begin{array}{c}\text { 2nd Chamber } \\
\text { Pressure }\end{array}$ & $\begin{array}{c}\text { 3rd Chamber } \\
\text { Pressure }\end{array}$ \\
\hline & $(\mathrm{psi})$ & $(\mathrm{psi})$ & $(\mathrm{psi})$ & $(\mathrm{psi})$ \\
\hline $\mathbf{1}$ & 100 & 20 & 20 & 30 \\
\hline $\mathbf{2}$ & 100 & 25 & 25 & 35 \\
\hline $\mathbf{3}$ & 100 & 30 & 30 & 40 \\
\hline $\mathbf{4}$ & 100 & 35 & 35 & 45 \\
\hline $\mathbf{5}$ & 100 & 40 & 40 & 50 \\
\hline
\end{tabular}

The Fluent model was run using the k- $\omega$ turbulence model which is a type of Reynolds-averaged Navier-Stokes (RANS) equation. It models the entire range of turbulence from small to large eddies, and is ideal for time-dependent flows which is the type used in this thesis. The RANS model uses an ensemble average to solve the different components. The following equation is the ensemble average of the velocity component in the i-direction.

$$
u_{i}=\bar{u}_{i}+u_{i}
$$

Where $\bar{u}_{i}$ is the average velocity and $u_{i}^{\prime}$ is the fluctuating velocity.

The $\mathrm{k}-\omega$ solves a variation of the Navier-Stokes equation where $\mathrm{k}$ is the turbulent kinetic energy and $\omega$ is the dissipation rate. This model solves two equations for both the $\mathrm{k}$ and $\omega$ terms which can be found in the Fluent users manual. 
The first step is to do a grid independence study on the model to determine the effect the grid size plays on the results. This will be done by varying the mesh spacing and increasing the number of nodes while keeping all the other parameters constant. The grid independence was done with the full sized model shown in Figure 2 shown in Chapter 1.

To verify the results the values for the gas velocity, temperature, and pressure were taken at every nodal point along the Y-axis centerline of the device which divides the model in half. To determine the variance, the percent difference with respect to the case with the most nodal points was taken for each of the centerline metrics.

\subsection{Analytic Approach}

The next step is to verify the results of the Fluent models by doing analytical calculations at various locations and comparing them to the results of the Fluent simulations. The following equations are given in a step by step fashion of how they will be used to solve for certain flow characteristics at various locations along the flow field of the device.

The first step is to determine the stagnation pressures and the downstream pressures in each of the chambers. These will determine how the flow behaves in the device. Since the gas will be traveling at supersonic speeds there will be compressible effects on the gas changing the density. The Fluent model will be done using the compressible ideal gas law which uses the following equation for the density of the gas.

$$
\rho_{0}=\frac{P_{0}}{R_{a i r} T_{0}}
$$


Where $P_{0}$ is the stagnation pressure, $R_{\text {air }}$ is the gas constant for air which is $287.05 \mathrm{~J} / \mathrm{kg}-\mathrm{K}$, and $T_{0}$ which is the stagnation temperature which is $300 \mathrm{~K}$ for all the cases.

The next step is to find the pressure and temperature drop in the nozzle throat. Since the gas will be traveling at Mach 1 through the throat the stagnation pressure ratio given by $P_{*} / P_{0}$ and the stagnation temperature ratio given by $T_{*} / T_{0}$ are needed. Where $P_{*}$ and $T_{*}$ are the static pressure and temperature in the throat, respectively. For the case of an isentropic sonic throat, the pressure ratio and the temperature ratio will always be 0.52828 and 0.8333 , respectively.

The velocity of the gas in the throat of the nozzle, which is equal to the speed of sound, is calculated with Equation 2.

$$
a_{*}=\sqrt{\gamma_{a i r} R_{a i r} T_{*}}
$$

Where $\gamma$ is the specific heat ratio of air which is $1.4, R_{\text {air }}$ is the gas constant for air, and $T_{*}$ is the static temperature of air $(\mathrm{K})$ in the throat of the nozzle.

Having predetermined the pressure in the chamber between the nozzle and the first skimmer, the isentropic Mach tables can be used to model the free expansion of the gas as it leaves the nozzle and enters the first chamber. The gas will expand from a higher pressure in the nozzle to the lower pressure in the chamber. This drop in pressure will cause the rapid acceleration of the gas. The isentropic Mach tables will be used to determine the speed, temperature, and density of the gas in the chamber. 


\section{Results}

This section details the results from both the CFD cases run in Fluent and the analytic calculations. In Fluent a grid independence study was done as well as five different pressure cases. Analytic calculations were done along the central axis in the nozzle throat, in the chambers after the nozzle and first skimmer, and in the throats of both skimmers. Properties found using CFD such as temperature, pressure, velocity, and density will be compared to analytic calculations to show the validity of the CFD models. The different pressure cases will also be compared to one another to show the effects that the pressure difference will have on the system.

\subsection{Fluent Results}

A grid independence study was done to determine the effect that different mesh sizes would have on the results. The inlet and outlet pressures for this grid independence study were $64.7 \mathrm{psi}$ at the inlet and $14.7 \mathrm{psi}$ at each of the outlets. The grid independence cases were run until third order convergence which is typical for a grid independence study [36]. The following table shows the different mesh sizes along with the number of node points used in the grid independence study.

Table 2: Mesh Sizes for the Grid Independence Cases

\begin{tabular}{|c|c|c|}
\hline Case & $\begin{array}{c}\text { Mesh } \\
\text { Spacing }\end{array}$ & $\begin{array}{c}\text { Number } \\
\text { of } \\
\text { Nodes }\end{array}$ \\
\hline & (inch) & \\
\hline 1 & 0.015 & 11,657 \\
\hline 2 & 0.009 & 31,850 \\
\hline 3 & 0.007 & 51,532 \\
\hline 4 & 0.005 & 277,834 \\
\hline
\end{tabular}


Figures 36-39 show the contour plots of the absolute pressure, density, Mach number and the static temperature of the gas within the device. As can be seen in Figure 38 , the expansion of the gas and the formation of the barrel shock are supported with previous work done in this area $[1,11]$. The drop in pressure, temperature, and density as the flow expands and accelerates into each chamber is shown by the following contour plots.

$6.47 \theta+01$
$6.16 \theta+01$
$5.85 e+01$
$5.54 \theta+01$
$5.23 e+01$
$4.92 \theta+01$
$4.61 e+01$
$4.30 \theta+01$
$3.99 \theta+01$
$3.68 \theta+01$
$3.37 \theta+01$
$3.06 \theta+01$
$2.75 e+01$
$2.44 \theta+01$
$2.13 e+01$
$1.82 \theta+01$
$1.51 \theta+01$
$1.20 \theta+01$
$8.90 \theta+00$
$5.80 \theta+00$
$2.70 \theta+00$

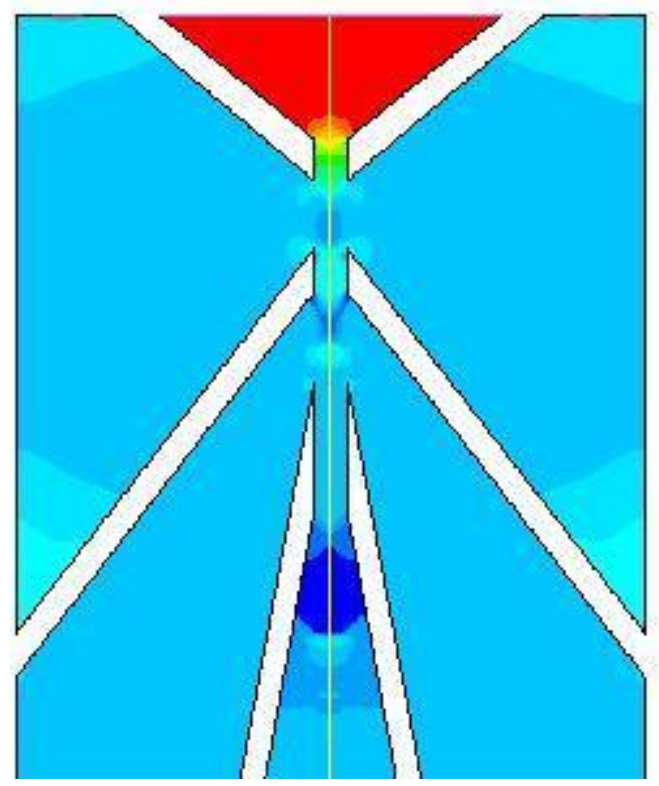

Figure 36: Contour Plot of Absolute Pressure in psi 
$5.18 \theta+00$

$4.94 \theta+00$

$4.70 \theta+00$

$4.46 \theta+00$

$4.22 \theta+00$

$3.98 \theta+00$

$3.74 \theta+00$

$3.50 \theta+00$

$3.26 \theta+00$

$3.02 \theta+00$

$2.78 \theta+00$

$2.54 \theta+00$

$2.29 \theta+00$

$2.05 \theta+00$

$1.81 \theta+00$

$1.57 \theta+00$

$1.33 \theta+00$

$1.09 \theta+00$

$8.5 e_{\theta}-01$

6.11e-01

$3.71 e^{-0}-01$

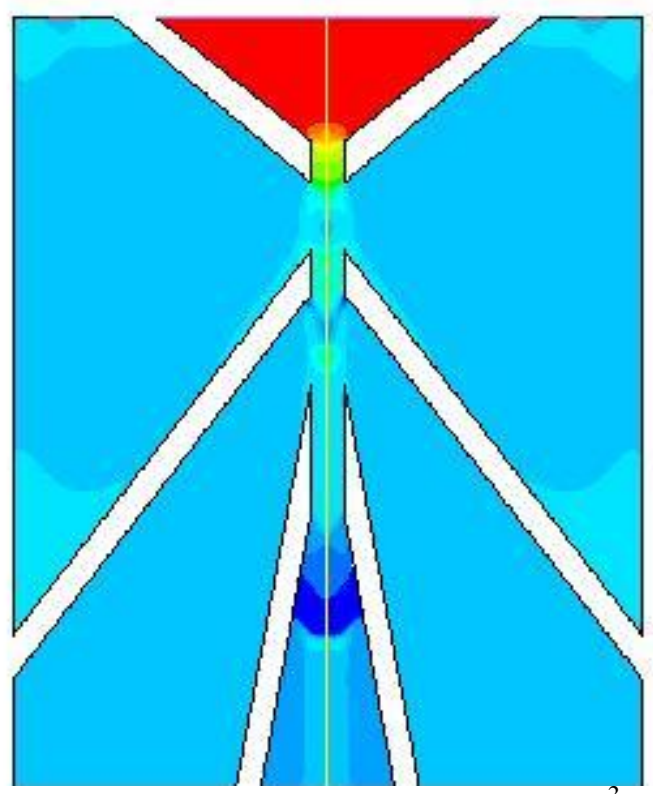

Figure 37: Contour Plot of Density in $\mathrm{Kg} / \mathrm{m}^{3}$

$2.40 \theta+00$

$2.28 \theta+00$

2. $16 \theta+00$

$2.04 \theta+00$

$1.92 \theta+00$

$1.80 \theta+00$

$1.68 \theta+00$

$1.56 e+00$

1. $44 \theta+00$

$1.32 \theta+00$

$1.20 \theta+00$

$1.08 \theta+00$

9.61e-01

8.41e-01

$7.21 \mathrm{e}-01$

6.01e-01

4.81e-01

3.61e-01

2.41e-01

1.21e-01

4. $98 \mathrm{e}-04$

Figure 38: Contour Plot of the Mach Number of the Gas 


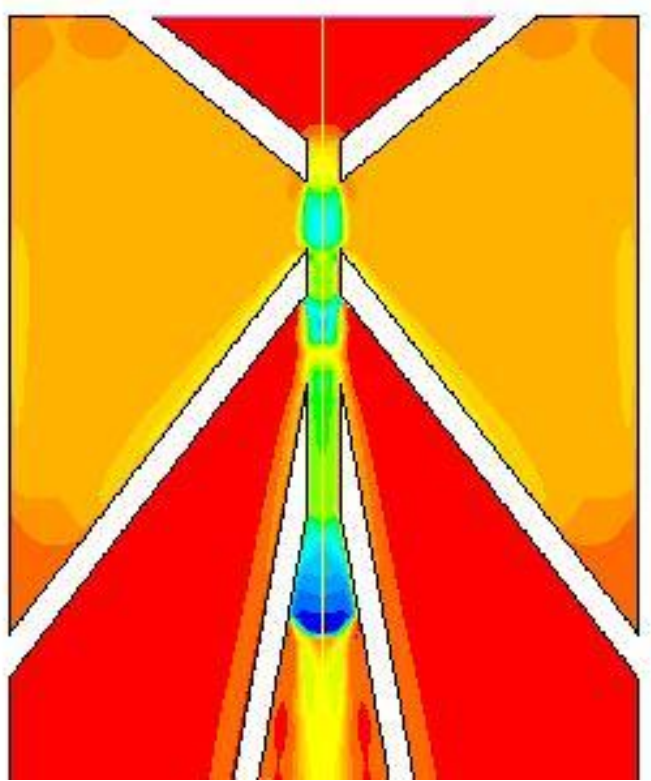

Figure 39: Contour Plot of The Static Temperature in Kelvin

To determine if the results are independent of the number of grid points the values of the velocity magnitude, temperature and pressure were found along the centerline for each of the different meshes. Figures 40-43 are comparisons of static pressure, density, velocity magnitude, and static temperature for each of the different grid independence cases. They start at the inlet on the left end of the x-axis then travel through the nozzle and each of the skimmers. The figures show that each of the grids generally models the flow like the others although there is some fluctuation in the values. 


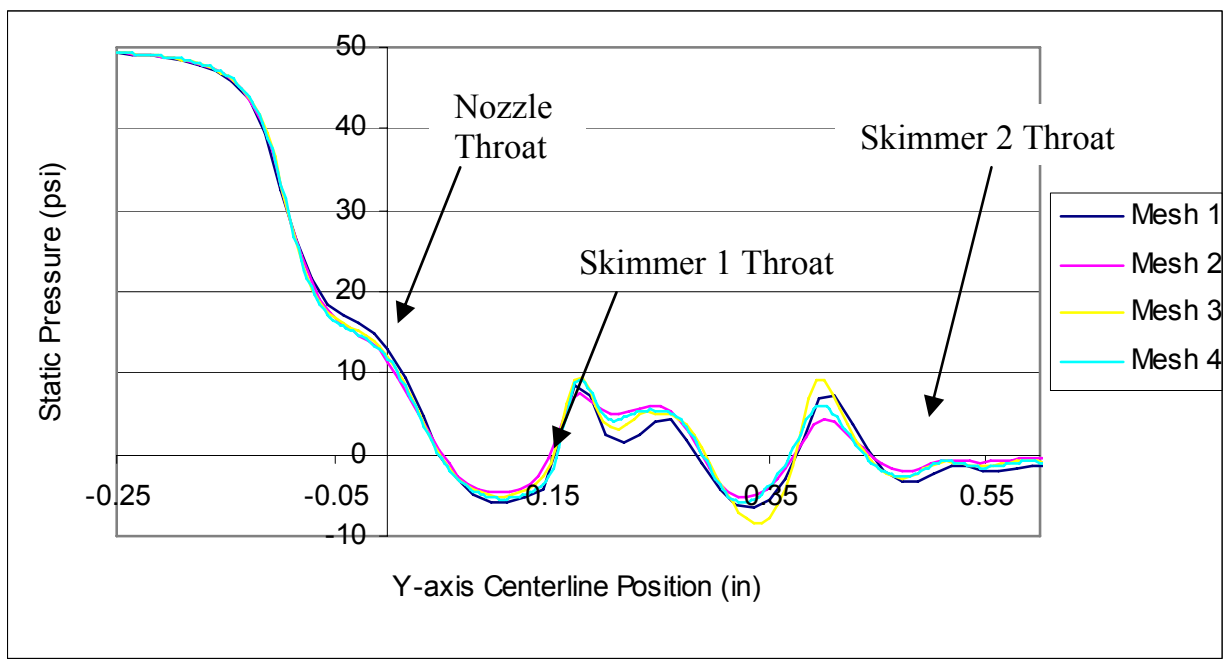

Figure 40: Different Mesh Comparisons of Static Pressure

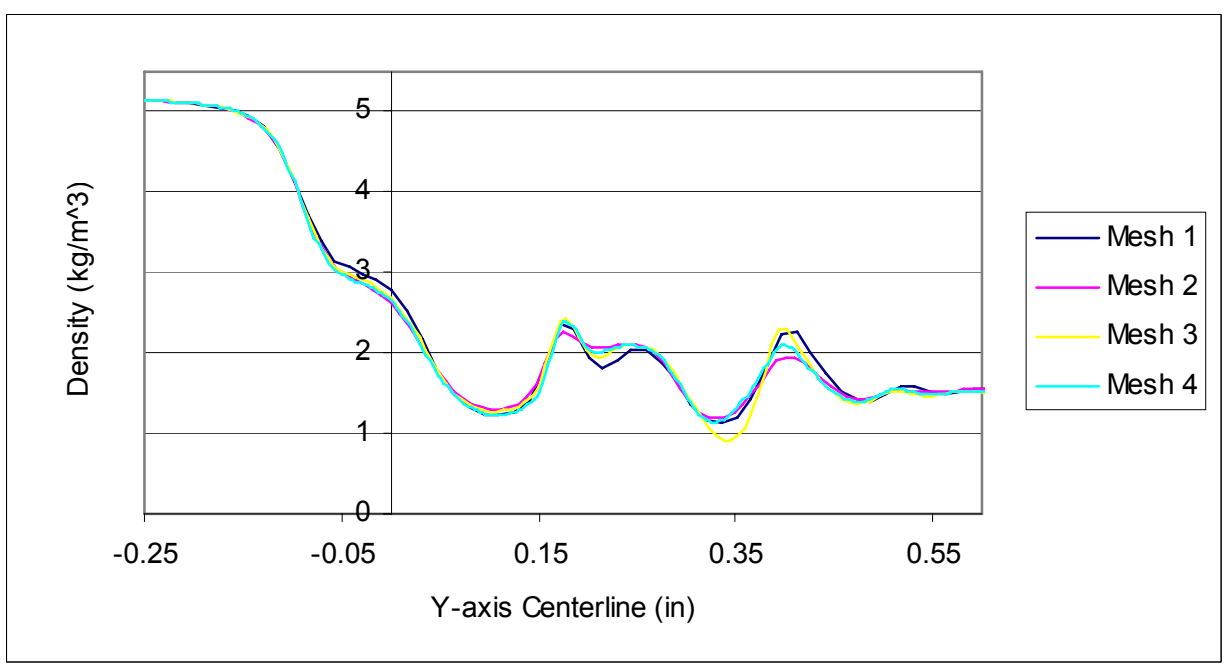

Figure 41: Different Mesh Comparisons of Density 


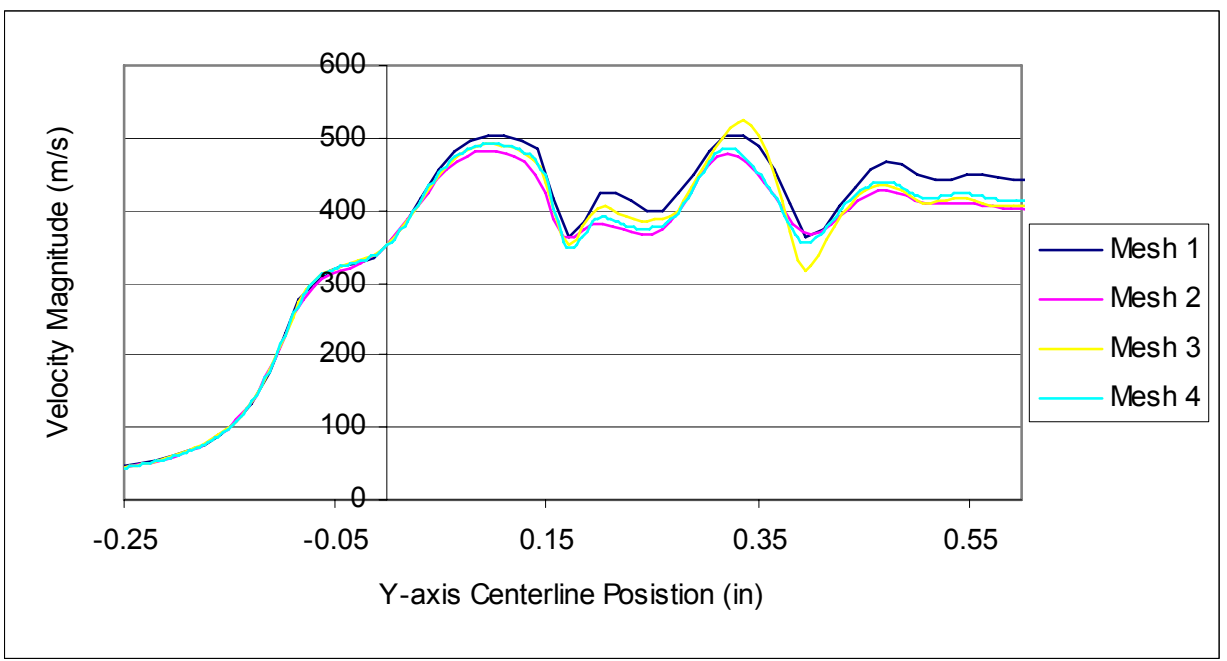

Figure 42: Different Mesh Comparisons of Velocity Magnitude

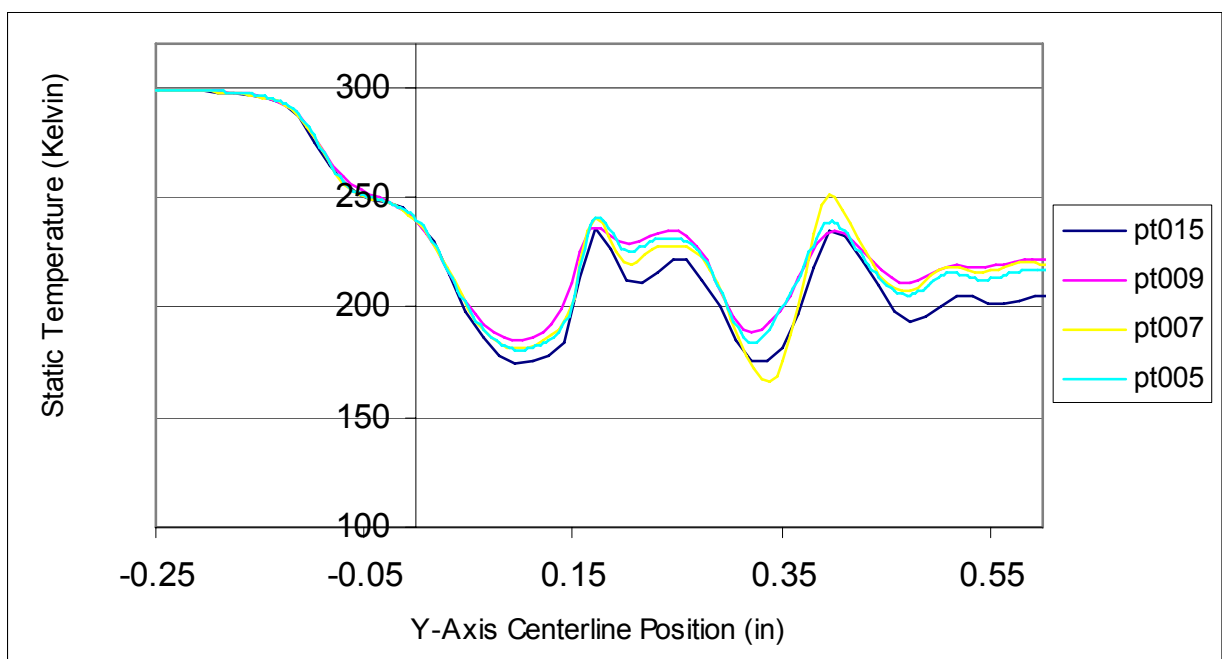

Figure 43: Different Mesh Comparisons of Static Temperature

The percent differences between each of the grid independence case were taken at the nozzle throat, chamber 1 , first skimmer throat, chamber 2 , and the second skimmer throat. The percent that cases 1-3 in Table 1 differed from case 4 were found at each of the five points for the static pressure and the velocity magnitude. The results were plotted in Figures 44 and 45 with cases 4, 3, 2, and 1 located at points 0, 1, 2, and 3 on the $\mathrm{x}$-axis, respectively. Figure 44 is the percent difference of the static pressure. The graph shows that the percent difference between the two smallest meshes is below $20 \%$ 
and below $10 \%$ for four of the five locations. Ideally a smaller difference is desired but a tradeoff between the accuracy required and the computational time a much finer mesh would cost must be determined.

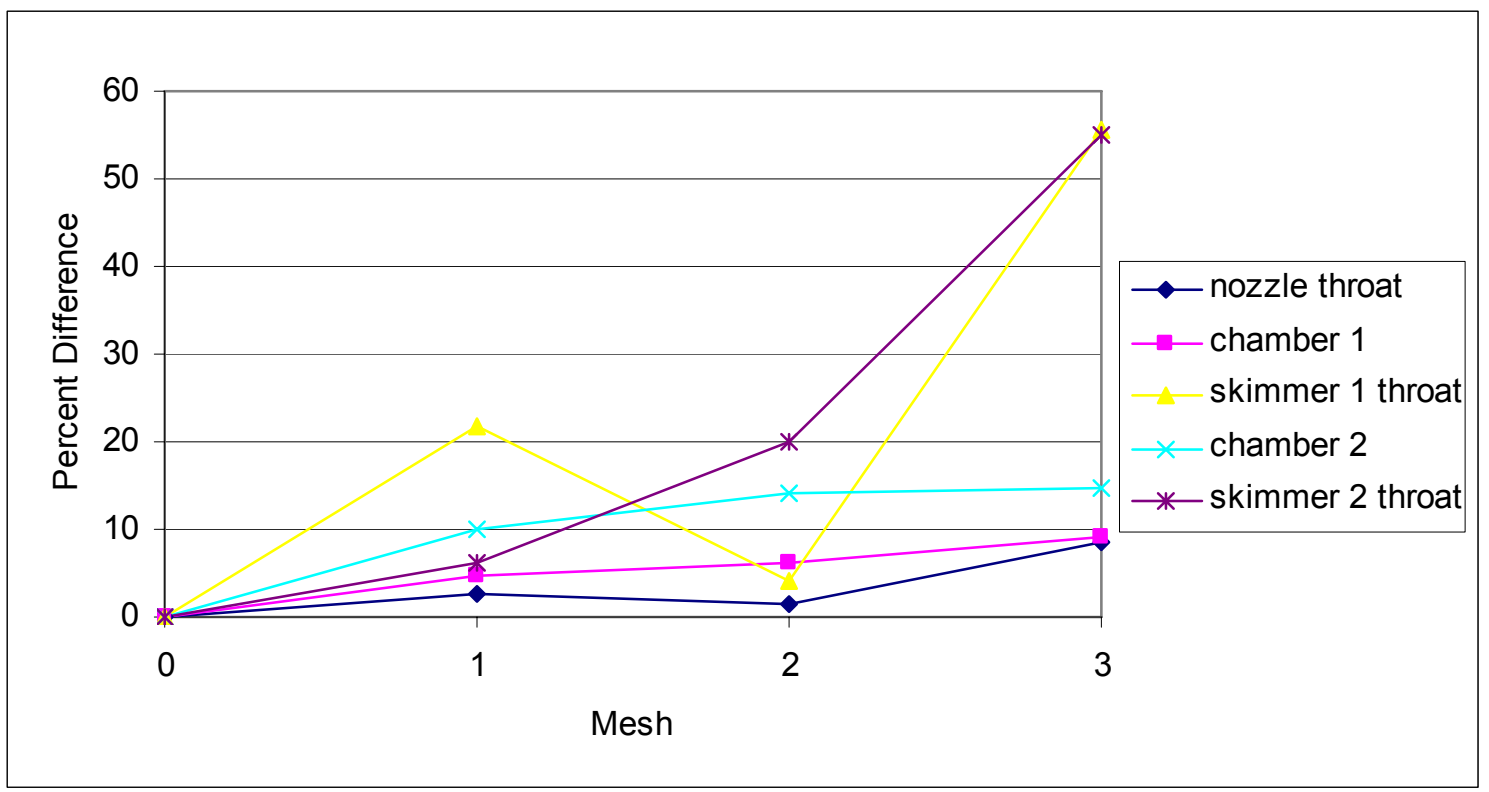

Figure 44: Grid Independence Static Pressure Percent Difference

Figure 45 is the plot of the percent differences for the velocity magnitude at each of the five locations for the different grid independence meshes. The plot shows that the results of the three coarsest meshes are within $10 \%$ of the finest mesh, and within $5 \%$ for cases 2 and 3 in Table 2. 


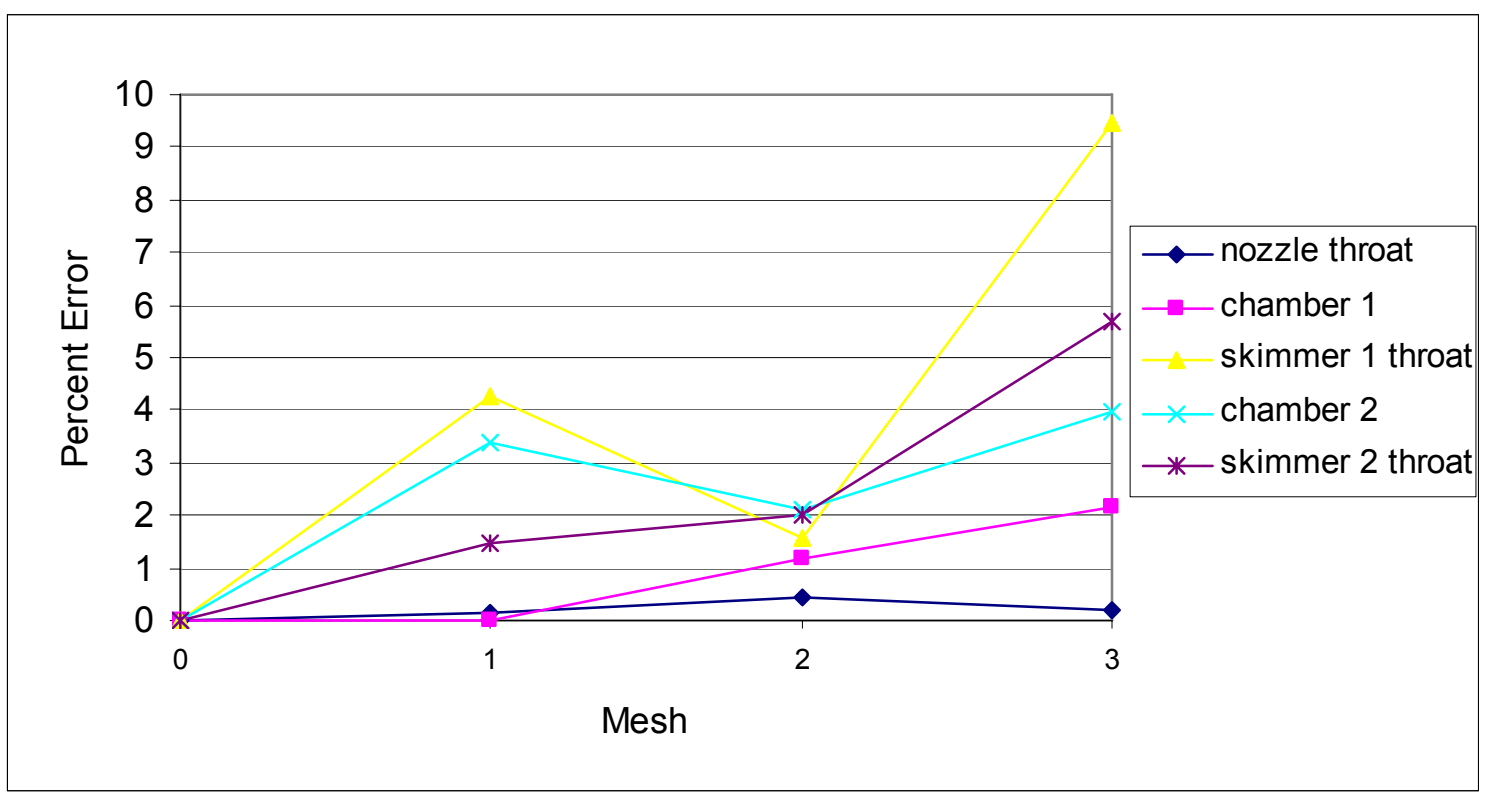

Figure 45: Grid Independence Velocity Magnitude Percent Difference

\subsection{The Fluent Pressure Cases}

The following Fluent results were done on a mesh using the 0.007 in mesh spacing used during the grid independence. Figure 46 shown below is the model meshed in Gambit that will be used for each of the cases in Table 3. Figure 47 is a zoomed in view of the meshed model which shows the concentration of nodes along the points of higher gradients in order to reduce computation time. 


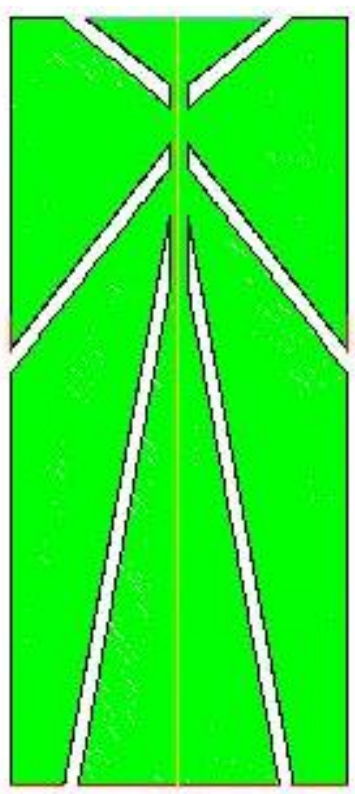

Figure 46: Grid Meshing of the Model

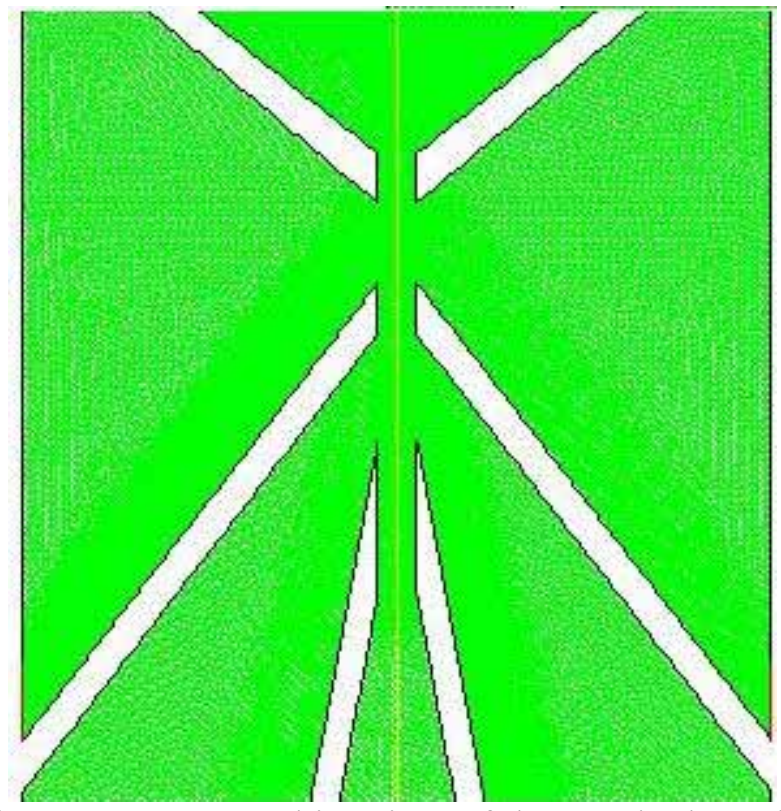

Figure 47: Zoomed in View of the Meshed Model

There were five different pressure setups used as shown in Table 1. In the following figures, contours of the different metrics were plotted to show the effect that the variation of the inlet and back pressures have on the device. They were run in excess of 400,000 iterations and show that the results are approaching the analytic results. Figures 43-46 show the contour plots of the absolute pressure, density, Mach number, 
and the static temperature respectively for case 3 in Table 1 . The other four cases are shown in Appendix B. Figure 48 is the absolute pressure contour plot in psi, and it shows the pressure dropping and rising as the gas passes through each of the throats and expands in each of the chambers. Figures 69, 74, 79, and 84 in Appendix B are the absolute pressure contour plots for the other four cases.

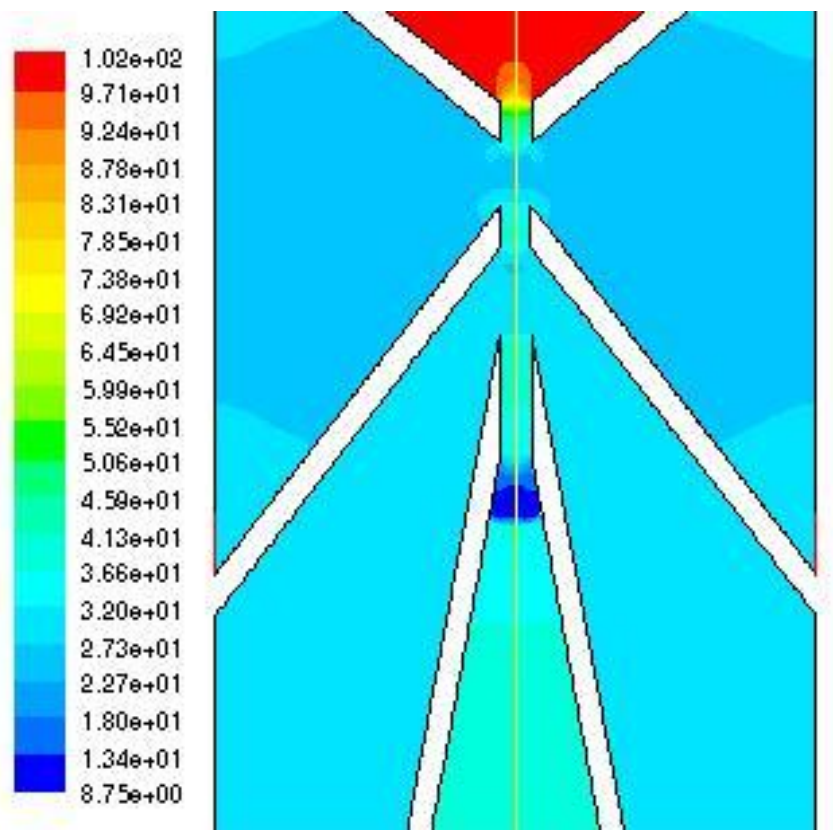

Figure 48: Contour Plot of the Absolute Pressure for Case 3

Figure 49 is the density plot in $\mathrm{kg} / \mathrm{m}^{3}$, and it shows the rise and drop in density as the temperature and pressure rises and drops, which correlates to the ideal gas law. Figures 70, 75, 80, and 85 in Appendix B are the density contour plots for the other four cases. 


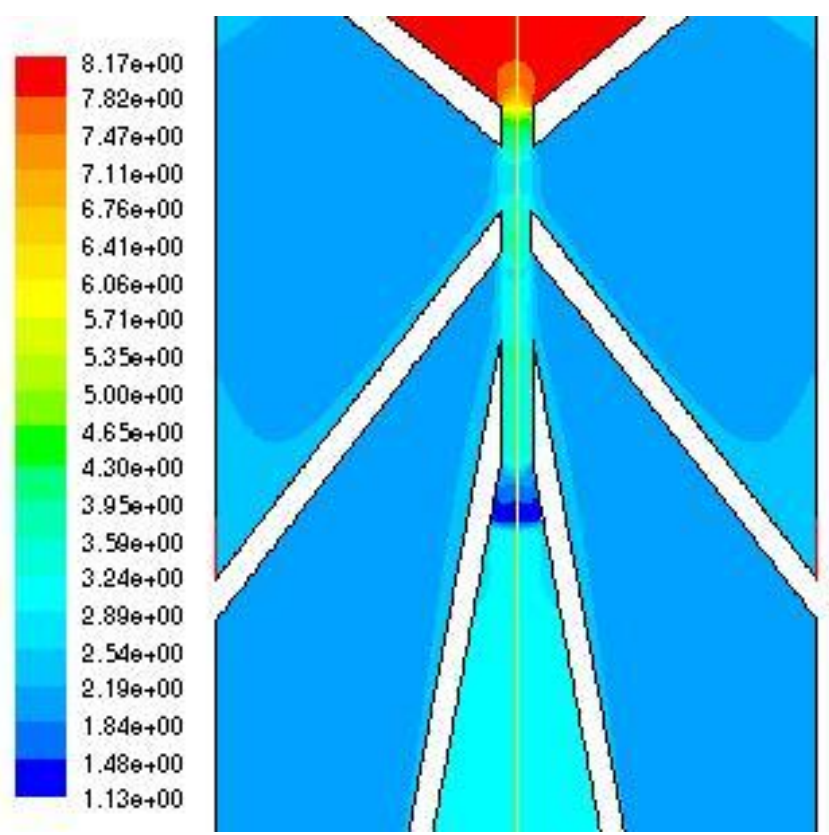

Figure 49: Contour Plot of the Density for Case 3

Figure 50 shows the Mach number through the device being sonic through each of the throats and expanding to meet the drop in pressure in each of the chambers. Figures 71, 76, 81, and 86 in Appendix B show the Mach number contour plots for the other four cases.

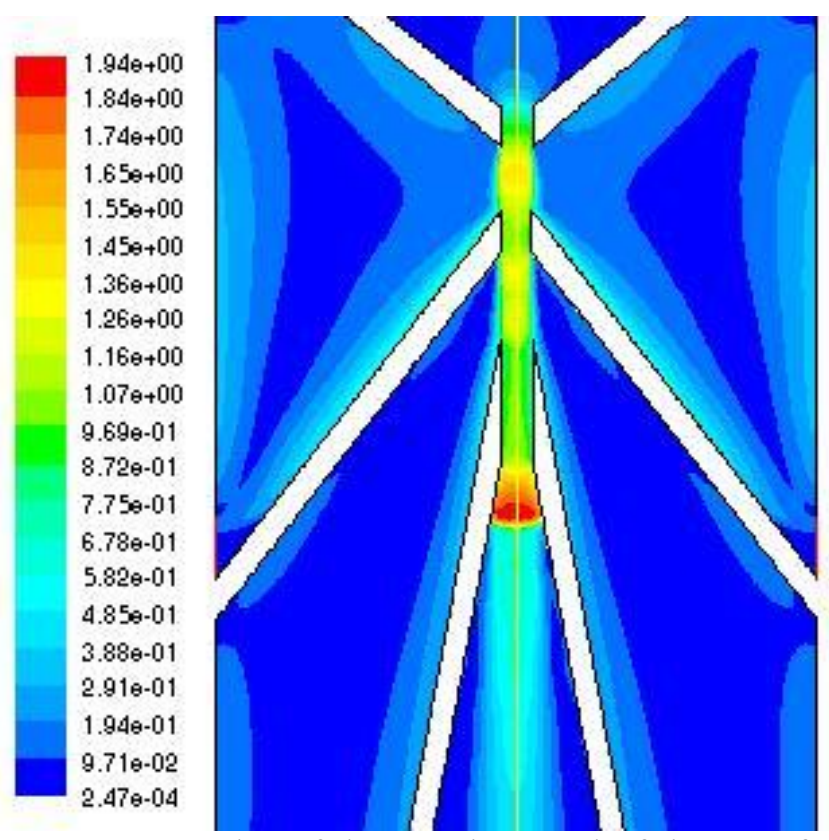

Figure 50: Contour Plot of the Mach Speed of the Gas for Case 3 
Figure 51 is the contour plot of the static temperature in Kelvin. The contour plot shows that the temperature drops dramatically as the gas accelerates through the nozzle and each of the skimmers. As can be seen in the Figure 51, the temperature increases above the inlet temperature of $300 \mathrm{~K}$, this is due to Fluent modeling the compressibility effects of the flow, viscous shear causing an increase in energy due to the greater swirl in the first and especially the second chambers, and the loss of pressure due to shock waves and the geometry which were taken into account by the energy and viscous equations in Fluent. Figures 72, 77, 82, and 87 in Appendix B are the static temperature contour plots for the other four cases.

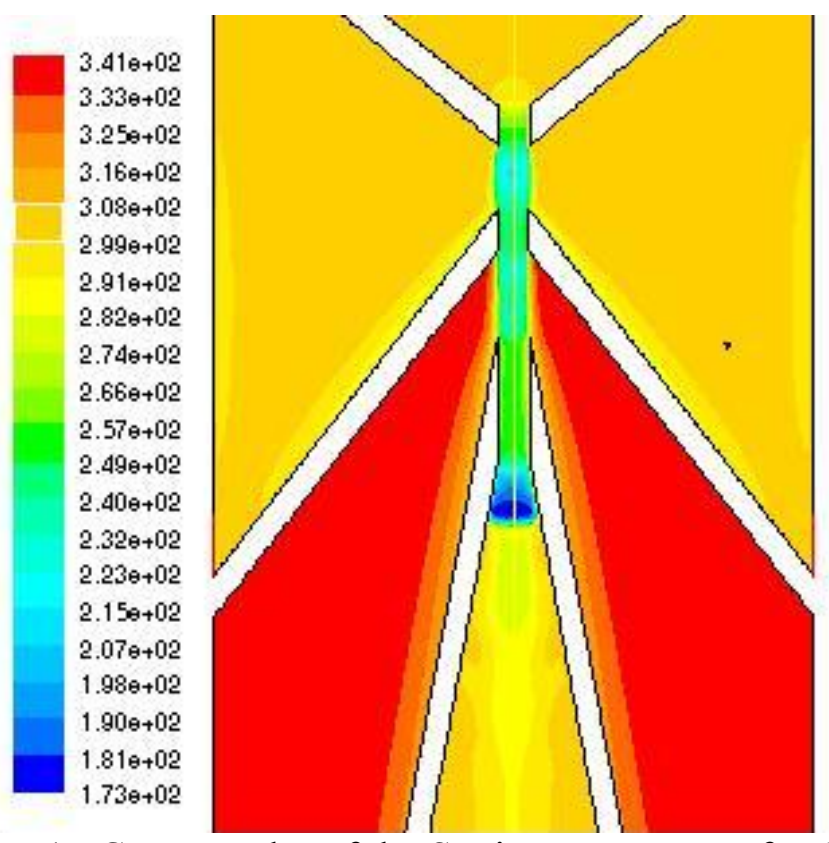

Figure 51: Contour Plot of the Static Temperature for Case 3

Figure 52 shown below is the contour plot of the velocity magnitude in $\mathrm{m} / \mathrm{s}$ for case 3. It shows the acceleration of the gas through each throat and into each chamber as well as the gas being skimmed off by each skimmer. Figures $73,78,83$, and 88 in Appendix B are the velocity magnitude contour plots for the other four cases. 


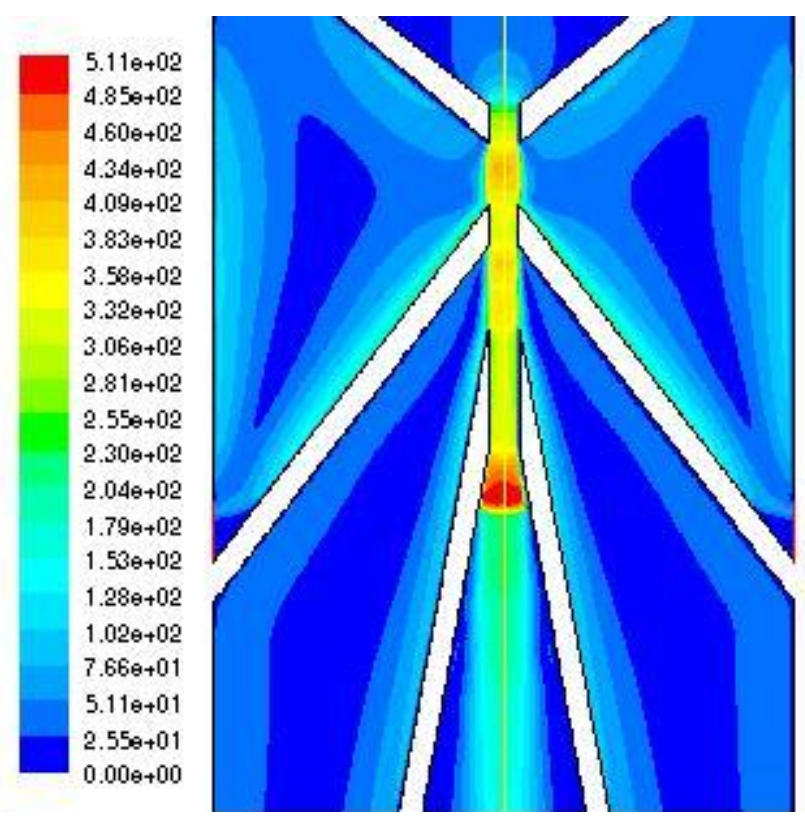

Figure 52: Contour Plot of the Velocity Magnitude for Case 3

\subsection{Analytic Results}

For the results done analytically for case 3 , the upstream stagnation pressure $\left(P_{0}\right)$ is $100 \mathrm{psi}$, the pressure in chamber 1 is $30 \mathrm{psi}$, the pressure in chamber 2 is $30 \mathrm{psi}$, and the pressure in the last chamber after the second skimmer is 40psi. All chamber pressures are absolute. The stagnation temperature is $300 \mathrm{~K}$ and is the same for all cases. Knowing these values the initial density is calculated using the ideal gas law as shown below.

$$
\begin{aligned}
& \rho_{0}=\frac{P_{0}}{R_{\text {air }} T_{0}} \\
& \rho_{0}=\frac{689475.7 \mathrm{~Pa}}{(287.05 \mathrm{~J} / \mathrm{kg} \cdot \mathrm{K})(300 \mathrm{~K})} \\
& \rho_{0}=8.006 \mathrm{~kg} / \mathrm{m}^{3}
\end{aligned}
$$

Given the initial conditions the initial density of the gas is $8.006 \mathrm{~kg} / \mathrm{m}^{3}$.

To find the temperature and pressure drop in the throat of the nozzle the isentropic Mach tables are used for an area ratio of $\mathrm{A} / \mathrm{A} *=1$ (area/throat area) and a throat Mach 
number $\left(M_{*}\right)$ of 1 . The throat to stagnation temperature ratio $\left(T_{*} / T_{0}\right)$ is 0.8333 which gives a throat temperature $\left(T_{*}\right)$ of $250 \mathrm{~K}$. The throat stagnation pressure ratio $\left(P_{*} / P_{0}\right)$ is 0.52828 for this case, which gives a throat static pressure $\left(P_{*}\right)$ of 52.828 psi. The density in the nozzle throat was found using the stagnation density ratio $\left(\rho_{*} / \rho_{0}\right)$ of 0.63394 for a sonic nozzle to be $5.0753 \mathrm{~kg} / \mathrm{m}^{3}$.

The velocity of the gas in the throat of the nozzle, which is equal to the speed of sound, is calculated below.

$$
\begin{aligned}
& a_{*}=\sqrt{\gamma_{a i r} R_{a i r} T_{*}} \\
& a_{*}=\sqrt{1.4(287.05 \mathrm{~J} / \mathrm{kg} \cdot \mathrm{K})(250 \mathrm{~K})} \\
& a_{*}=316.97 \mathrm{~m} / \mathrm{s}
\end{aligned}
$$

This gives the speed of sound in the throat of the nozzle of $316.97 \mathrm{~m} / \mathrm{s}$ and since the nozzle can only have a top speed of Mach 1, this is also the velocity of the gas.

The next step is to calculate the changes in the flow as it freely expands from the nozzle into chamber 1. The chamber pressure for this case is $30 \%$ of the stagnation pressure $\left(P_{1} / P_{0}=0.3\right)$. Interpolating from the Isentropic Mach tables [33], the temperature of the expanded flow will drop to $70.893 \%$ of the stagnation temperature, and the density will drop to $42.316 \%$ of the initial inlet density. The following equation shows the calculation of the new temperature of the expanded gas.

$$
\begin{aligned}
& \frac{T_{1}}{T_{0}}=.70893 \\
& T_{1}=0.70893 T_{0} \\
& T_{1}=0.70893(300 \mathrm{~K}) \\
& T_{1}=212.68 \mathrm{~K}
\end{aligned}
$$


The temperature in chamber 1 drops to $212.68 \mathrm{~K}$ due to the expansion of the gas. The next calculation shows the new density of the gas.

$$
\begin{aligned}
& \frac{\rho_{1}}{\rho_{0}}=0.42316 \\
& \rho_{1}=0.42316 \rho_{0} \\
& \rho_{1}=0.42316\left(8.006 \mathrm{~kg} / \mathrm{m}^{3}\right) \\
& \rho_{1}=3.388 \mathrm{~kg} / \mathrm{m}^{3}
\end{aligned}
$$

Having predetermined the pressure in the chamber between the nozzle and the skimmer, the isentropic Mach tables can be used to model the free expansion of the gas as it leaves the nozzle and enters the chamber. The gas will expand from a higher pressure in the nozzle to the lower pressure in the chamber. This drop in pressure will cause the rapid acceleration of the gas. The isentropic Mach tables will be used to determine the speed, temperature, and density of the gas in the chamber.

Since the skimmer throats are sonic the same ratios can be use as was done with the throat of the nozzle. The static temperature in the throat was found to be $250 \mathrm{~K}$ and the static pressure in the throat is 52.828 psi. The density is found again using the ideal gas equation to be $5.0753 \mathrm{~kg} / \mathrm{m}^{3}$.

The next step is to calculate the change in the flow as it leaves the first skimmer and expands into the chamber between skimmer 1 and skimmer 2. The Prandtl-Meyer expansion from skimmer 1 should differ from that of the nozzle due to the differing geometry of the nozzle and first skimmer, although this goes beyond the scope of this thesis. Since the pressure ratio $\left(P / P_{0}\right)$ is the same for this section as it was for the expansion from the nozzle. The temperature drop is $212.68 \mathrm{~K}$, and the density is $3.388 \mathrm{~kg} / \mathrm{m}^{3}$. These results are for the expansion of the gas in the second chamber which is between the first and second chamber. 


\subsection{Comparison of the Analytic and CFD Results}

Table 3 shows the percent difference of Fluent from the analytic values for case 3 in Table 3 with the analytic being assumed to be correct. The results for the other four cases are shown in Tables 6-9 in Appendix B.

Table 3: Percent Difference of CFD and Analytic Values at Various Locations

\begin{tabular}{|c|c|c|c|}
\hline & Mach Number & Static Temperature & Absolute Pressure \\
\hline Parameter & $(\%)$ & $(\%)$ & $(\%)$ \\
\hline Nozzle Throat & 0.33 & 0.75 & 22.24 \\
\hline Chamber 1 & 1.18 & 0.74 & 22.06 \\
\hline Skimmer 1 Throat & 9.11 & 2.50 & 33.32 \\
\hline Chamber 2 & 9.23 & 5.69 & 11.88 \\
\hline Skimmer 2 Throat & 0.76 & 1.17 & 28.57 \\
\hline
\end{tabular}

Table 4 below shows the theoretical analytic throat velocity of the gas and the value calculated in Fluent and the percent difference between them. The Fluent results are under 4\% different than the theoretical, which shows that Fluent accurately models the throat of the nozzle.

Table 4: Velocity Percent Difference for Nozzle Throat

\begin{tabular}{|c|c|c|c|}
\hline Case & $\begin{array}{c}\text { Analytic } \\
\text { Throat } \\
\text { Velocity }\end{array}$ & $\begin{array}{c}\text { Fluent } \\
\text { Throat } \\
\text { Velocity }\end{array}$ & $\begin{array}{c}\text { Percent } \\
\text { Difference }\end{array}$ \\
\hline & $(\mathrm{m} / \mathrm{s})$ & $(\mathrm{m} / \mathrm{s})$ & $(\%)$ \\
\hline 1 & 316.97 & 319.78 & 0.89 \\
\hline 2 & 316.97 & 318.52 & 0.49 \\
\hline 3 & 316.97 & 316.28 & 0.22 \\
\hline 5 & 316.97 & 312.37 & 1.45 \\
\hline 5 & 316.97 & 304.97 & 3.79 \\
\hline
\end{tabular}

The percent difference for each of the cases between the isentropic analytic values and the Fluent results for the Mach number, static temperature, and the absolute pressure are shown below. The results were compared at five different locations which were the 
nozzle throat, the first chamber, the first skimmer throat, the second chamber, and the second skimmer throat. Figure 53 is the percent difference of the Mach number at each location starting at the nozzle throat at location and zero and going through each location ending at the second skimmer throat at point four on the plot. The plot shows that at location two which is the first skimmer throat the error dramatically increases for cases 1 and 2. This is because as the pressure drops the gas expands and the barrel shock attaches to the first skimmer. This causes the skimmer to stop acting like a sonic throat. The supersonic core of the gas passes through the skimmer and the device begins to act as a supersonic beam.

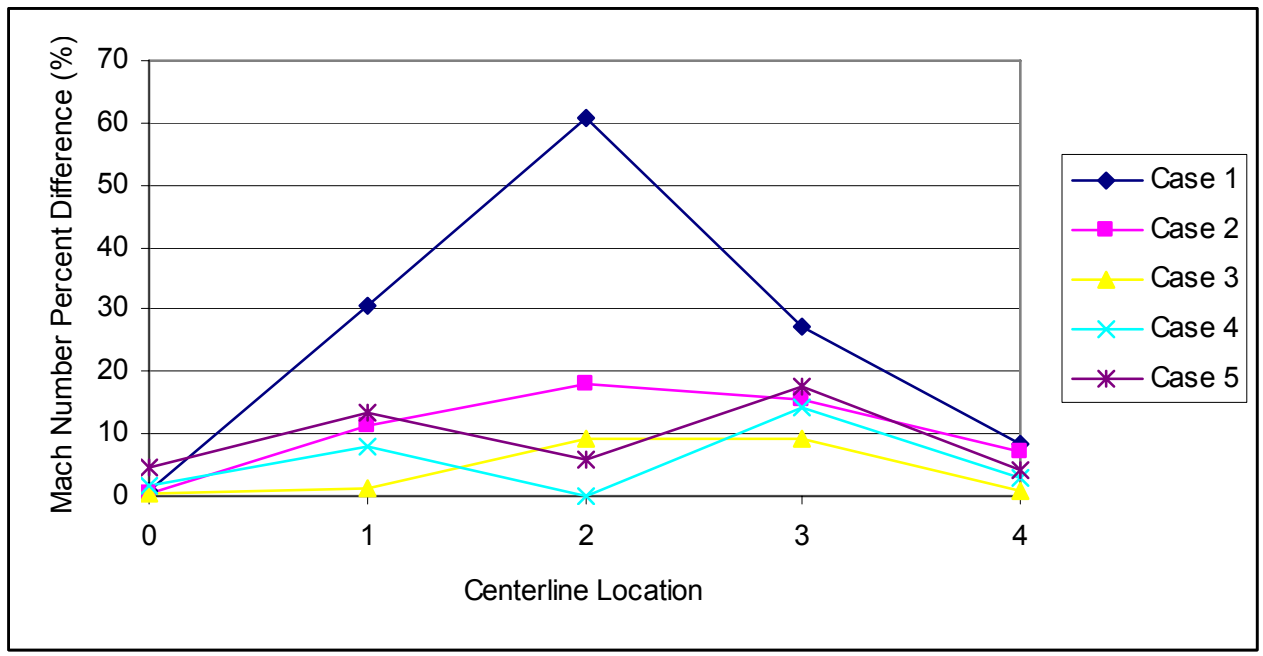

Figure 53: Mach Number Percent Difference between Fluent and Analytic 
Figure 54 is the percent difference of the static temperature along the centerline axis of the device. This correlates with the error shown in Figure 53 as the downstream pressure drops.

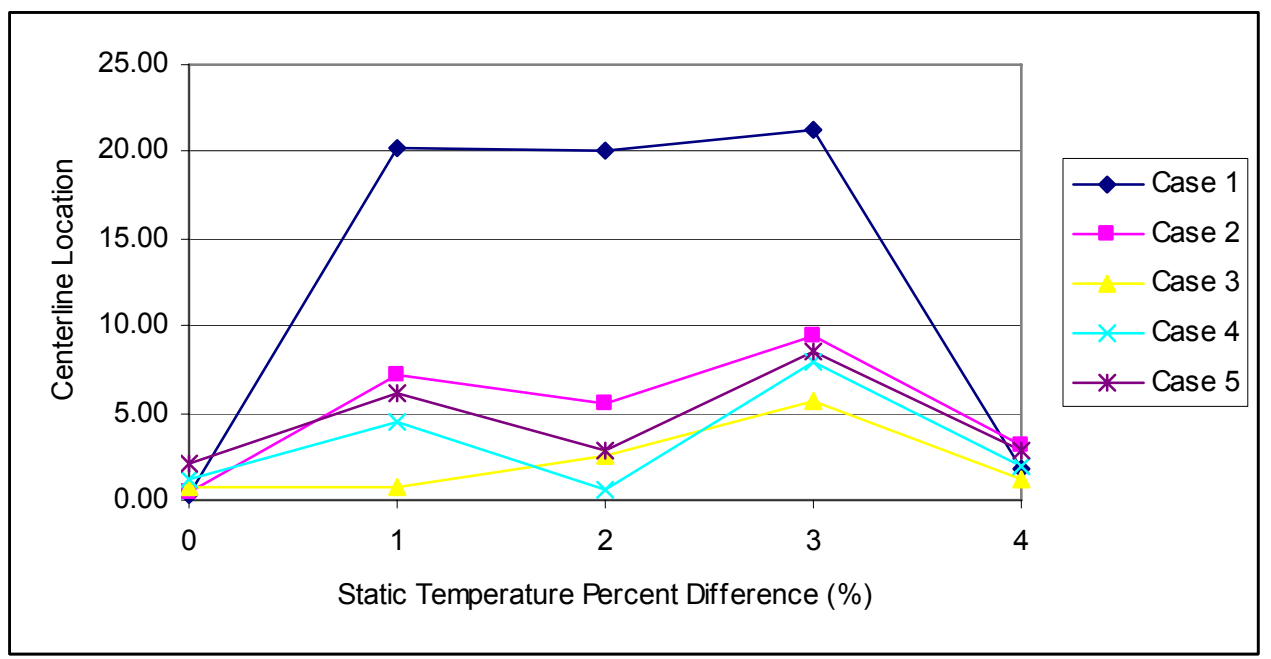

Figure 54: Static Temperature Percent Difference between Fluent and Analytic

Figure 55 is the percent difference plot of the absolute pressure along the centerline axis of the device. It shows that the error increases as the difference between the stagnation and downstream pressures increases. This is because there is a drop in the stagnation pressure due to the geometry of the device, gas leaving through chambers 1 and 2, viscous losses calculated by Fluent.

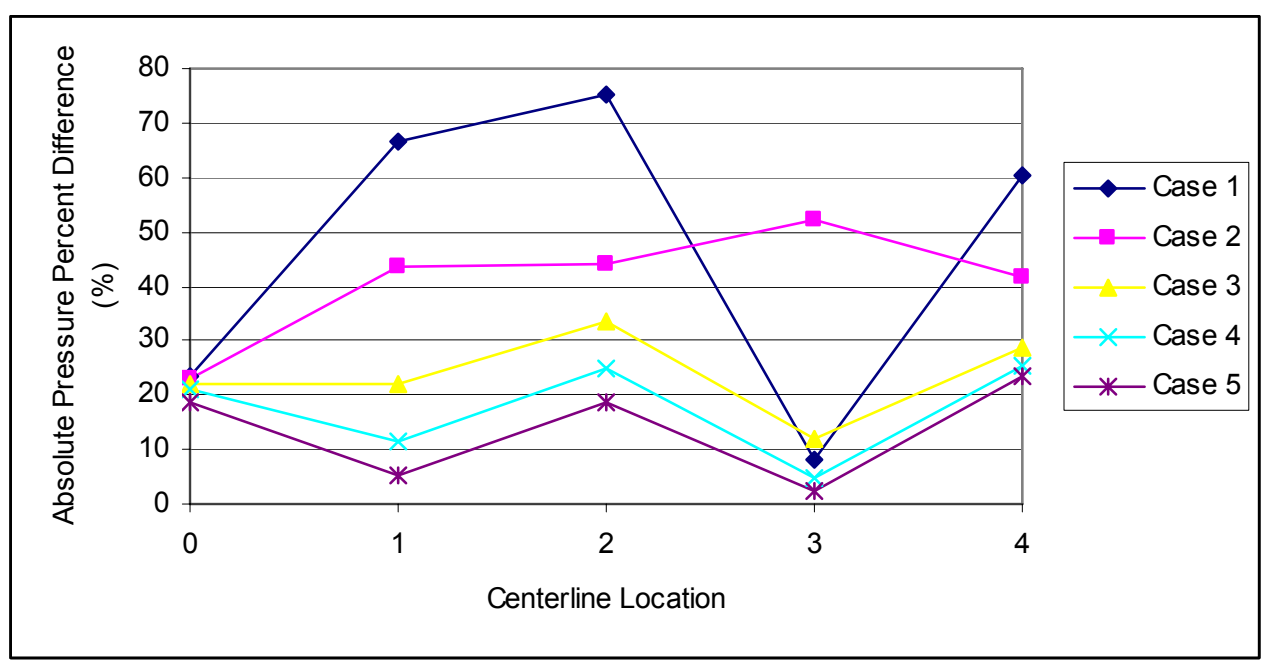

Figure 55: Absolute Pressure Percent Difference between Fluent and Analytic 
The mass flow rate of air through each of the inlets and outlets of the Fluent model were found by Fluent. Table 5 contains the results of the mass flow rate through each opening in the device calculated in Fluent as well as the excess flow difference which is the error that says how much more flow is entering than leaving or vice versa.

Table 5: Percent Difference of Mass Flow Rate of CFD and Analytic Values

\begin{tabular}{|c|c|c|c|c|c|}
\hline \multicolumn{7}{|c|}{ Fluent Mass Flowrate } \\
\hline Case & Inlet & Chamber 1 & Chamber 2 & Chamber 3 & Difference \\
\hline 1 & 1.2473 & -0.6655 & 0.0111 & -0.5835 & 0.0093 \\
\hline 2 & 1.247 & -0.2554 & -0.1895 & -0.7903 & 0.0118 \\
\hline 3 & 1.2392 & -0.1401 & -0.0707 & -1.0155 & 0.0129 \\
\hline 4 & 1.2382 & -0.1425 & -0.065 & -1.0348 & -0.0042 \\
\hline 5 & 1.2364 & -0.101 & -0.0692 & -1.0502 & 0.016 \\
\hline
\end{tabular}

Figure 56 is the mass flow rate entering the inlet and leaving through each chamber for the five different pressure cases. The inlet, chamber 1, chamber 2 , and chamber 3 are located at points $0,1,2$, and 3 respectively in Figure 56. It shows that lowering the pressure increases the amounts of gas leaving through chambers 1 and 2 and decreases the amount leaving through chamber 3.

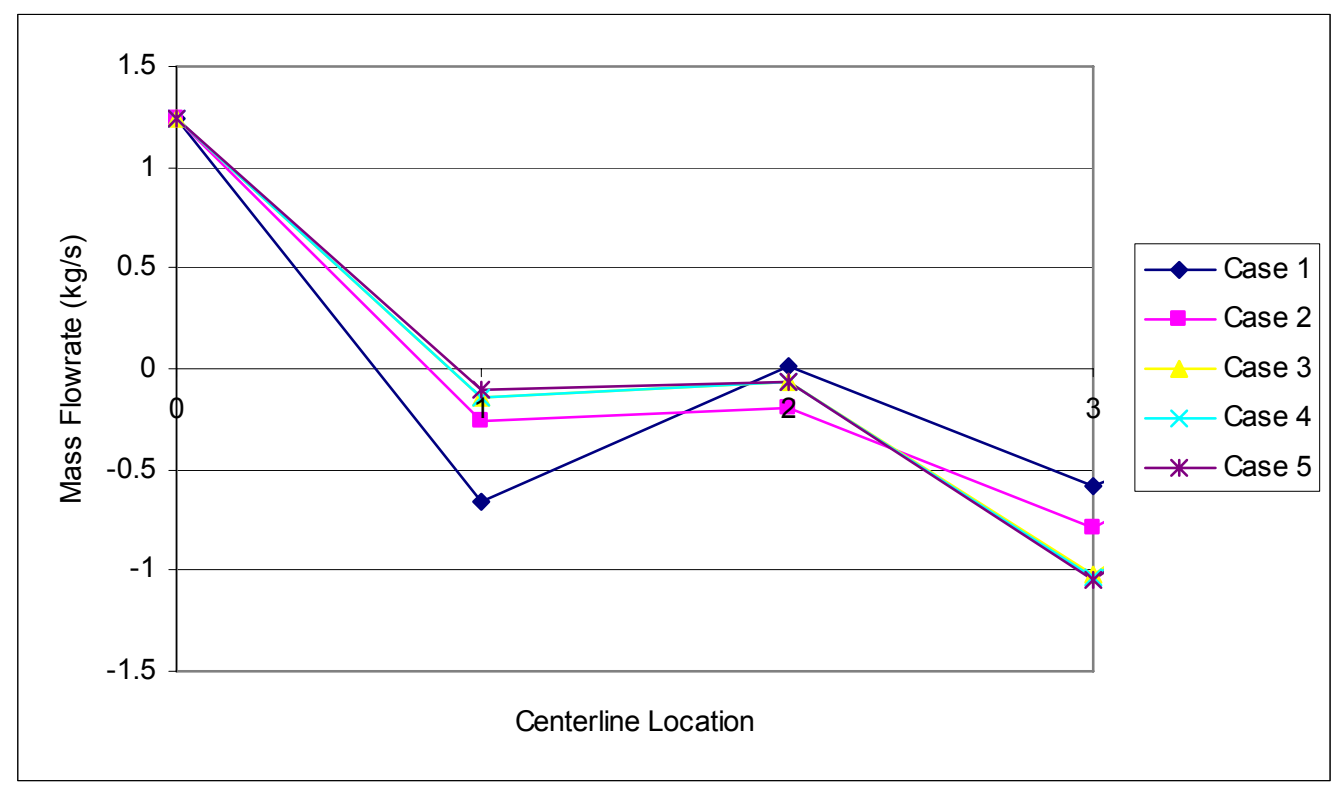

Figure 56: The Mass Flow through each Outlet for each Case 
Figures 57 and 58 show the center-line plots along the y-axis for the Mach number and the static temperature. This shows that as the difference in the pressure ratio increasing the gas accelerates in each of the chambers. There is also a correlated drop in temperature with the increase in speed of the gas.

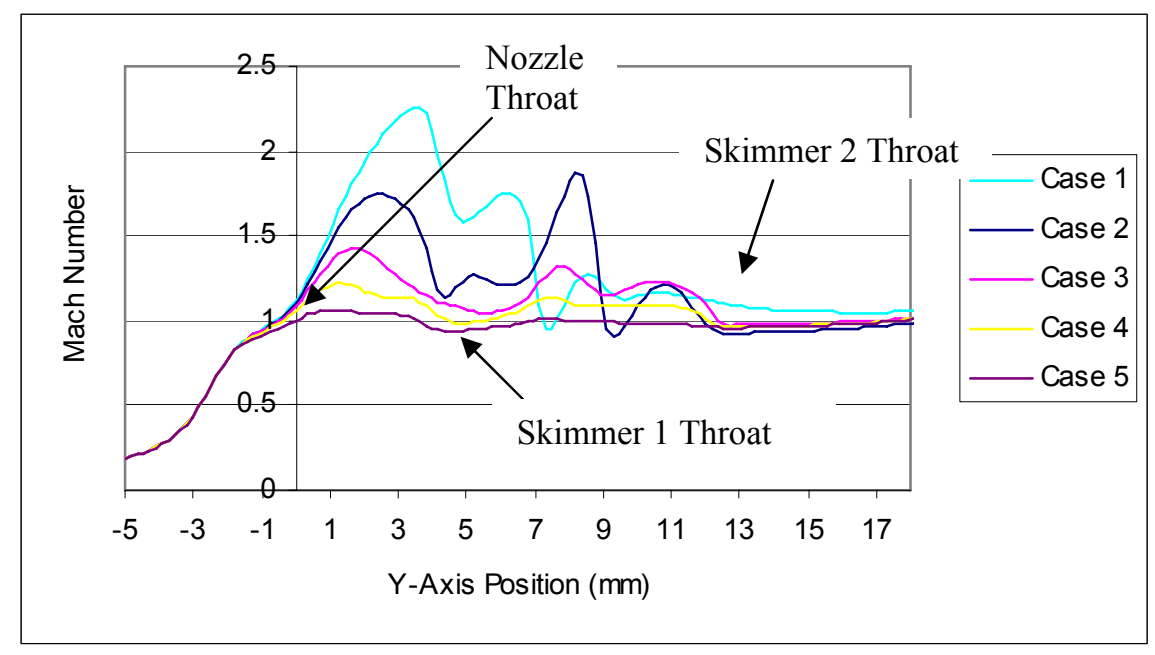

Figure 57: Centerline Mach Number for each of the Pressure Cases

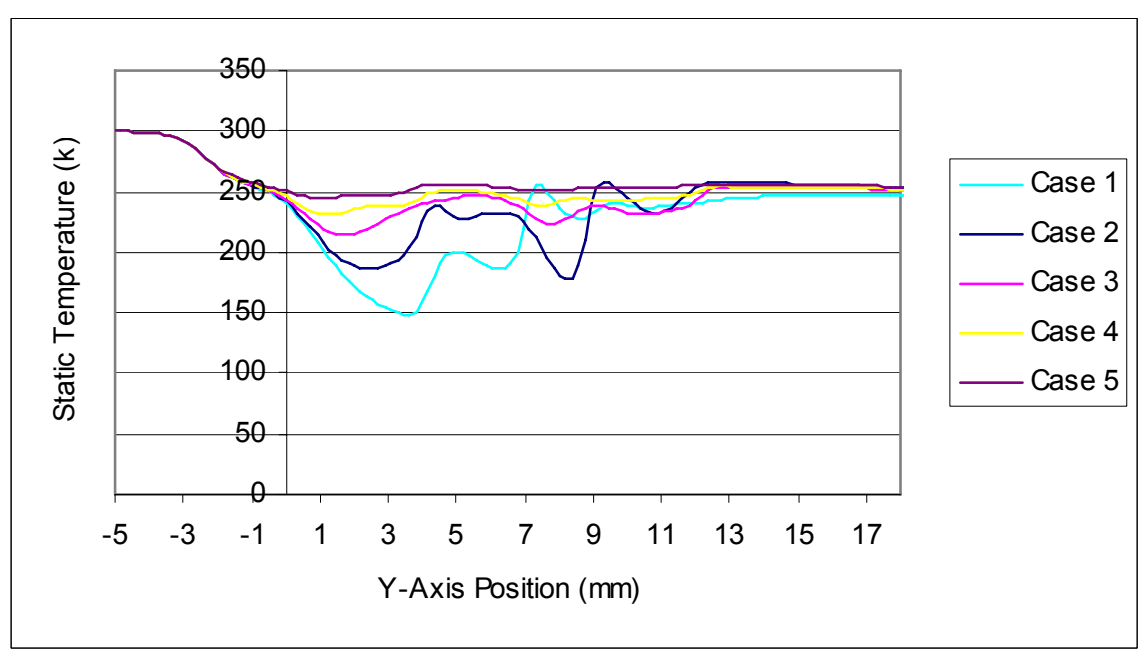

Figure 58: Centerline Static Temperature Plot for each of the Pressure Cases

Figures 59 and 60 are centerline plots of the absolute and stagnation pressures.

Figure 59 shows the drop in absolute pressure with the exit plane of the nozzle located at point zero on the x-axis. In an ideal situation the stagnation pressure should remain constant through the system, but for this case the stagnation pressure lowers as the gas 
travels through the device. This is because Fluent calculates a continual loss in the stagnation pressure caused by the geometry of the device, gas leaving, and viscous effects. This causes the absolute pressure to be lower than the expected 52.828psi in each of the throats to below 40psi.

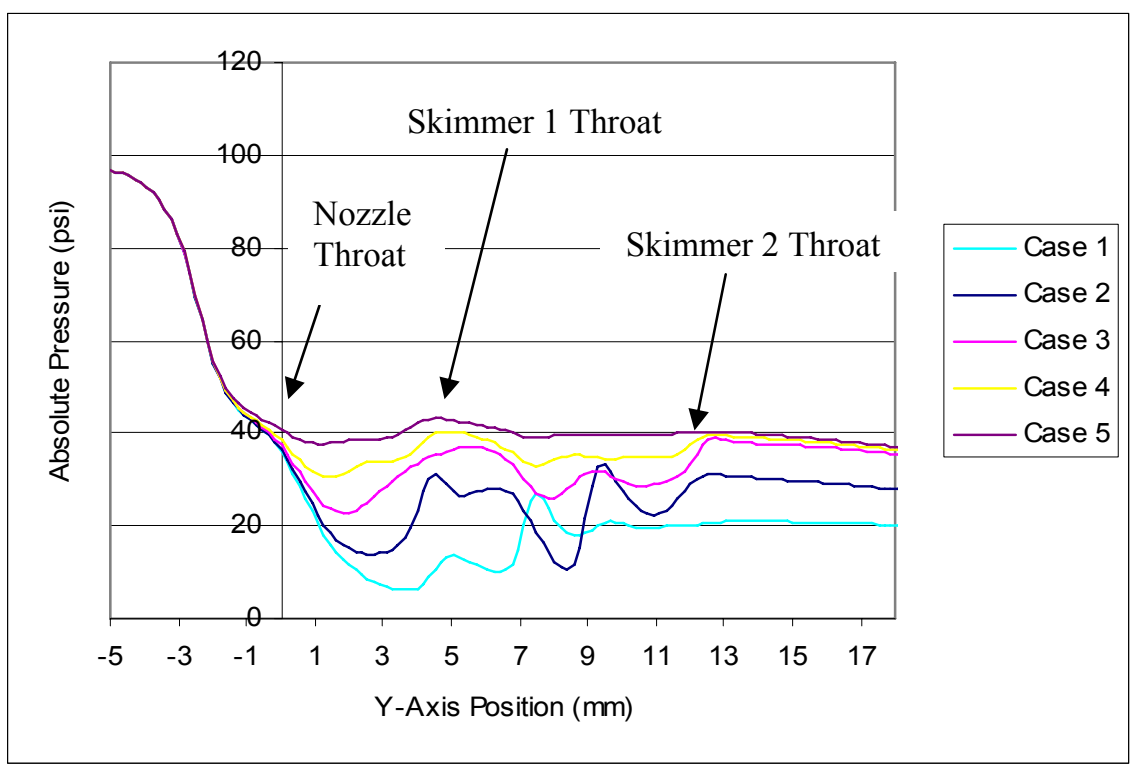

Figure 59: Centerline Absolute Pressure Plot for each of the Pressure Cases

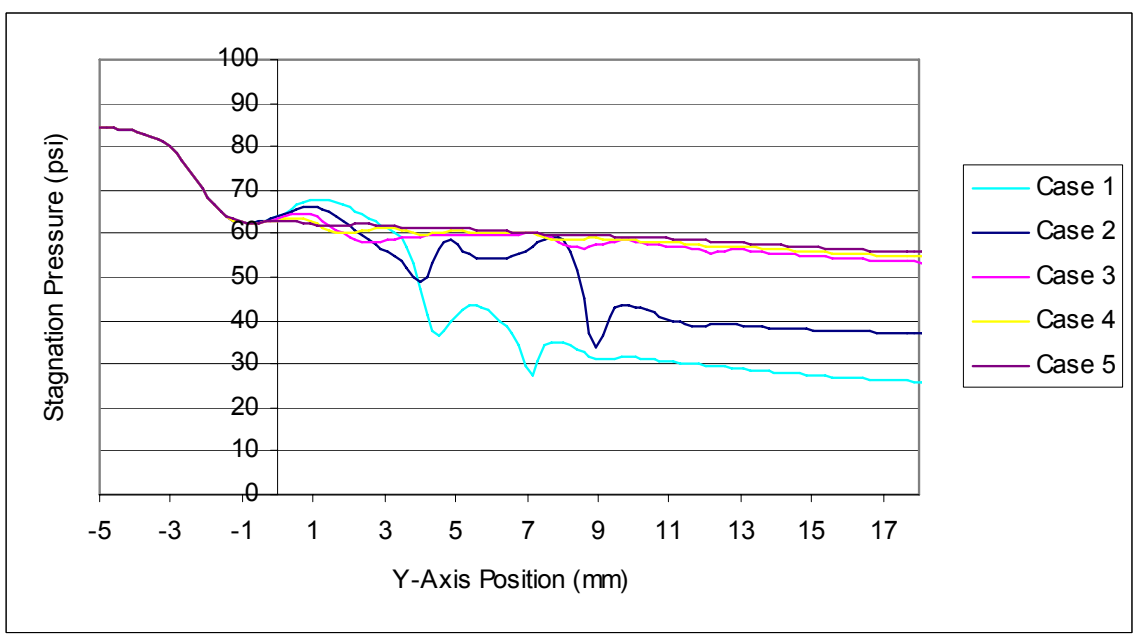

Figure 60: Case 3 Centerline Stagnation Pressure Plot 


\section{Conclusions}

A supersonic gas separator with a single nozzle and two skimmers was modeled and analyzed using the CFD software called Fluent. The Fluent model was run using five different pressure cases and compared to each other to see the effect that the change in pressure had on the system. The Fluent results were compared to the analytic to view the accuracy of Fluent in modeling the flow characteristics of the device.

The contour plots shown in Figures 48-52 show the gas acting as was expected. It accelerated as it expanded due to the drop in pressure. The temperature and density dropped according isentropic and ideal gas theory [33]. Figures 71 and 76 in Appendix B show the device taking on the aspects of a molecular beam as the downstream pressure drops causing the barrel shock to grow and to attach onto the skimmer. This causes the first skimmer to cease acting as a throat and it allows the supersonic core of the barrel shock to pass through while skimming off the outer layer. This corresponds to the results found in literature based on the characteristics of a molecular beam $[9,15,19,20,23-26]$

The results of case 3-5 were that the combination of the nozzle and skimmers acted as a converging diverging nozzle with sonic speeds through each of the throats and supersonic speeds as the gas expands into each of the chambers. This too is expected according to compressible gas theory [33]. The results in Figures 53-55 also correspond to this since as the pressure drops the percent error between the Fluent results and the analytic increases. This is because when the barrel shock attaches to the first skimmer it ceases to act like a converging nozzle and begins to act as a supersonic beam $[8,9,11$, $15,19,24-28]$. 
The results of the cases run in Fluent show that it can model the flow characteristics of the device and it corresponds to previous work as well as compressible gas theory. Therefore Fluent can be a useful tool to gain a better understanding of how the flow will act in a nozzle-skimmer supersonic gas separator. Although it was shown that the CFD results were reasonable a comparison to physical results will be needed to truly validate the level of accuracy of the results given by Fluent. 


\section{Recommendations for Future Work}

Due to the vast number of directions that could be taken with a process such as this, there are many things that were unable to be covered but should be analyzed in future studies. The next step that needs to be taken to validate and correlate the Fluent and analytic results is to get experimental data. Since only five pressure cases were done and pressure is the main driving force for the device, more variation of the pressure should be done to gain a better feel for the effects it will have on the flow. Varying the initial temperature can also be done to further model the flow. A parametric study in Fluent needs to be done on the properties of the gas such as specific heat, thermal conductivity and viscosity. This will show the effects that the properties will have on the results. Nozzle and skimmer geometry such as throat areas and angles as well as offset distances between the throats of the nozzle and the skimmers need to be varied to further understand their effect on the flow. To gain a better understanding on the behavior of the flow, Prandtl-Meyer Expansion fans and the barrel and bow shocks that form around the skimmer need to be modeled. Eventually the creation of a computer program to automate much of the calculations and increase the speed of the design process will be created. This program will be useful since determination of the actual separation ability of the device without actual experimental data to back up the findings is difficult to do and there will need to be a new model created for each change in a parameter such as the offset difference or throat area, that to get a model to match the desired flow parameters or when flow data is eventually correlated to separation efficiency to determine the optimal settings, this program can be used to help design the next model for test and CFD runs to save valuable time. Looking into the diffusive characteristics of the gas and how they 
should affect the flow and the separation of a mixture. Reduction of the throat length of the skimmers needs to be done to increase the molecular beam formation. 


\section{References}

1. Fenn, John B., "Method and Apparatus for Separation of Components from Gaseous Streams," United States Patent 3465500, 1969.

2. Fenn, J. B., and White, J. R., "Process for Separating Uranium Isotopes," United States Patent 3626665, 1971.

3. Andres, R. P., "Particle Separation Method and Apparatus," United States Patent 4284418, 1981.

4. Nasikas, A., "Method and Mechanism for the Supersonic Separation of Droplets from a Gas Stream," United States Patent 5306330, 1994.

5. Betting, M. M., Holton, T. V., Hans, J. M., and Veen M. V., "Supersonic Separator Apparatus and Method," United States Patent 6776825, 2004.

6. Bart, P., Schinkelshoek, P., Lammers, B., and Betting, M., "CFD for Supersonic Gas Processing," Multiphase Separation and Multiphase Pumping Technologies Conference, 2005.

7. Prast, B., Schinkelshoek, P., Lammers, B., and Betting, M., "CFD for Supersonic Gas Processing," Multiphase Separation and Multiphase Pumping Technologies Conference, Sept. 2005.

8. Campargue, R., "Aerodynamic Separation Effect on Gas and Isotope Mixtures Induced by Invasion of the Free Jet Shock Wave Structure," Journal of Chemical Physics, Volume 52, Number 4, Feb. 1970.

9. Campargue, R., "Process and Device for the Separation of Molecules of Different Masses," United States Patent 3616596, 1971.

10. Dickens, S. P., Coghlan, C. A., and Morrow, P. G., "Separation of Gases from Mixtures Thereof," United States Patent 2607439, 1952.

11. Brandt, R., and Nordman, R., "Interface for Liquid Chromatography-Mass spectrometry Systems," United States Patent 4863491, 1989.

12. Becker, E., "Process for Separating Gaseous or Vaporous Substances, Especially Isotopes," United States Patent 3362131, 1968.

13. Becker, E., Ehrfeld, W., and Eisenbeiss, G, "Method and Device for Separating Gaseous or Vaporous Materials, Especially Isotopes, by Means of Separation Nozzles," United States Patent 3989483, 1976. 
14. Becker, E. W., Bley, P., Ehrfeld, U., and Ehrfeld, W., "The Separation Nozzle - An Aerodynamic Device for Large-Scale Enrichment of Uranium-235," AIAA, Rarefied Gas Dynamics, Progress in Astronautics and Aeronautics, Volume 51, Part $1,1976$.

15. Campargue, R., "Methods and Devices for Producing Jets by Free Expansions of a Gas,” United States Patent 3583633, 1971.

16. Dahneke, B. E., "Apparatus for Separation of Gas Borne Particles," United States Patent 4358302, 1982.

17. Maldague, P. E., "Process and Apparatus for Aerodynamic Separation of Components of a Gaseous Stream," United States Patent 4886523, 1989.

18. Alferov, V. I., Baguirov, L. A., Feygin, V. I., Arbatov, A. A., Imaev, S. Z., Dmitriev, L. M., and Rezunenko, V. I., "Method and Apparatus for the Separation of Components of Gas Mixtures and Liquefaction of a Gas," United States Patent 6372019, 2002.

19. Campargue, R., "High Intensity Supersonic Molecular Beam Apparatus," American Institute of Physics, Review of Scientific Instruments, Volume 35, Number 1, Jan. 1964.

20. Campargue, R., Lebehot, A., and Lemonnier, J. C., "Nozzle Beam Speed Ratios above 300 Skimmed in a Zone of Silence of He Freejets," AIAA, Rarefied Gas Dynamics, Progress in Astronautics and Aeronautics, Volume 51, Part 2, 1976.

21. Buckland, J. R., Folkerts, R. L., Balsod, R. B., and Allison, W., “A simple nozzle Design for High Speed-Ratio Molecular Beams," Journal of Measurements and Science Technology, Volume 8, IOP Publishing, 1997.

22. Hillenkamp, M., Keithan, S., and Even, U., "Condensation Limited Cooling in Supersonic Expansions," American Institute of Physics, Journal of Chemical Physics, Volume 118, Number 19, May 2003.

23. Mohamed, A., Hamed, A., and Lehnig, T., "Supersonic Rectangular Over-Expanded Jets of Single and Two-Phase Flows," International Symposium of Airbreathing Engines, 2003.

24. Waterman, P. C., and Stern S. A., "Separation of Gas Mixtures in a Supersonic Jet," The Journal of Chemical Physics, Volume 32, Number 2, pg 405, Aug. 1959.

25. Reis, V. H., and Fenn, J. B., "Separation of Gas Mixtures in Supersonic Jets," The Journal of Chemical Physics, Volume 39, Number 12, pg 3240, Dec. 1963. 
26. Campargue, R., "Progress in Overexpanded Supersonic Jets and Skimmed Molecular Beams in Free-Jet Zones of Silence," Journal of Physical Chemistry, Volume 88, No. 20, pg 4466, 1984.

27. Campargue, R., "Historical Account and Branching to Rarefied Gas Dynamics of Atomic and Molecular Beams: A Continuing and Fascinating Odyssey Commemorated by Nobel Prizes Awarded to 23 Laureates in Physics and Chemistry," American Institute of Physics, $24^{\text {th }}$ International Symposium, 2005.

28. Murphy, H. R., and Miller, D. R., "Effects of Nozzle Geometry on Kinetics in FreeJet Expansions," American Chemical Society, Journal of Physical Chemistry, Volume 88, pp. 4474-4478, 1984.

29. Braun, J., Day, P. K., Toennies, J. P., and Witte, G., "Micro-Sized Nozzles and Skimmers for the Production of Supersonic He Atom Beams," American Institute of Physics, Review of Scientific Instruments 68 (8), Aug 1997.

30. Jordan, D. C., Barling, R., and Doak, R. B., "Refractory Graphite Skimmers for Supersonic Free-Jet, Supersonic Arc-Jet, and Plasma Discharge Applications," Review of Scientific Instruments, Volume 70, Number 3, Mar. 1999.

31. Ono, L. K., Majima, T., Hamamoto, Y., Norizawa, K., Yoshida, K., and Itoh, A., "Preliminary Study of Gas Cluster Ion Beam Source," Department of Nuclear Engineering, Kyoto University.

32. Pilipenko, Y. K., "Molecular Beams and Jets," Dubna, Moscow region, Russia.

33. Saad, M. A., “Compressible Fluid Flow,” Prentice-Hall, New Jersey, 1985.

34. Kusner, Y. S., Nikolaev, G. F., and Prikhod'ko, V. G., "Spatial Separation of Components of Gas Mixtures and Isotopes in a Free Supersonic Jet," American Institute of Physics, Sov. Phys. Tech. Phys. 26(9), Sept. 1981.

35. Niemann, H. J., and Sprehe, J., "Method for the Separation of Uranium Isotope Compounds Already Converted Isotope-Selectivity," United States Patent 4512957, 1985.

36. Anderson, J. D., "Computational Fluid Dynamics; the Basics with Applications," McGraw-Hill Inc., 1995.

37. Deckers, J., Fenn, J. B., "High Intensity Molecular Beam Apparatus," Review of Scientific Instruments, Volume 34, Number 1, Jan. 1963. 


\section{Appendix A}
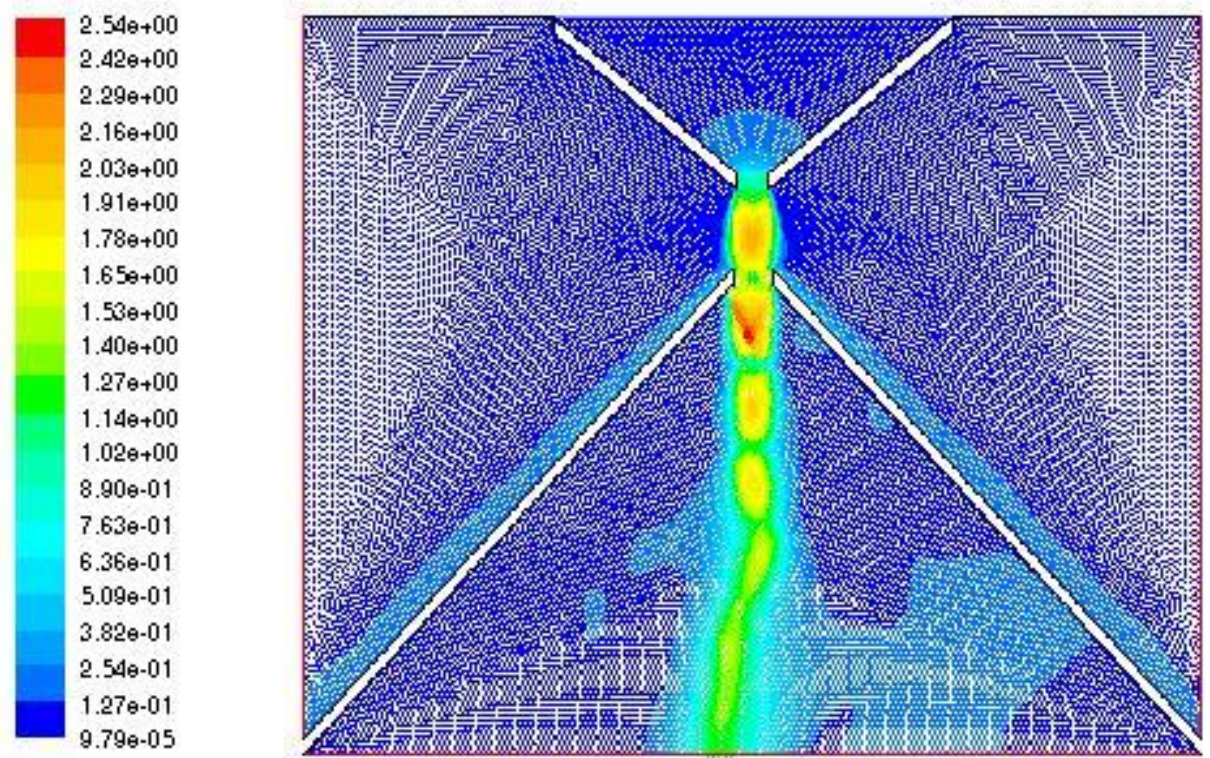

Figure 61: Mach Contour Plot of the Single Skimmer Model
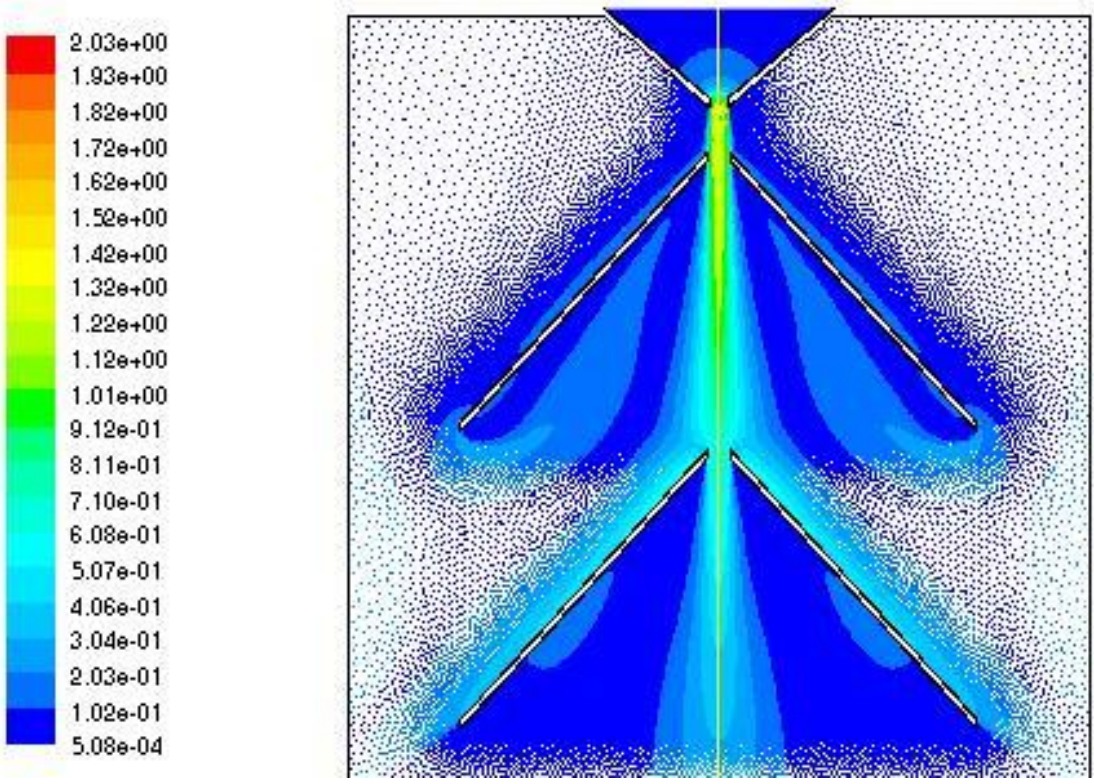

Figure 62: Mach Contour Plot of the Single Chamber Two Skimmer Model 


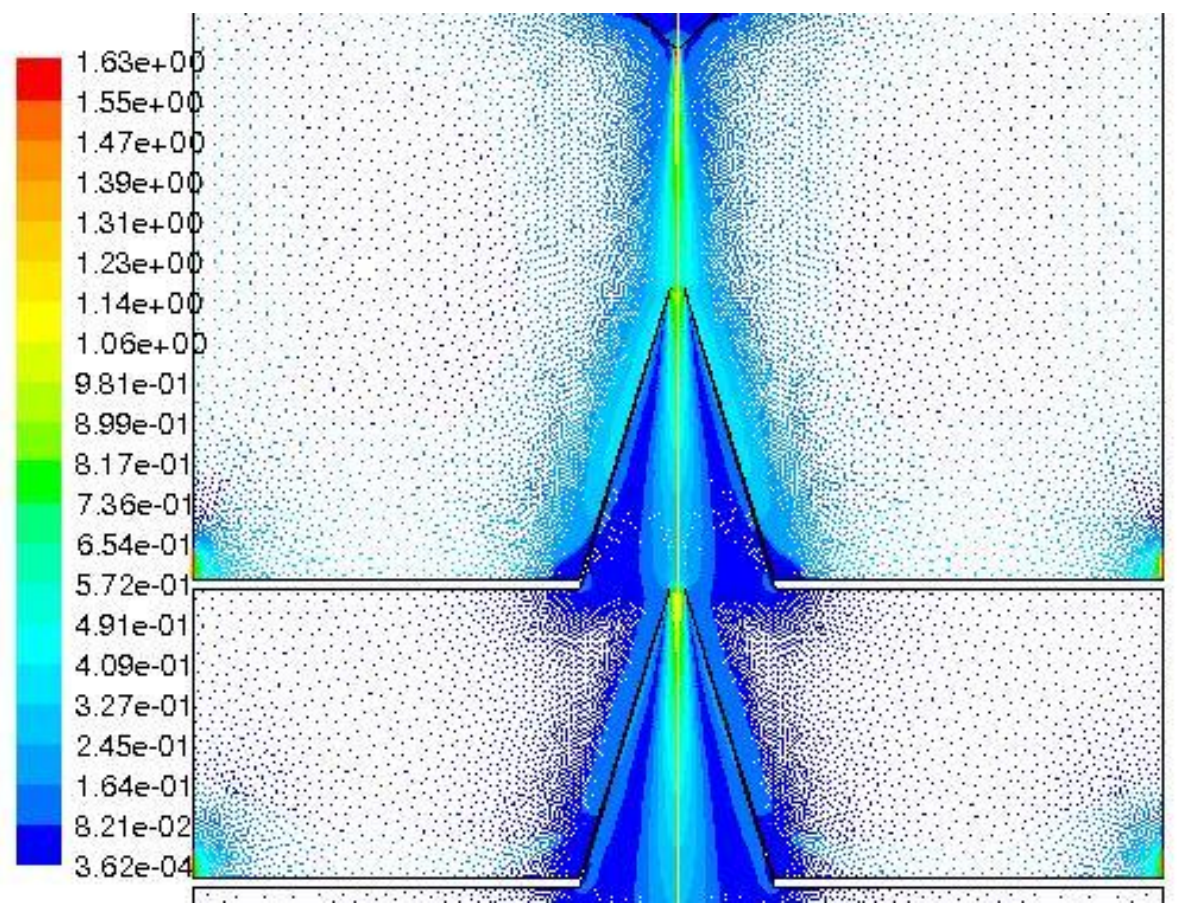

Figure 63: Mach Vector Plot of the Two Skimmer Model with Segregated Chambers
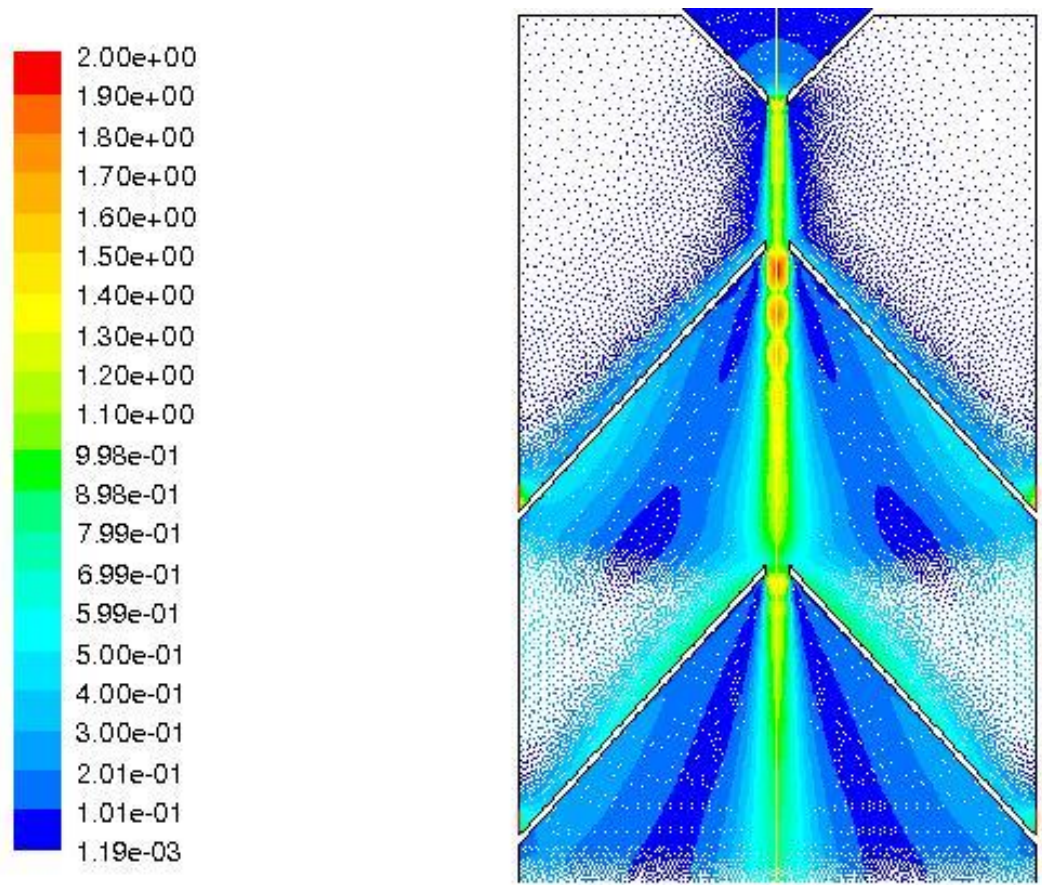

Figure 64: Mach Contour Plot of Two Skimmer Model with Side Walls 

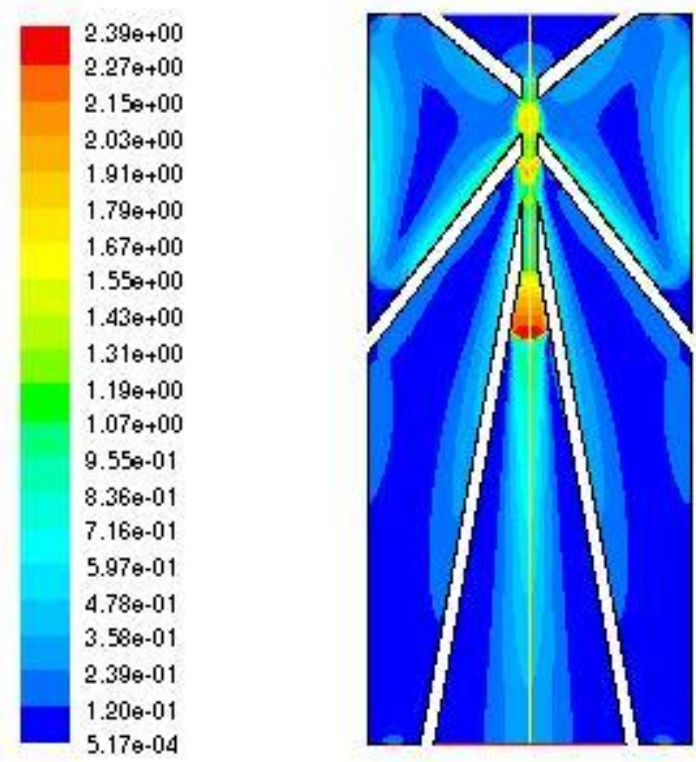

Figure 65: Mach Contour Plot of the Two Skimmer Model with the Final Dimensions

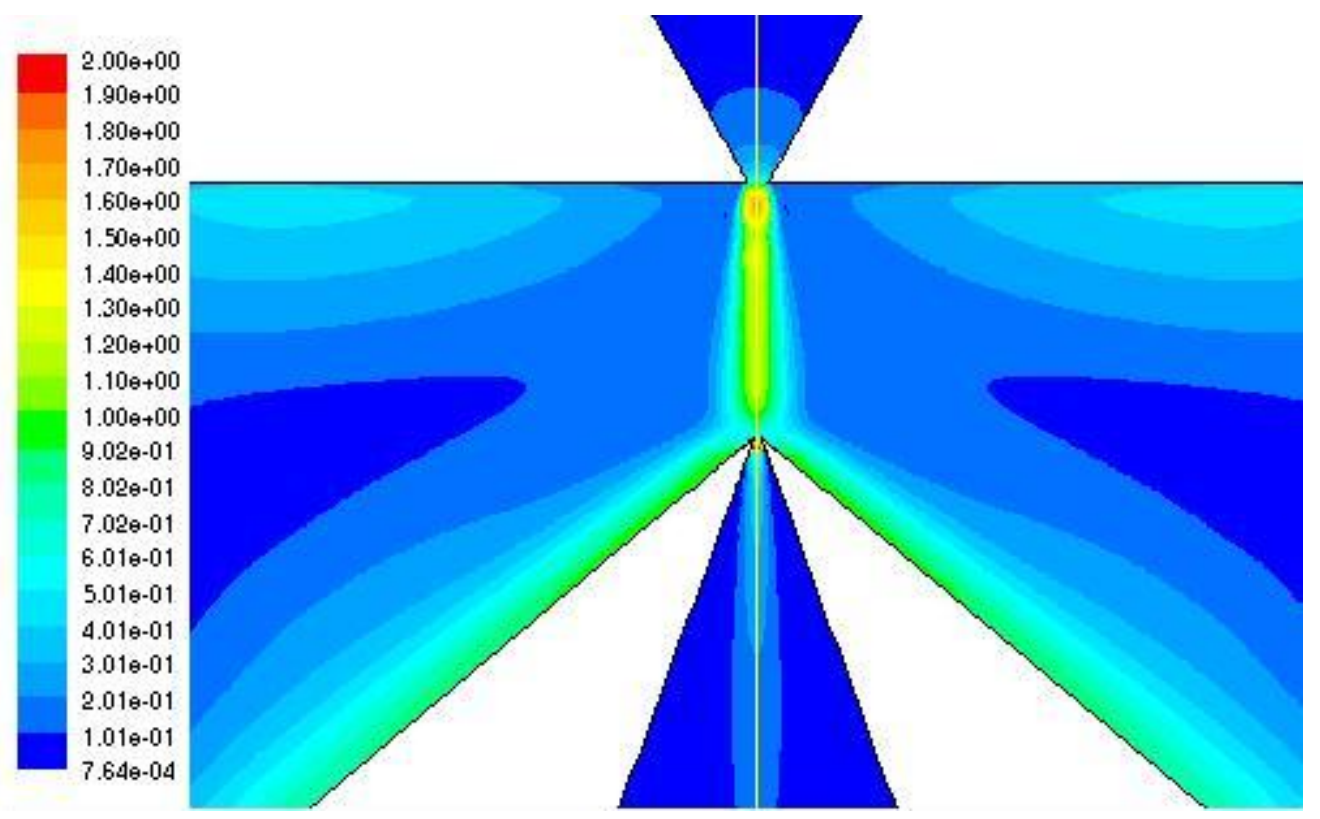

Figure 66: Mach Contour Plot of the Second Physical Design 


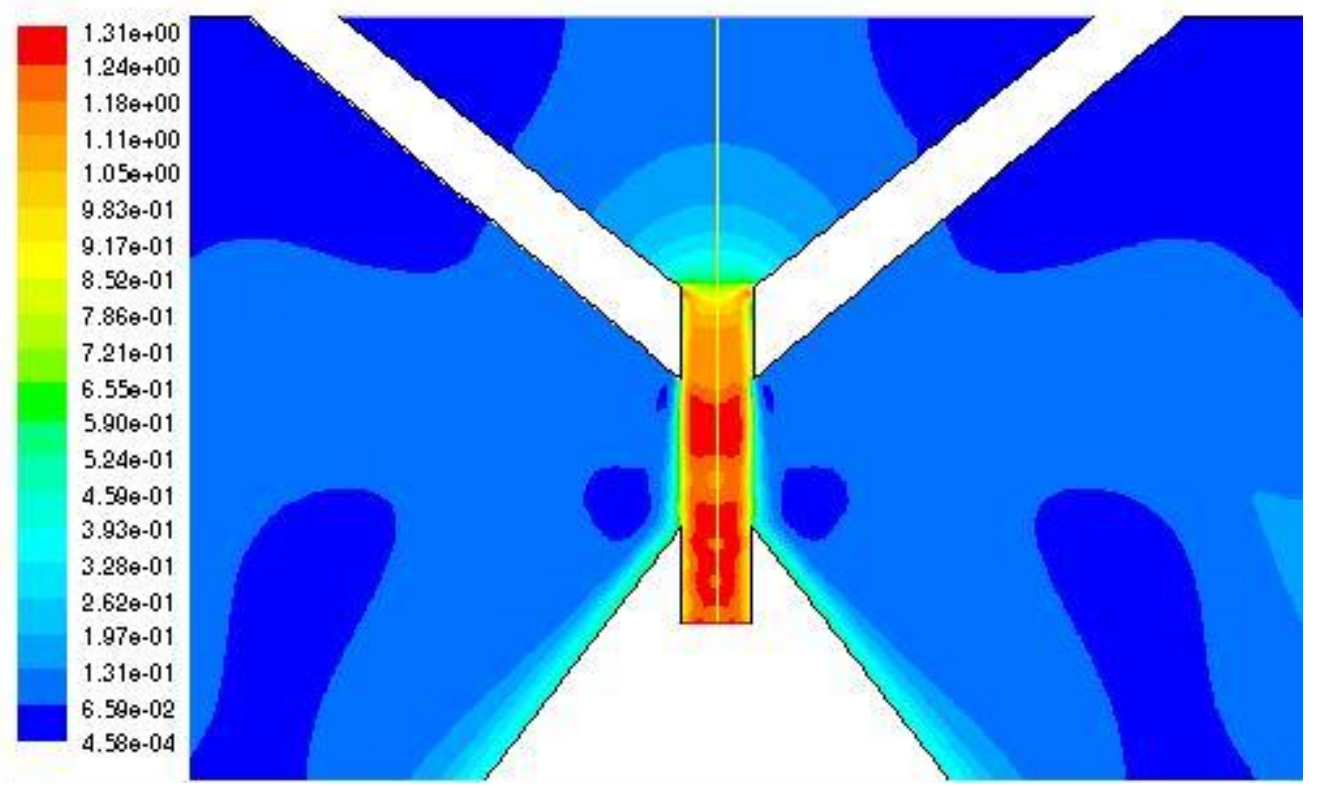

Figure 67: Mach Contour Plot of the First Section of the First Physical Model

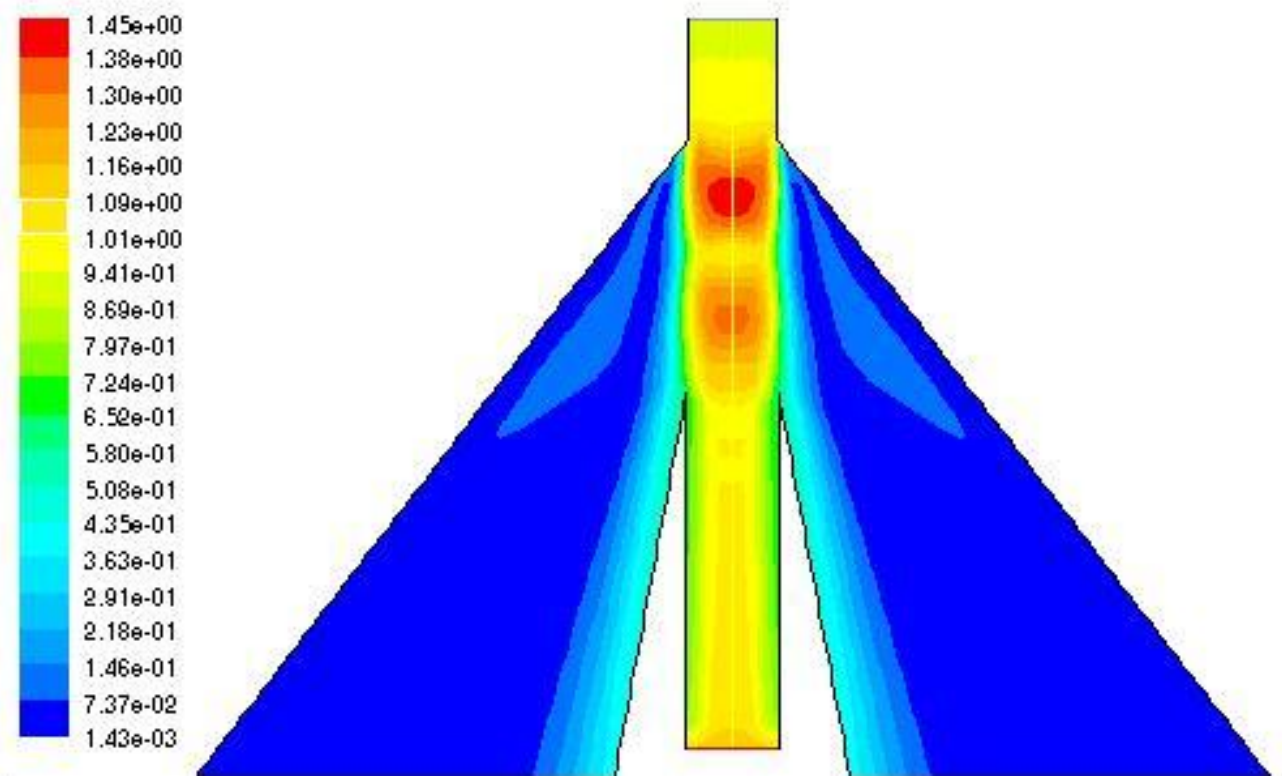

Figure 68: Mach Contour Plot of the Second Section of the First Physical Model 


\section{Appendix B}

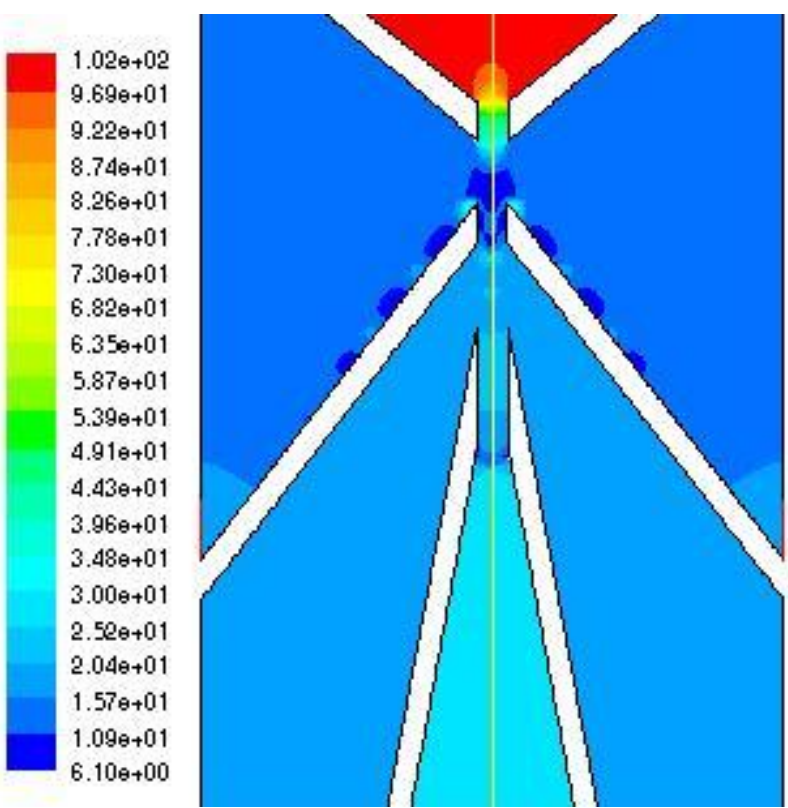

Figure 69: Case 1 Absolute Pressure Contour Plot

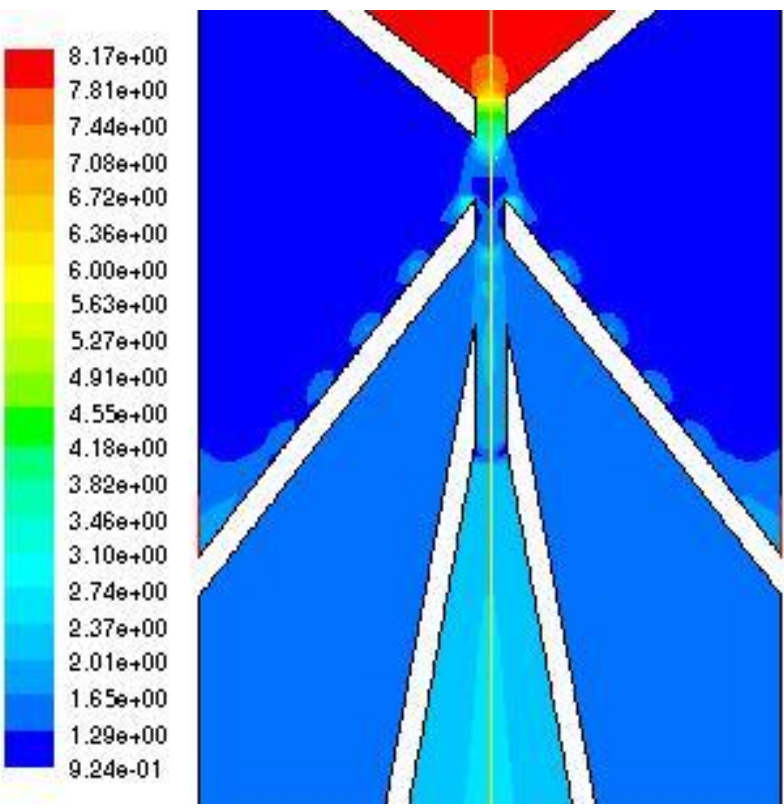

Figure 70: Case 1 Density Contour Plot 

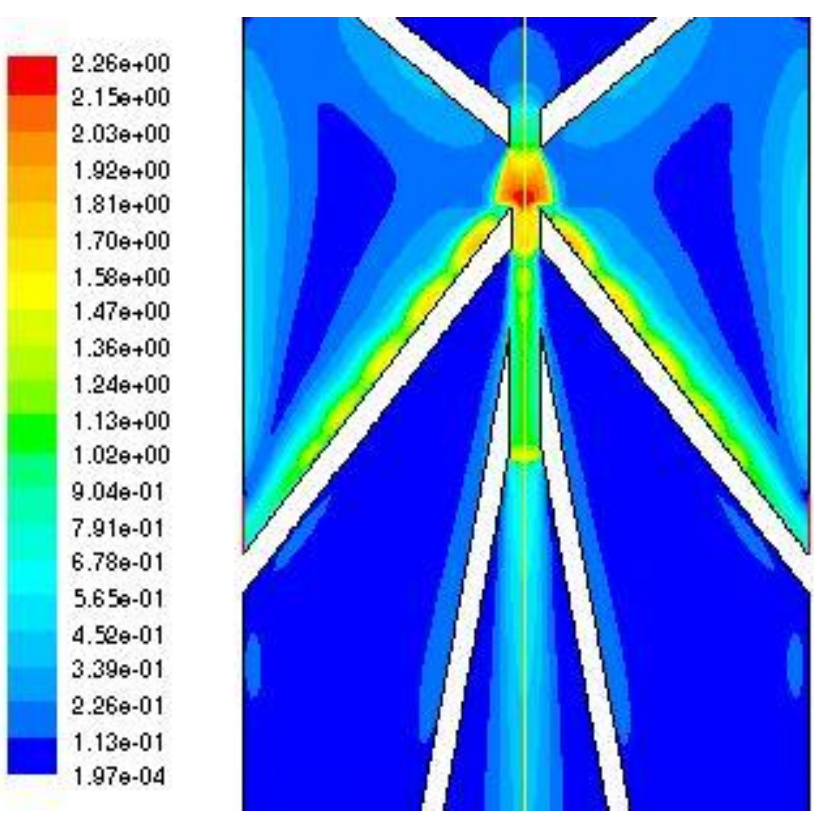

Figure 71: Case 1 Mach Number Contour Plot
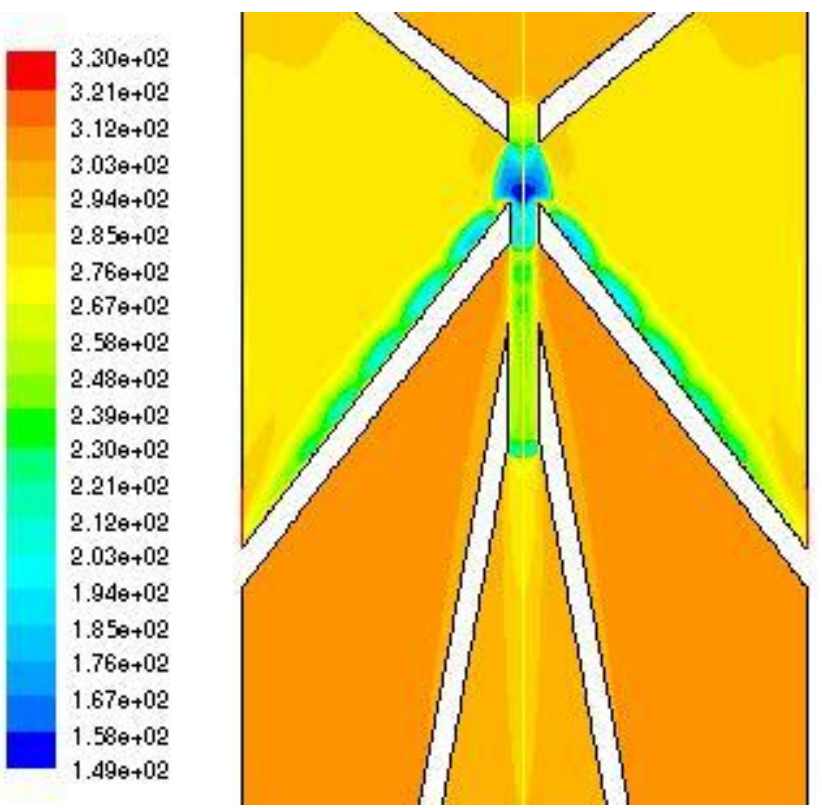

Figure 72: Case 1 Static Temperature Contour Plot 

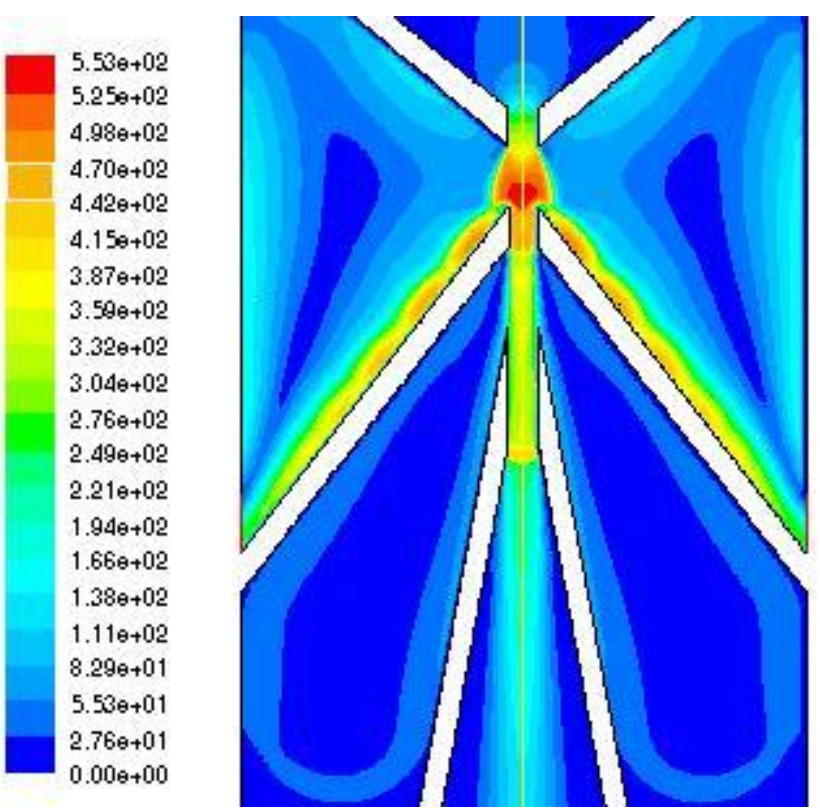

Figure 73: Case 1 Velocity Magnitude Contour Plot

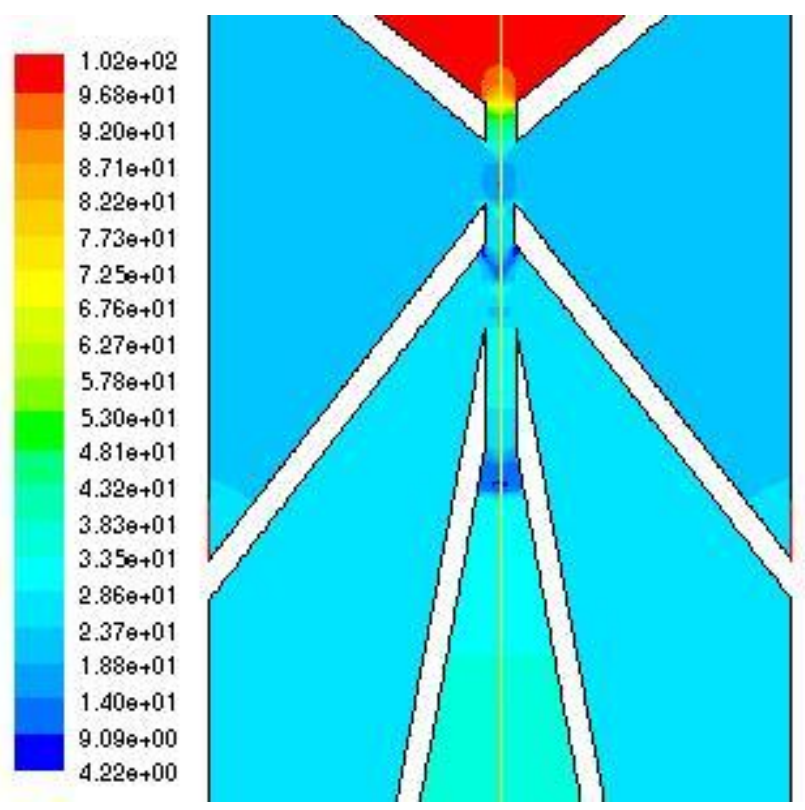

Figure 74: Case 2 Absolute Pressure Contour Plot 


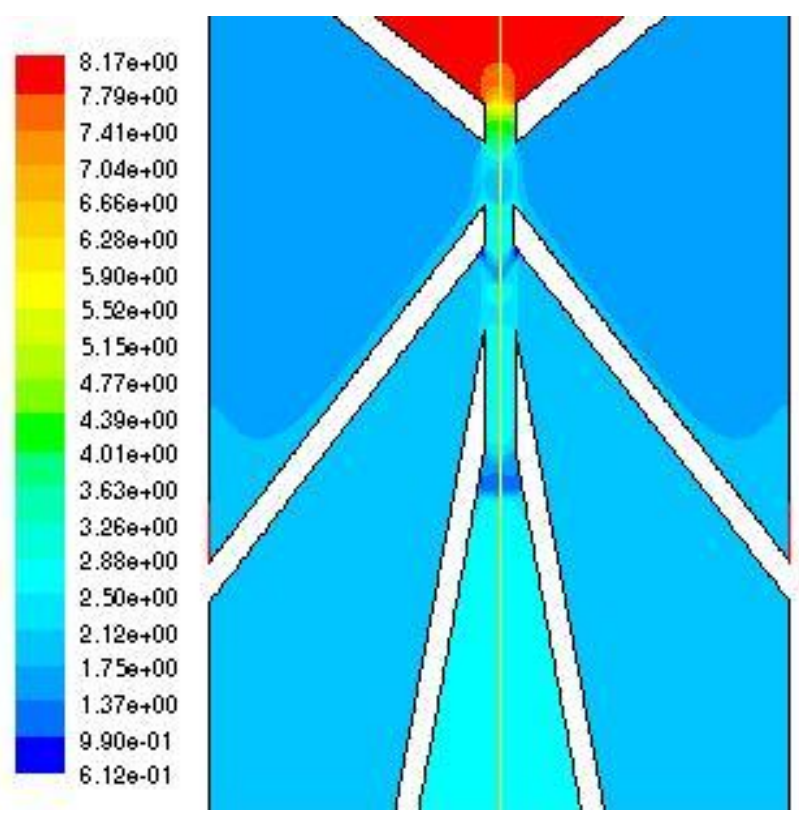

Figure 75: Case 2 Density Contour Plot

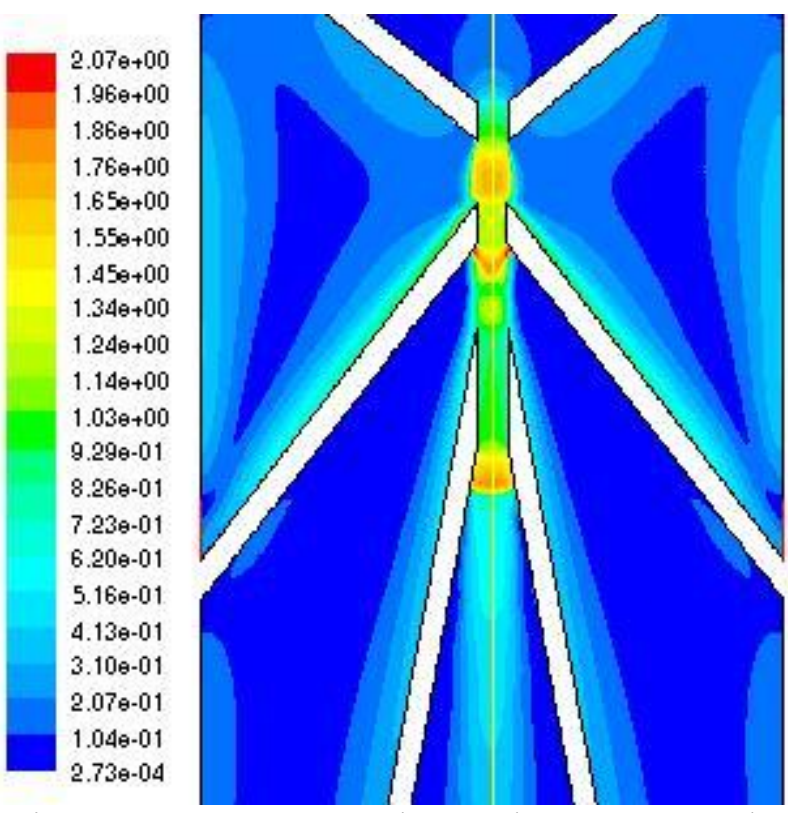

Figure 76: Case 2 Mach Number Contour Plot 


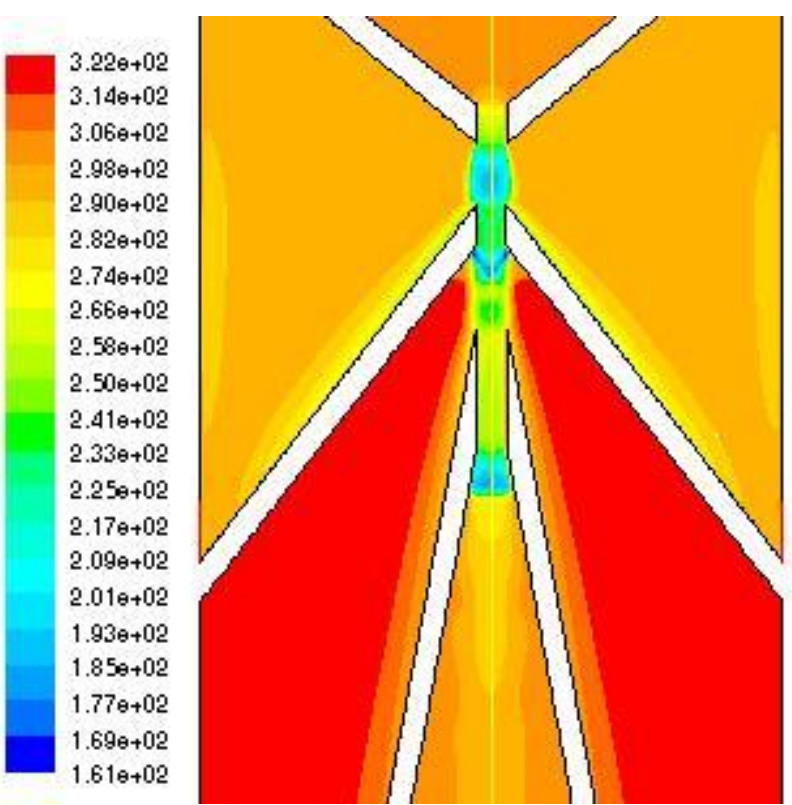

Figure 77: Case 2 Static Temperature Contour Plot
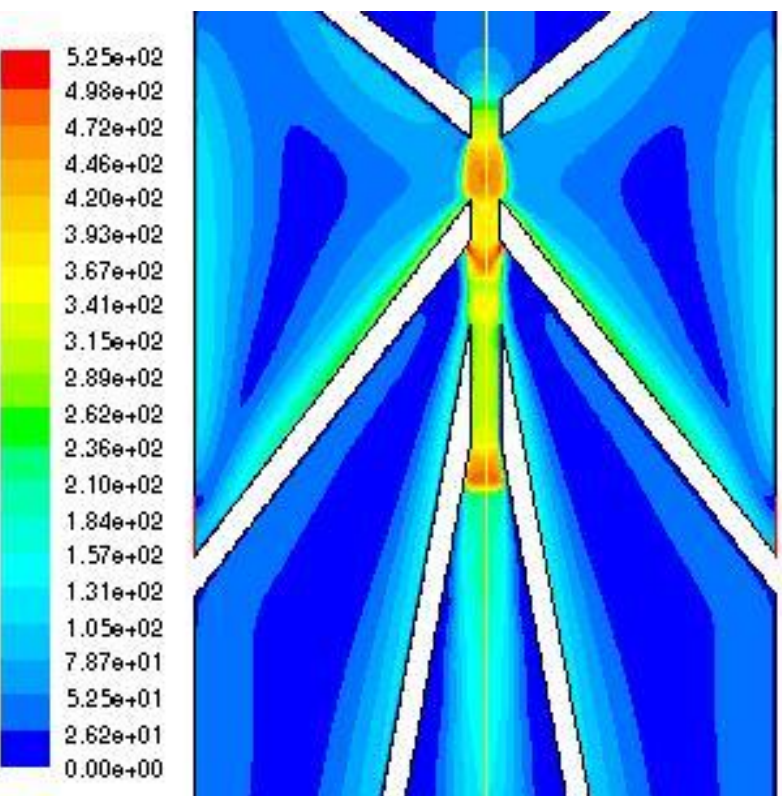

Figure 78: Case 2 Velocity Magnitude Contour Plot 

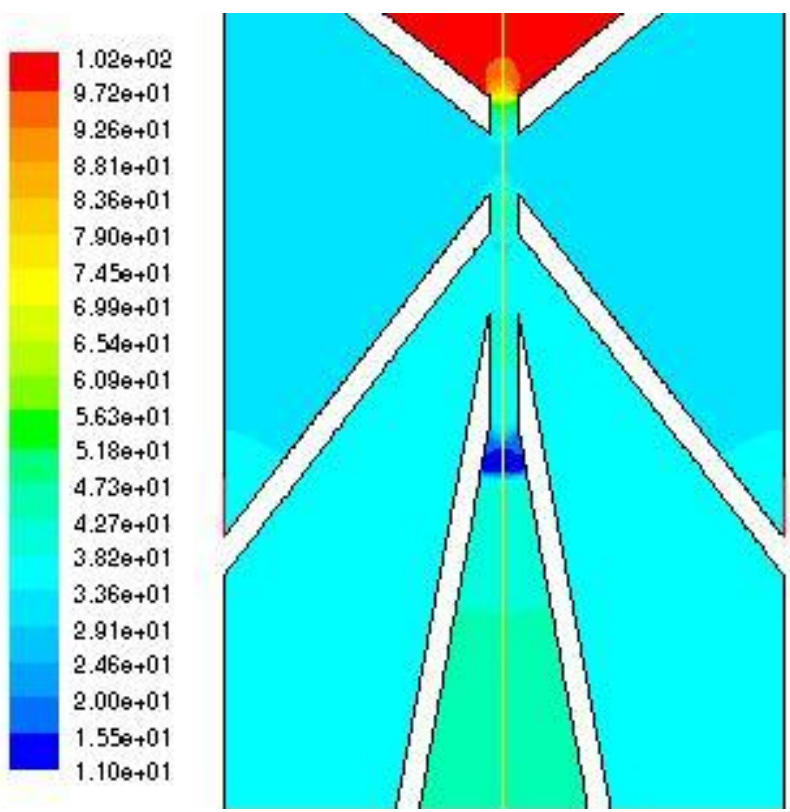

Figure 79: Case 4 Absolute Pressure Contour Plot
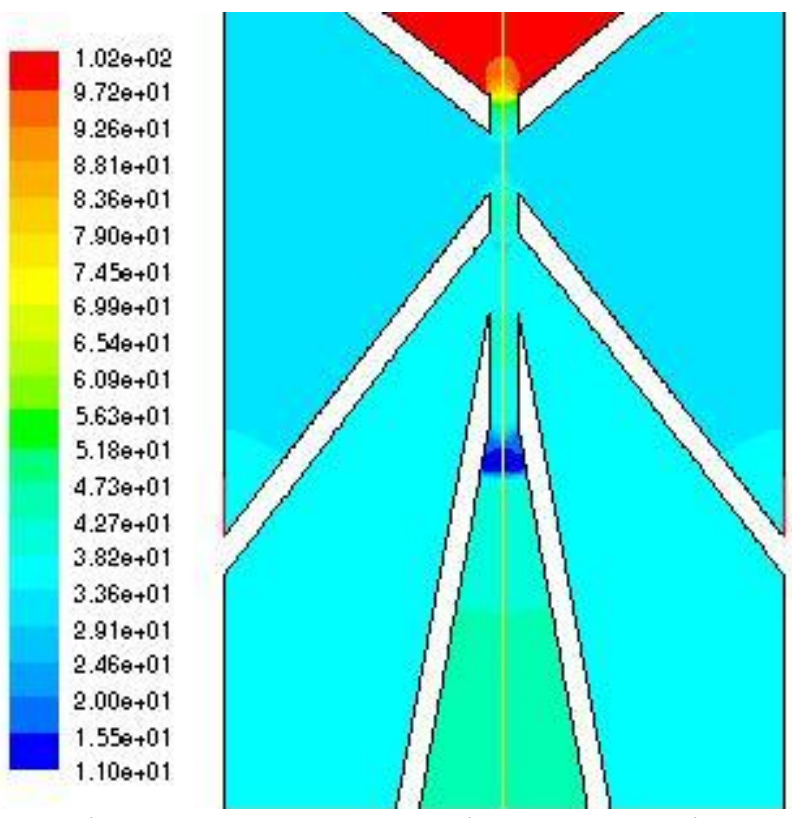

Figure 80: Case 4 Density Contour Plot 


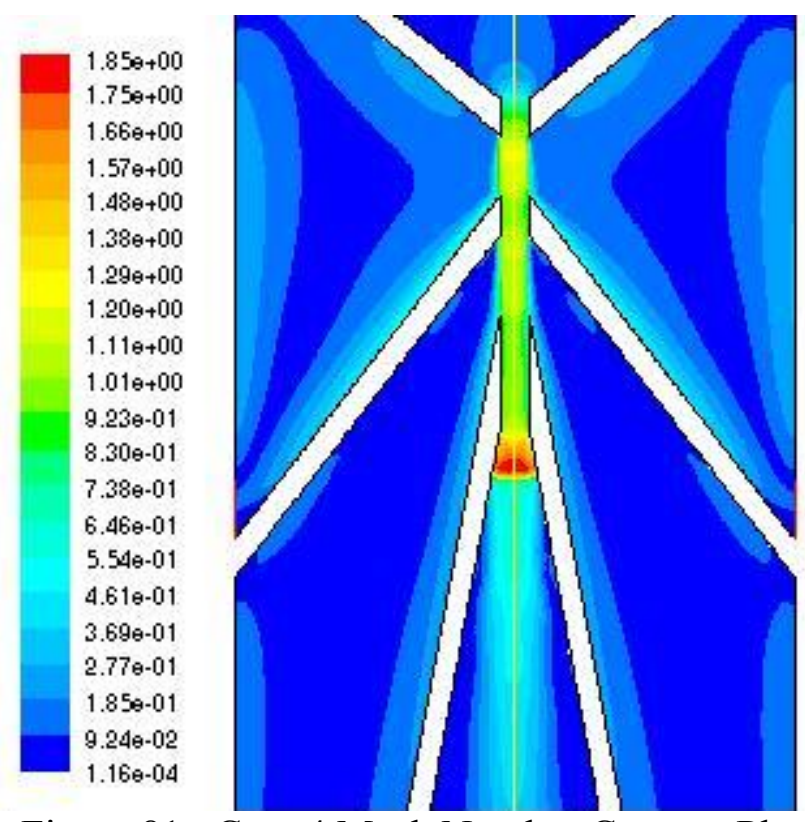

Figure 81: Case 4 Mach Number Contour Plot

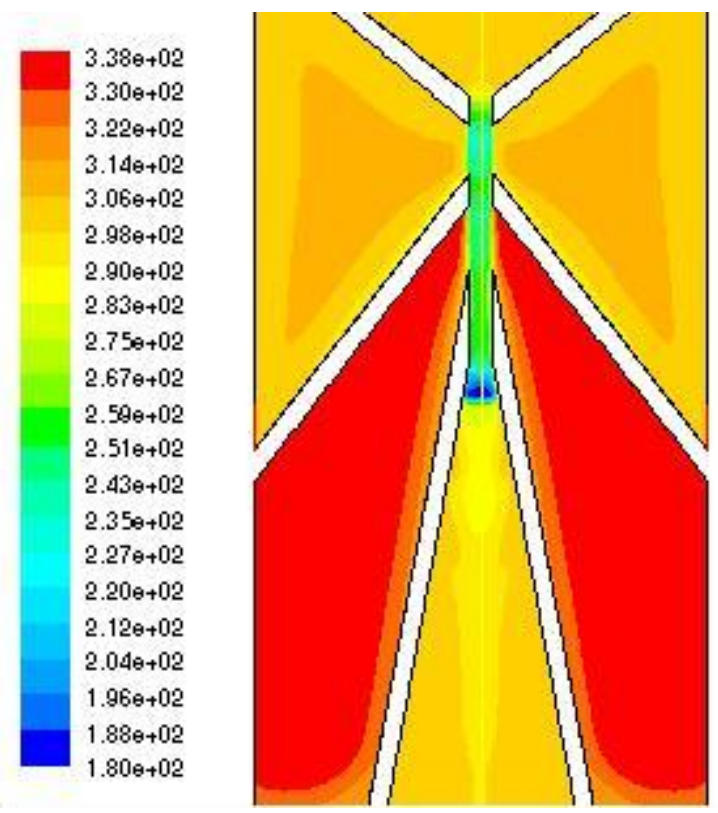

Figure 82: Case 4 Static Temperature Contour Plot 


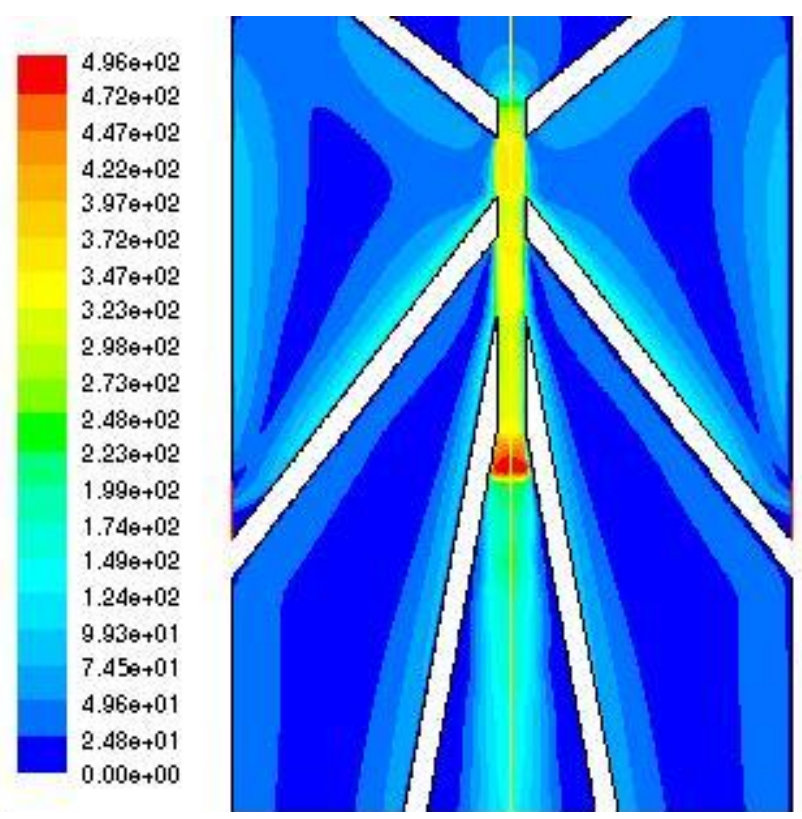

Figure 83: Case 4 Velocity Magnitude Contour Plot
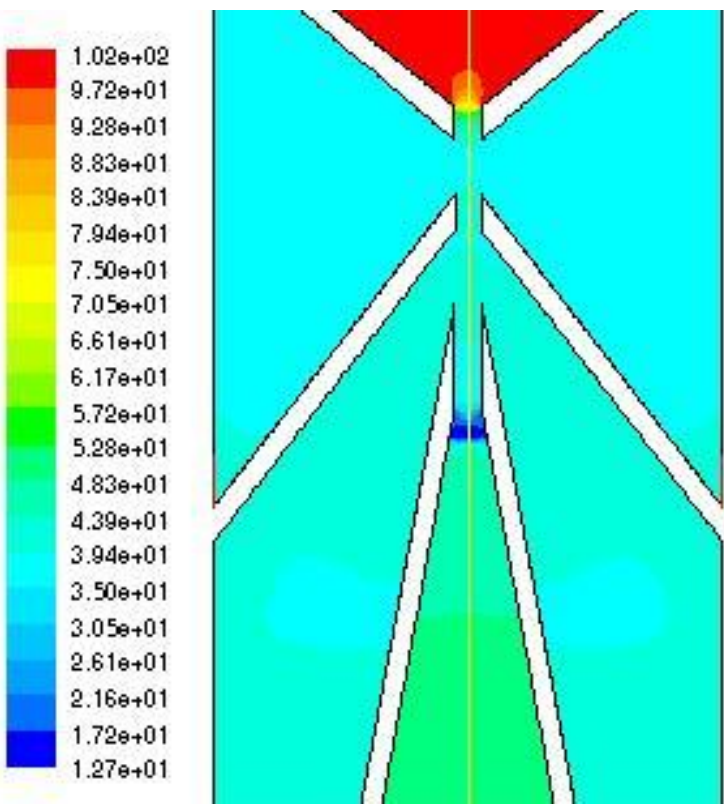

Figure 84: Case 5 Absolute Pressure Contour Plot 

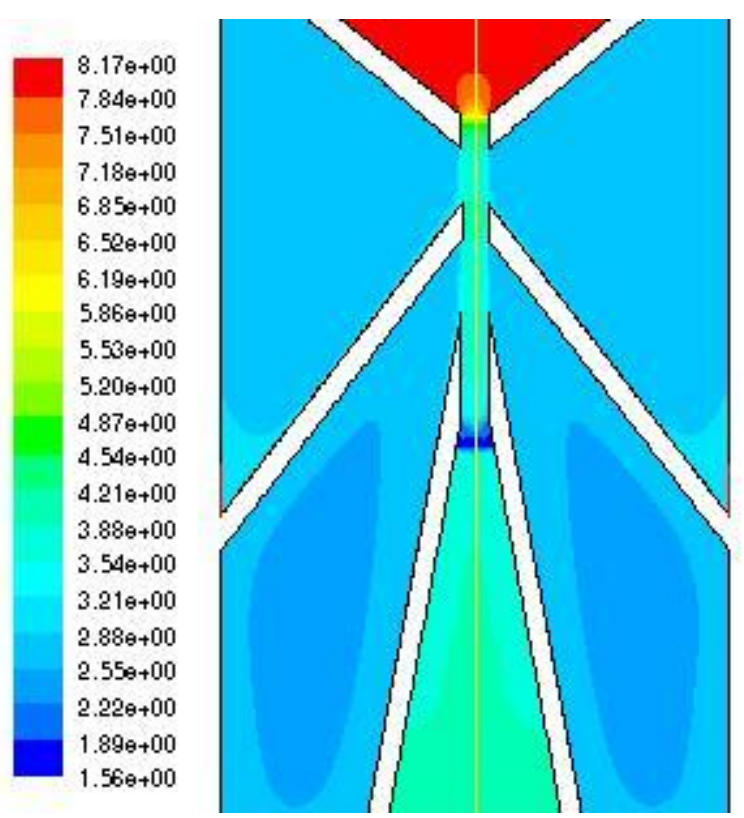

Figure 85: Case 5 Density Contour Plot
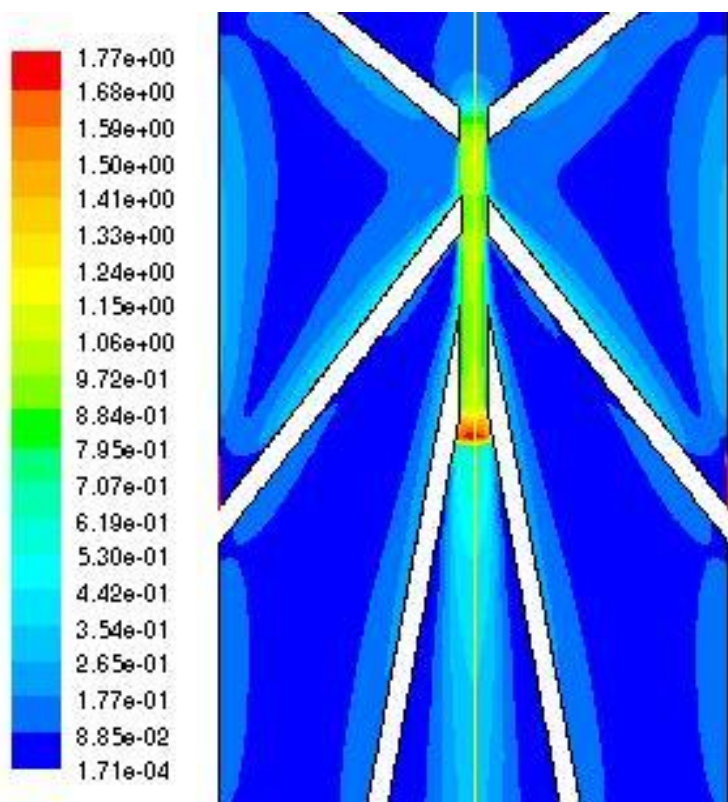

Figure 86: Case 5 Mach Number Contour Plot 


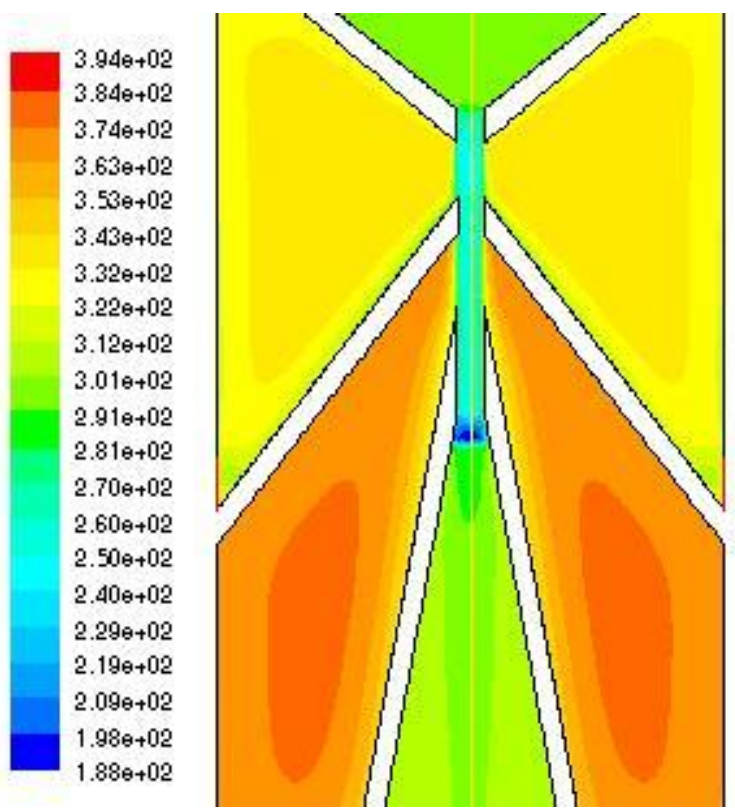

Figure 87: Case 5 Static Temperature Contour Plot
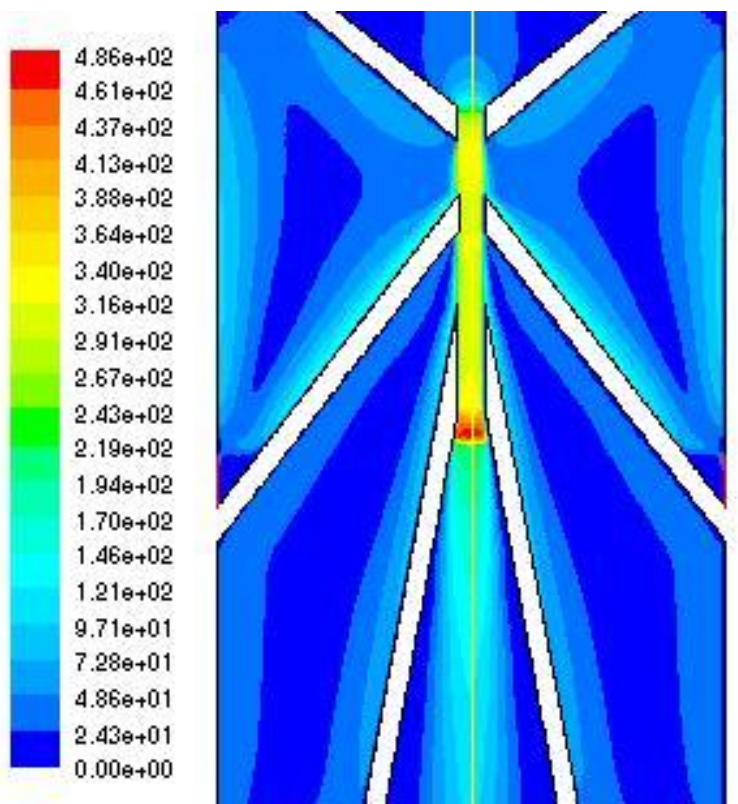

Figure 88: Case 5 Velocity Magnitude Contour Plot 
Table 6: Case 1 Percent Difference of CFD and Analytic Results

\begin{tabular}{|c|c|c|c|}
\hline & $\begin{array}{c}\text { Mach } \\
\text { Number }\end{array}$ & $\begin{array}{c}\text { Static } \\
\text { Temperature }\end{array}$ & $\begin{array}{c}\text { Absolute } \\
\text { Pressure }\end{array}$ \\
\hline Parameter & $(\%)$ & $(\%)$ & $(\%)$ \\
\hline Nozzle Throat & 1 & 0.31 & 23.34 \\
\hline Chamber 1 & 30.4 & 20.17 & 66.6 \\
\hline Skimmer 1 Throat & 60.82 & 20.11 & 75.44 \\
\hline Chamber 2 & 27.1 & 21.3 & 8.09 \\
\hline Skimmer 2 Throat & 8.26 & 1.84 & 60.51 \\
\hline
\end{tabular}

Table 7: Case 2 Percent Difference of CFD and Analytic Results

\begin{tabular}{|c|c|c|c|}
\hline & $\begin{array}{c}\text { Mach } \\
\text { Number }\end{array}$ & $\begin{array}{c}\text { Static } \\
\text { Temperature }\end{array}$ & $\begin{array}{c}\text { Absolute } \\
\text { Pressure }\end{array}$ \\
\hline Parameter & $(\%)$ & $(\%)$ & $(\%)$ \\
\hline Nozzle Throat & 0.52 & 0.47 & 22.95 \\
\hline Chamber 1 & 11.25 & 7.16 & 43.76 \\
\hline Skimmer 1 Throat & 17.86 & 5.53 & 43.88 \\
\hline Chamber 2 & 15.47 & 9.5 & 52.08 \\
\hline Skimmer 2 Throat & 7.03 & 3.21 & 41.67 \\
\hline
\end{tabular}

Table 8: Case 4 Percent Difference of CFD and Analytic Results

\begin{tabular}{|c|c|c|c|}
\hline & $\begin{array}{c}\text { Mach } \\
\text { Number }\end{array}$ & $\begin{array}{c}\text { Static } \\
\text { Temperature }\end{array}$ & $\begin{array}{c}\text { Absolute } \\
\text { Pressure }\end{array}$ \\
\hline Parameter & $(\%)$ & $(\%)$ & $(\%)$ \\
\hline Nozzle Throat & 1.8 & 1.22 & 20.97 \\
\hline Chamber 1 & 8.12 & 4.5 & 11.65 \\
\hline Skimmer 1 Throat & 0.03 & 0.57 & 25.01 \\
\hline Chamber 2 & 14.38 & 7.96 & 4.61 \\
\hline Skimmer 2 Throat & 2.99 & 1.94 & 25.59 \\
\hline
\end{tabular}


Table 9: Case 5 Percent Difference of CFD and Analytic Results

\begin{tabular}{|c|c|c|c|}
\hline & $\begin{array}{c}\text { Mach } \\
\text { Number }\end{array}$ & $\begin{array}{c}\text { Static } \\
\text { Temperature }\end{array}$ & $\begin{array}{c}\text { Absolute } \\
\text { Pressure }\end{array}$ \\
\hline Parameter & $(\%)$ & $(\%)$ & $(\%)$ \\
\hline Nozzle Throat & 4.57 & 2.15 & 18.5 \\
\hline Chamber 1 & 13.28 & 6.21 & 5.29 \\
\hline $\begin{array}{c}\text { Skimmer 1 } \\
\text { Throat }\end{array}$ & 5.89 & 2.79 & 18.61 \\
\hline Chamber 2 & 17.44 & 8.57 & 2.19 \\
\hline $\begin{array}{c}\text { Skimmer 2 } \\
\text { Throat }\end{array}$ & 4.17 & 2.88 & 23.55 \\
\hline
\end{tabular}

